\title{
Bidirectional contact tracing dramatically improves COVID-19 control
}

\author{
William J. Bradshaw ${ }^{1}$, Ethan C. Alley ${ }^{2,3}$, Jonathan H. Huggins ${ }^{4}$, Alun L. Lloyd ${ }^{5}$, and Kevin M. Esvelt ${ }^{2, *}$ \\ ${ }^{1}$ Max Planck Institute for Biology of Ageing, Joseph-Stelzmann-Str. 296, 50937 Cologne, Germany \\ ${ }^{2}$ Media Laboratory, Massachusetts Institute of Technology, Cambridge, MA 02139, USA \\ ${ }^{3}$ Alt. Technology Labs, Berkeley, CA 94702, USA \\ ${ }^{4}$ Department of Mathematics \& Statistics, Boston University, Boston, MA 02215, USA \\ ${ }^{5}$ Biomathematics Graduate Program and Department of Mathematics, North Carolina State University, Raleigh, NC 27695, USA \\ * For correspondence: esvelt@mit.edu
}

\begin{abstract}
Contact tracing is critical to controlling COVID-19, but most protocols only "forward-trace" to notify people who were recently exposed. Using a stochastic branching-process model, we show that "bidirectional" tracing to identify infector individuals and their other infectees robustly improves outbreak control, reducing the effective reproduction number $\left(R_{\text {eff }}\right)$ by at least $\sim 0.3$ while dramatically increasing resilience to low case ascertainment and test sensitivity. Adding smartphone-based exposure notification can further reduce $R_{\text {eff }}$ by 0.25 , but only if nearly all smartphones can detect exposure events. Our results suggest that with or without digital approaches, implementing bidirectional tracing will enable health agencies to control COVID-19 more effectively without requiring high-cost interventions.
\end{abstract}

\section{Introduction}

Contact tracing, isolation, and testing are some of the most powerful public health interventions available. The nations that have most effectively controlled the ongoing COVID-19 pandemic are noteworthy for conducting comprehensive and sophisticated tracing and testing ${ }^{1}$. Current "forward-tracing" protocols seek to identify and isolate individuals who may have been infected by the known case, preventing continued transmission (Fig. 1a). For example, the European Union and World Health Organization call for the identification of contacts starting two days prior to the development of symptoms ${ }^{2,3}$.

However, chains of SARS-CoV-2 transmission may persist despite excellent medical monitoring and forward-tracing programs due to substantial rates of undiagnosed or asymptomatic transmission ${ }^{4}$ (Fig. 1a). Asymptomatic carriers, who reportedly bear equivalent viral loads to patients exhibiting symptoms ${ }^{5}$, have been estimated to account for $18 \%{ }^{6}$ to $79 \%{ }^{7}$ of cases, with multiple population surveys indicating intermediate values around $45 \%^{8-10}$.

We hypothesized that when asymptomatic carriers are common, "bidirectional" contact tracing could identify and isolate undiscovered branches of the transmission tree, preventing many additional cases (Fig. 1b). Bidirectional contact tracing uses "reverse-tracing" to identify the parent case who infected a known case, then continues tracing to iteratively discover other cases related to the parent. It has been successfully used to identify clusters and community transmission in Japan ${ }^{12}$ and Singapore ${ }^{13,14}$, but is 
medRxiv preprint doi: https://doi.org/10.1101/2020.05.06.20093369; this version posted July 14, 2020. The copyright holder for this preprint (which was not certified by peer review) is the author/funder, who has granted medRxiv a license to display the preprint in perpetuity. It is made available under a CC-BY 4.0 International license .

otherwise uncommon. Because the incubation time for SARS-CoV-2 is longer than 48 hours, existing tracing protocols cannot identify parent cases $^{2,3}$, and previous studies of COVID-19 contact tracing have neglected the possibility of gains from bidirectional tracing.

Numerous ongoing efforts aim to use smartphones emitting randomized Bluetooth and/or ultrasound "chirps" to notify people exposed to infected individuals (Fig. 1d-e). Digital approaches may offer considerable advantages in speed ${ }^{15}$, scale, efficacy ${ }^{4}$, and confidentiality ${ }^{16}$. To investigate the efficacy of bidirectional tracing, we adapted and extended a stochastic branching-process model of SARS-CoV-2 forward-tracing ${ }^{17}$ and used it to explore the efficacy of different tracing strategies under plausible epidemiological scenarios.

a

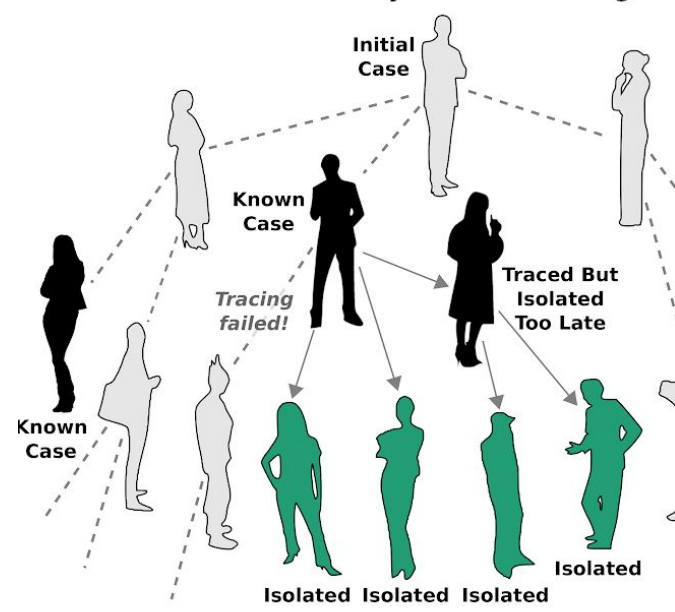

C

Manual Contact Tracing

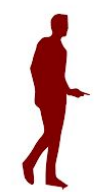

Individuals try to remember the people they encountered d

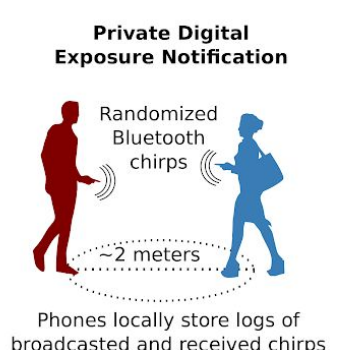

b

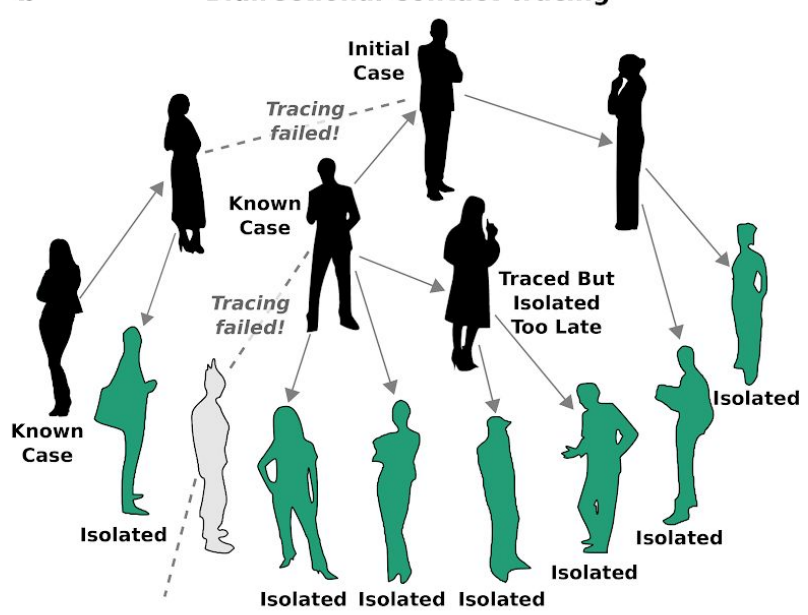

e

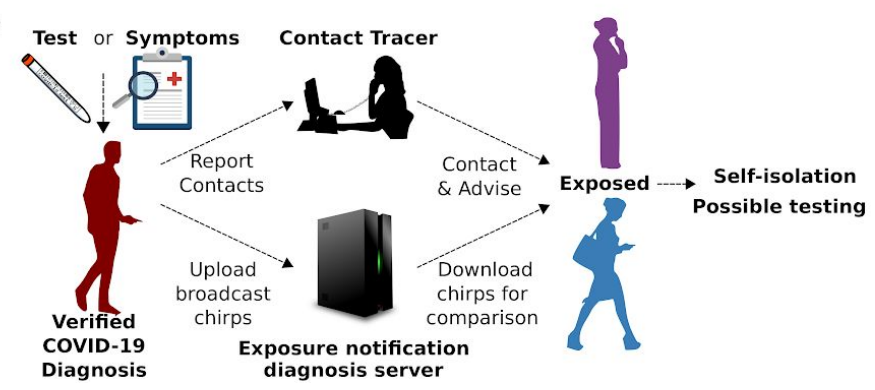

Figure 1. Forward-only and bidirectional contact tracing and digital exposure notification. (a) Notifying people exposed to known cases (black) and isolating them (green) can prevent further transmission, but will miss asymptomatic and undiagnosed cases (gray) and descendants. (b) Bidirectional tracing also notifies and tests potential infectors, enabling isolation of additional cases. (c) Manual contact tracing requires individuals to share recent contacts with health authorities. (d) In digital exposure notification, smartphones broadcast rotating pseudorandom "chirps" and record those emitted by nearby devices ${ }^{11}$. (e) Individuals diagnosed with COVID-19 can "opt-in" by uploading broadcasted chirps to a diagnosis server ${ }^{11}$. All devices frequently check the server and alert the user if calculated exposure exceeds a threshold set by the local health authority. In hybrid manual+digital systems, human tracers would seek to identify contacts without smartphones. 
medRxiv preprint doi: https://doi.org/10.1101/2020.05.06.20093369; this version posted July 14, 2020. The copyright holder for this preprint (which was not certified by peer review) is the author/funder, who has granted medRxiv a license to display the preprint in perpetuity.

It is made available under a CC-BY 4.0 International license.

\section{Results}

\section{Bidirectional tracing improves epidemic control in manual and idealized digital scenarios}

In our model, each case generates a number of new cases drawn from a negative binomial distribution, with incubation and generation-time distributions based on the published literature (Table 1 \& Table S1). Cases could be identified and isolated based on symptoms alone or through contact tracing (Methods). Each outbreak was initialized with 20 index cases to minimize stochastic extinction, and designated as "controlled" if it reached extinction (zero new cases) before reaching 10,000 cumulative cases.

We began by investigating a median scenario in which $10 \%$ of transmission was assumed to be environmental (and therefore untraceable), $48 \%$ of transmission occurred pre-symptomatically, and $45 \%$ of cases were asymptomatic with reduced (50\%) infectiousness. For the initial analysis we assumed a fixed basic reproduction number $\left(R_{0}\right)$ of 2.5 (Fig. 2), but explored other $R_{0}$ values below.

Table 1: Key parameters of the branching-process model.

\begin{tabular}{|c|c|c|c|c|}
\hline \multirow[t]{2}{*}{ Parameter } & \multicolumn{3}{|l|}{ Value } & \multirow[t]{2}{*}{ Sources and Notes } \\
\hline & Median & Optimistic & Pessimistic & \\
\hline$\%$ asymptomatic carriers & $45 \%$ & $40 \%$ & $55 \%$ & $8-10,37$ \\
\hline $\begin{array}{l}\text { Relative infectiousness of } \\
\text { asymptomatic carriers }\end{array}$ & $50 \%$ & $45 \%$ & $60 \%$ & $\begin{array}{l}\text { Informed by viral loads and tracing } \\
\text { results described in }{ }^{5,9,26,30-32}\end{array}$ \\
\hline$\%$ environmental transmission & $10 \%$ & $5 \%$ & $15 \%$ & 4,38 \\
\hline $\begin{array}{l}\text { Proportion of pre-symptomatic } \\
\text { transmission }\end{array}$ & $48 \%$ & $38 \%$ & $53 \%$ & Informed by $5,26,32,39-44$ \\
\hline$\%$ of cases with chirping smartphones & \multicolumn{3}{|c|}{$53 \%$ (low-uptake) / 80\% (high-uptake) } & Survey data ${ }^{22,23,45}$ \\
\hline Test sensitivity & \multicolumn{3}{|l|}{$80 \%$} & 20,21 \\
\hline$R_{0}$ (default) & \multicolumn{3}{|l|}{2.5} & $\begin{array}{l}\text { Most estimates cluster between } 2.0 \\
\text { and 3.0: } 4,9,25-28\end{array}$ \\
\hline Incubation period & \multicolumn{3}{|c|}{$5.5 \pm 2.1$ days (lognormal distribution) } & 46 \\
\hline Delay from onset to isolation & \multicolumn{3}{|c|}{$3.8 \pm 2.4$ days (Weibull distribution) } & 19 \\
\hline Delay for testing & \multicolumn{3}{|c|}{$1 \pm 0.3$ days (gamma distribution) } & Assumed \\
\hline Delay for manual tracing & \multicolumn{3}{|c|}{$\begin{array}{l}1.5 \pm 4.8 \text { days (lognormal distribution); } \\
\text { median } 0.5 \text { days }\end{array}$} & $\begin{array}{l}\text { Previous reports suggest most contacts } \\
\text { can be traced within one day, but some } \\
\text { take much longer }{ }^{47}\end{array}$ \\
\hline Delay for digital tracing & \multicolumn{3}{|l|}{0 days } & Assumed \\
\hline
\end{tabular}


In this scenario, manual forward tracing of contacts occurring up to 48 hours before symptom onset per current guidelines ${ }^{2}$ reduced $R_{\text {eff }}$ as anticipated, but not nearly enough to control the pandemic without other measures: even if all non-environmental contacts within that time window were successfully traced, $R_{\text {eff }}$ remained in excess of 1.4 (Fig. 2a). Extending the tracing window to 7 days before symptom onset yielded a moderate improvement, reducing the best-case $R_{\text {eff }}$ by roughly 0.2 (Fig. 2a and Fig. $\mathrm{S} 1$ ); further widening of the tracing window resulted in minimal additional benefit (Fig. S2). Switching from forward-only to bidirectional tracing offered a further gain of similar magnitude, bringing the best-case $R_{\text {eff }}$ close to the critical threshold of 1.0. Even here, however, the fraction of outbreaks controlled was less than $50 \%$ (Fig. 2e).

Compared to manual tracing, digital exposure notification is both faster and scalable to much wider time windows. When all contacts in the past 14 days were available for analysis ${ }^{11}$, idealized digital forward-tracing produced markedly superior outcomes relative to manual forward-tracing (Fig. 2b), in agreement with earlier models ${ }^{4}$. Crucially, bidirectional digital tracing exhibited an even more dramatic improvement over the forward-only approach, successfully bringing $R_{\text {eff }}$ below 1.0 without any other control measures (Fig. 2b) and more than doubling the best-case probability of control (Fig. S5).

\section{Digital tracing is fragile to network fragmentation}

Idealized digital contact tracing appears promising, but assumes all individuals carry exposure-detecting smartphones and upload their broadcasted chirps when diagnosed with COVID-19. We hypothesized that the effectiveness of digital tracing would rapidly degrade when fewer people participated, in line with or worse than the quadratic dependence noted by others ${ }^{4,16,18}$.

As predicted, even small decreases in the proportion of individuals carrying a participating smartphone or (to a lesser extent) sharing their broadcasted chirps resulted in fragmentation of the tracing network (Fig. 2c, and Fig. S3 \& S6), increasing $R_{\text {eff }}$ to levels comparable to, or even worse than, manual tracing alone. As a consequence of this fragility, our results suggest that digital tracing alone cannot currently substitute for traditional manual tracing, even under very optimistic assumptions about uptake and use $\mathrm{e}^{19,20}$.

\section{Hybridizing manual and digital tracing improves performance}

Neither manual nor digital contact tracing alone sufficed to control COVID-19 in our median scenario. Digital tracing is fast and comprehensive but highly fragile to network fragmentation; manual tracing is slower and limited to a narrow time window, but more robust. We hypothesized that the two methods could complement each other, with manual contact tracers focusing their effort on tracing contacts invisible to the digital system, and that this hybrid approach might outperform either method in isolation.

When $80 \%$ of cases participated in the digital system, supplementing bidirectional manual with digital tracing substantially improved epidemic control (Fig. 2d), reducing best-case $R_{\text {eff }}$ by roughly 0.15 compared to manual tracing and more than 0.5 compared to digital tracing with equivalent uptake. Compared to manual tracing, a hybrid approach roughly doubled the probability of controlling individual outbreaks (Fig. 2e). Control under hybrid tracing was still somewhat sensitive to uptake of the digital 
medRxiv preprint doi: https://doi.org/10.1101/2020.05.06.20093369; this version posted July 14, 2020. The copyright holder for this preprint (which was not certified by peer review) is the author/funder, who has granted medRxiv a license to display the preprint in perpetuity.

It is made available under a CC-BY 4.0 International license .

system (Fig. 2f); but far less so than digital tracing alone. Performing only forward-tracing, or reducing the width of the manual tracing window, substantially degraded performance (Fig. 2d-e \& Figs. S3-S7).

a

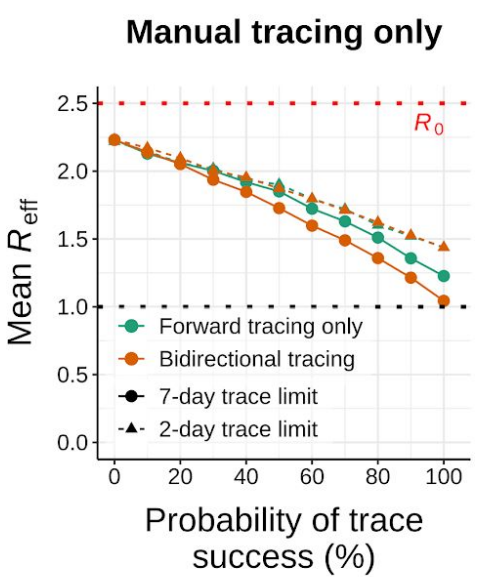

d

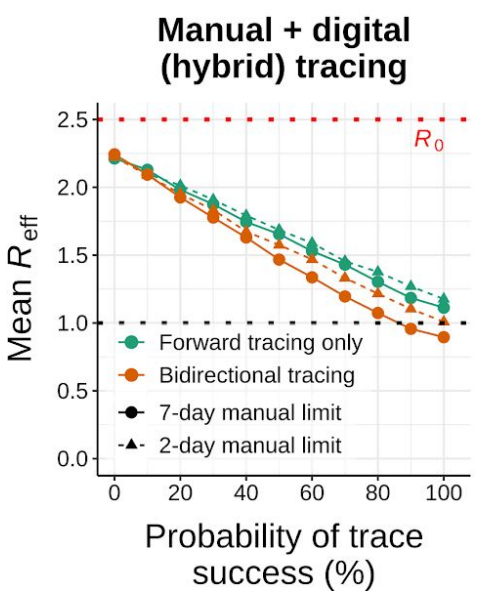

b

\section{Digital tracing only} (universal coverage)

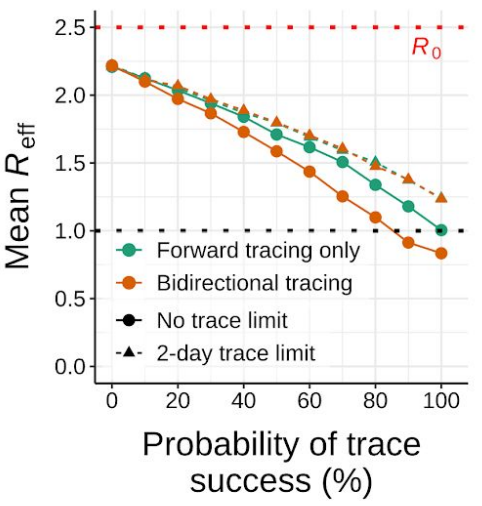

e

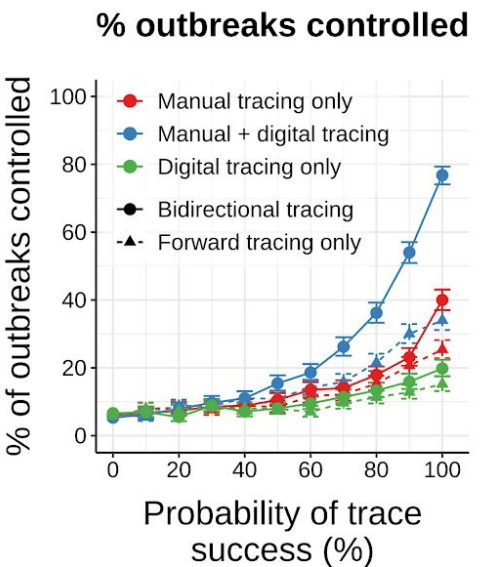

C Bidirectional digital
tracing (partial coverage)

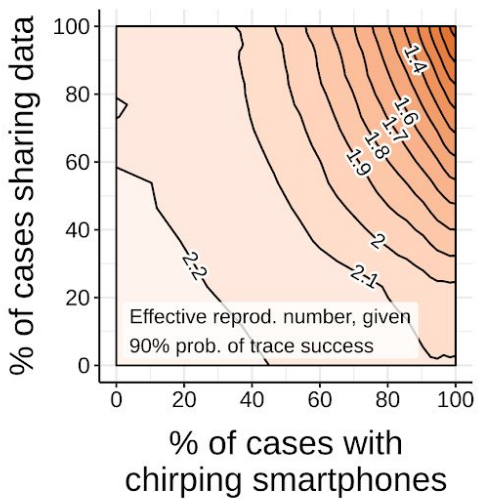

f
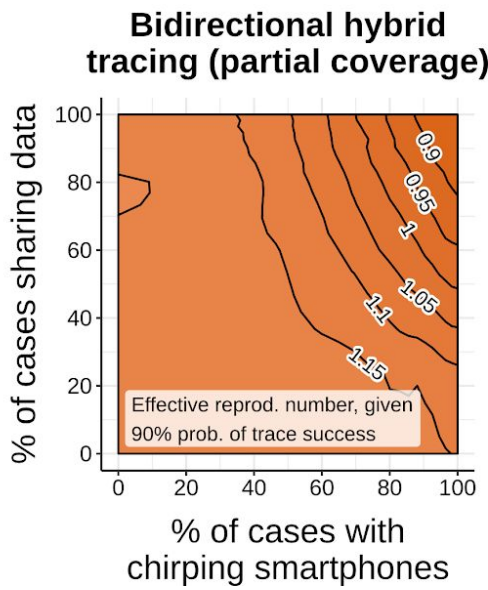

Figure 2. Comparing forward and bidirectional contact tracing at $\boldsymbol{R}_{\mathbf{0}}=\mathbf{2 . 5}$. (a) Average $\mathrm{R}_{\text {eff }}$ achieved by manual tracing with 2-day and 7-day manual tracing windows. (b) Average $\mathrm{R}_{\text {eff }}$ achieved using digital tracing alone, assuming universal smartphone coverage and data sharing. (c) Neighbor-averaged contour plot depicting $R_{\text {eff }}$ for digital-only tracing with varying smartphone coverage and data-sharing, assuming $90 \%$ probability of trace success. (d) Average $\mathrm{R}_{\text {eff }}$ achieved using hybrid manual+digital tracing, assuming 90\% data sharing and $80 \%$ smartphone usage. (e) Percentage of outbreaks controlled under manual, digital and hybrid tracing, assuming $90 \%$ data sharing, $80 \%$ smartphone usage, and a 7-day manual tracing window. (f) Neighbor-averaged contour plot of $R_{\text {eff }}$ for hybrid tracing, assuming a 7-day manual tracing window and $90 \%$ probability of trace success. All panels assume median disease parameters (Table S1). "Probability of trace success" refers to trace attempts that are not otherwise blocked by environmental transmission or fragmentation of the digital network. Points in $(\mathrm{a}, \mathrm{b}, \mathrm{d})$ and contours in $(\mathrm{c}, \mathrm{f})$ represent average values across 1000 runs; error bars in (e) represent $95 \%$ credible intervals under a uniform prior. 
medRxiv preprint doi: https://doi.org/10.1101/2020.05.06.20093369; this version posted July 14, 2020. The copyright holder for this preprint (which was not certified by peer review) is the author/funder, who has granted medRxiv a license to display the preprint in perpetuity.

It is made available under a CC-BY 4.0 International license .

\section{Bidirectional tracing is robust to low case ascertainment and test sensitivity}

Our results thus far assume that $90 \%$ of symptomatic cases can be identified based on symptoms alone, corresponding to an overall ascertainment rate (including asymptomatic cases) of roughly $50 \%$. Unsurprisingly, reducing the percentage of symptomatic cases so identified impaired epidemic control (Fig. 3a \& Fig. S31). However, bidirectional tracing was far more robust to these changes than forward-only tracing, resulting in dramatically lower $\mathrm{R}_{\text {eff }}$ values across a wide range of ascertainment rates.

When symptomatic cases can be traced immediately based on symptoms alone (our default assumption), both forward-only and bidirectional tracing were fairly robust to deviations in test sensitivity from our default assumption of $80 \%$, with $R_{\text {eff }}$ values increasing only slowly as sensitivity falls (Fig. 3b). In contrast, if a positive test result was required before tracing from symptomatic cases (as is the case in many countries ${ }^{21}$ ), the efficacy of forward-tracing became dramatically more dependent on a high test sensitivity: low sensitivities yielded greatly increased $\mathrm{R}_{\text {eff }}$ values (Fig. 3c \& Fig. S30), consistent with previous modeling studies reporting impaired performance under these conditions ${ }^{21}$. In sharp contrast, the performance of bidirectional tracing remained relatively robust to changes in test sensitivity even under these conditions.

a

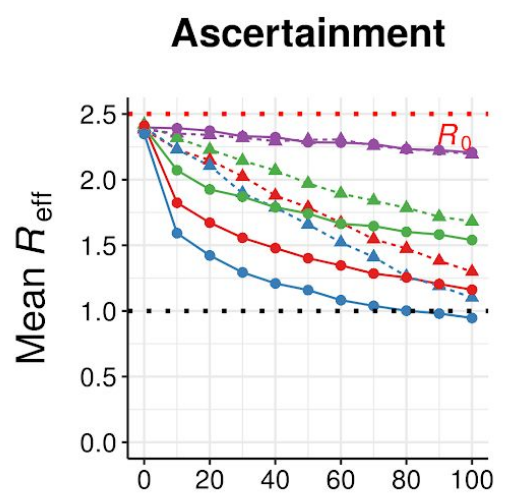

$\%$ symptomatic cases identified b

\section{Sensitivity (Test not required)}

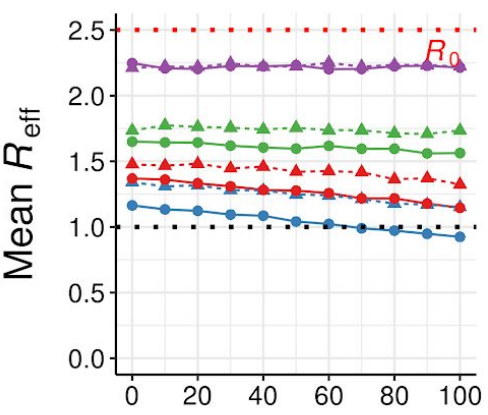

Test sensitivity (\%)
C
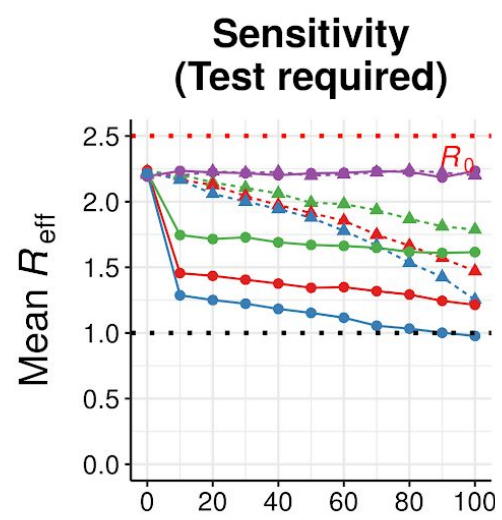

Test sensitivity (\%)

$\begin{array}{lll} & \rightarrow \text { Manual only } \rightarrow \text { Digital only } & \rightarrow \text { Bidirectional } \\ \text { Trace type } & \rightarrow \text { Manual }+ \text { digital } \rightarrow \text { No tracing } & - \text { - F Forward-only }\end{array}$

Figure 3. Bidirectional tracing under reduced ascertainment and test sensitivity. Mean effective reproduction number $\left(R_{\text {eff }}\right)$ achieved across 1000 runs per scenario by different tracing strategies (manual, digital, both or neither; forward-only or bidirectional) as a function of (a) the percentage of symptomatic cases that can be identified by health authorities based on symptoms or (b-c) test sensitivity, assuming 90\% probability of trace success, a 7-day manual tracing window, high-uptake digital tracing, and median disease parameters (Table S1). In (a-b), tracing can be initiated from symptomatic cases without a test, while in (c) a positive test result is required; in both cases, a positive test result is required to initiate tracing from pre- or asymptomatic cases. (a) assumes test sensitivity of $80 \%$, while (b-c) assume $90 \%$ of symptomatic cases are identified on the basis of symptoms. "Probability of trace success" refers to trace attempts that are not otherwise blocked by environmental transmission or fragmentation of the digital network. 
medRxiv preprint doi: https://doi.org/10.1101/2020.05.06.20093369; this version posted July 14, 2020. The copyright holder for this preprint (which was not certified by peer review) is the author/funder, who has granted medRxiv a license to display the preprint in perpetuity.

It is made available under a CC-BY 4.0 International license.

\section{High-uptake hybrid bidirectional tracing robustly doubles the probability of outbreak control}

To evaluate the epidemiological robustness of our findings, we repeated our analysis using $R_{0}$ values ranging from 1.0 to 4.0 (Fig. 4 , left) ${ }^{4,9,22-24}$. We assumed tracing of $90 \%$ of non-environmental contacts, a 7-day manual trace window, immediate tracing of symptomatic cases, and high uptake of the digital system. A wider range of assumptions are explored in Figures S9-S31.

Small reductions in $R_{0}$ resulted in large increases in control probability across all forms of tracing (Fig. 4, left). Hybrid bidirectional tracing robustly outperformed all other tracing strategies, with the greatest degree of outperformance observed when $1.75 \leq R_{0} \leq 3.5$. When $R_{0} \leq 1.75$, manual and hybrid tracing both achieved nearly $100 \%$ control, while when $R_{0} \geq 3.5$, no strategy achieved control probabilities over $10 \%$. Even in these low-control scenarios, however, hybrid bidirectional tracing consistently reduced $\mathrm{R}_{\text {eff }}$ by roughly $20 \%$ relative to manual tracing alone (Fig. 4 \& Figs. S19-S20, S22, S32). Constraining manual tracing to a 2- rather than 7-day window substantially impaired performance (Fig. S10), while lowering uptake of the digital system from $80 \%$ to $53 \%$ of cases - in line with existing survey data ${ }^{19-21}$ and current plans for opt-in participation ${ }^{11}$ - mostly abrogated the advantage of hybrid over manual approaches (Figs. S16 and S21-S22).

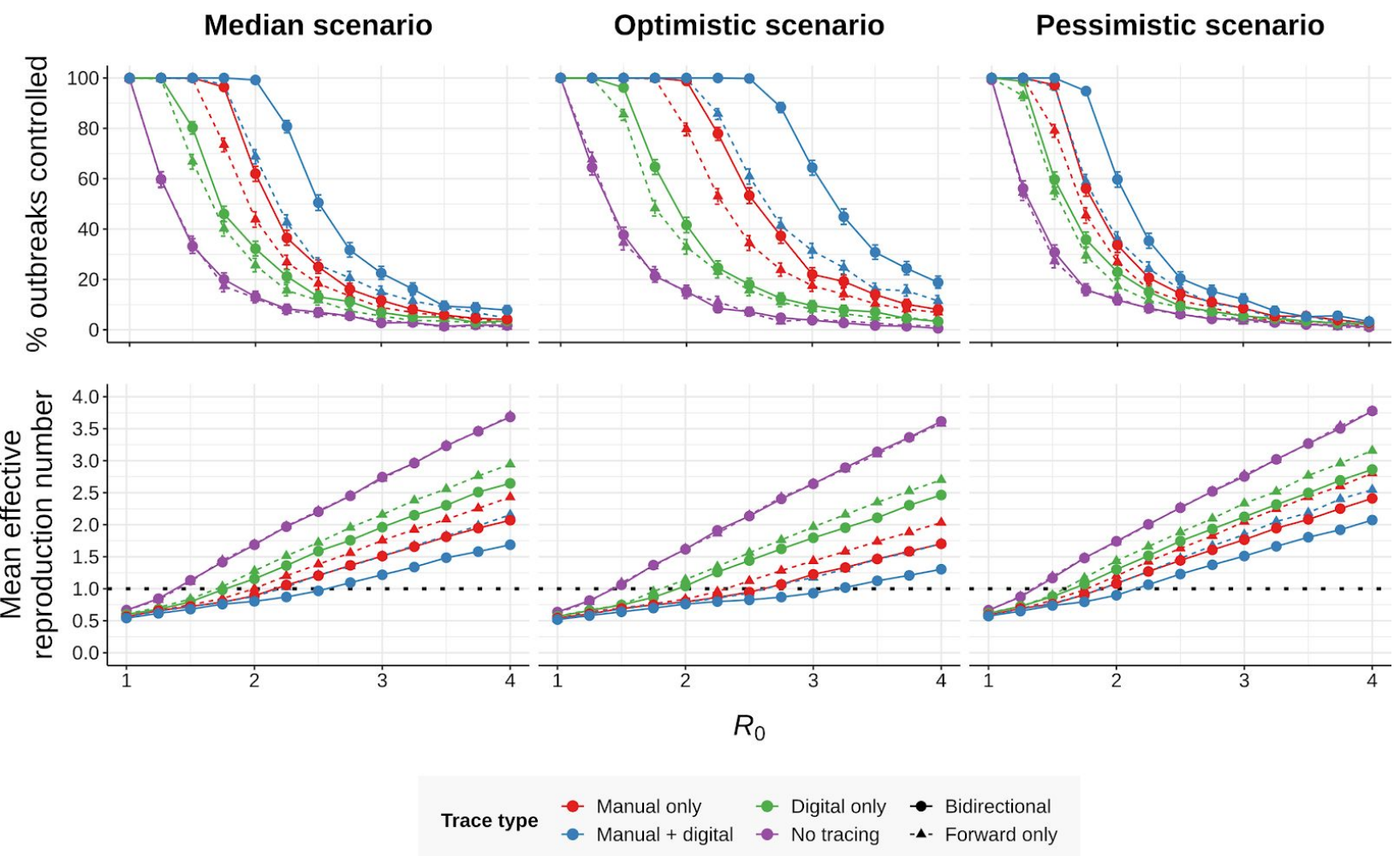

Figure 4. Effect of $\boldsymbol{R}_{\mathbf{0}}$ and disease parameters on performance. (top row) Percentage of outbreaks controlled and (bottom row) average effective reproduction number under various forms of contact tracing (manual, digital, both or neither; forward-only or bidirectional) as a function of the basic reproduction number $R_{0}$, assuming (left) median, (middle) optimistic or (right) pessimistic disease parameters (Table S1), 90\% non-environmental contacts traced, a 7-day manual trace window, and high-uptake digital tracing. Error bars in the top row represent $95 \%$ credible intervals across 1000 runs under a uniform beta prior; points in the bottom row represent average values over the same. Isolating symptomatic cases can dampen the outbreak at low $R_{0}$, even in the absence of tracing. 
While COVID-19 is clearly a challenging disease to control, there remains substantial uncertainty around the exact rates of asymptomatic, presymptomatic, and environmental transmission. To explore a wider range of scenarios, we aggregated our collective best estimates to define optimistic and pessimistic values for these parameters, with $5 / 15 \%$ environmental transmission, $38 / 53 \%$ pre-symptomatic transmission, and $40 / 55 \%$ asymptomatic carriers which were $45 / 60 \%$ as infectious as symptomatic cases. We repeated our simulations under these new assumptions for a range of $R_{0}$ values (Fig. 4 , middle \& right).

While hybrid bidirectional tracing continued to robustly outperform other configurations (Figs. S17-S22), the probability of control varied substantially between scenarios: in the optimistic scenario, high-uptake hybrid bidirectional tracing was sufficient to reliably control outbreaks whenever $R_{0} \leq 2.5$, while in the pessimistic scenario reliable control was only achieved at $R_{0} \leq 1.75$. Restricting uptake of the digital system or the width of the manual tracing window impaired performance across all scenarios (Figs. S10 \& S16-S22).

To summarize the predicted effects of different approaches, we compared the percentage of outbreaks controlled and $R_{\text {eff }}$ values achieved under all three scenarios, in the absence of any other interventions (Fig. 5, \& Figs. S33-S36). Relative to optimal current practice (i.e. 2-day forward-only manual tracing), 7-day bidirectional manual tracing achieved a reduction in $R_{\text {eff }}$ of roughly 0.3 across all scenarios. Supplementing manual tracing with a low-uptake digital system provided a further reduction of 0.1 in the median and pessimistic scenarios, increasing to 0.25 (i.e., 0.55 total) when uptake was high. In total, switching from current practice to high-uptake hybrid bidirectional tracing approximately tripled the probability of controlling the spread of SARS-CoV-2 across all three scenarios.

\section{Discussion}

Given the tremendous suffering inflicted by the COVID-19 pandemic and the potentially critical role of expanding contact-tracing systems in its control, there is an urgent need to optimize the implementation of these systems.

Our model predicts that making tracing bidirectional would markedly improve COVID-19 control. Indeed, for a contact-tracing system to reach the levels of control cited by earlier studies ${ }^{4,21}$, we find that bidirectional tracing is required. Bidirectional tracing outperforms forward-tracing regardless of how the tracing is done. Simply switching to manual bidirectional tracing is sufficient to reduce $R_{\text {eff }}$ by 0.3 if the time window for tracing is sufficiently wide, while high-uptake bidirectional hybrid tracing is predicted to be approximately three times as effective at controlling outbreaks as current best practice. The case for bidirectional tracing becomes even stronger when case ascertainment is otherwise suboptimal, or if a positive test result is required before tracing the contacts of a symptomatic case. 


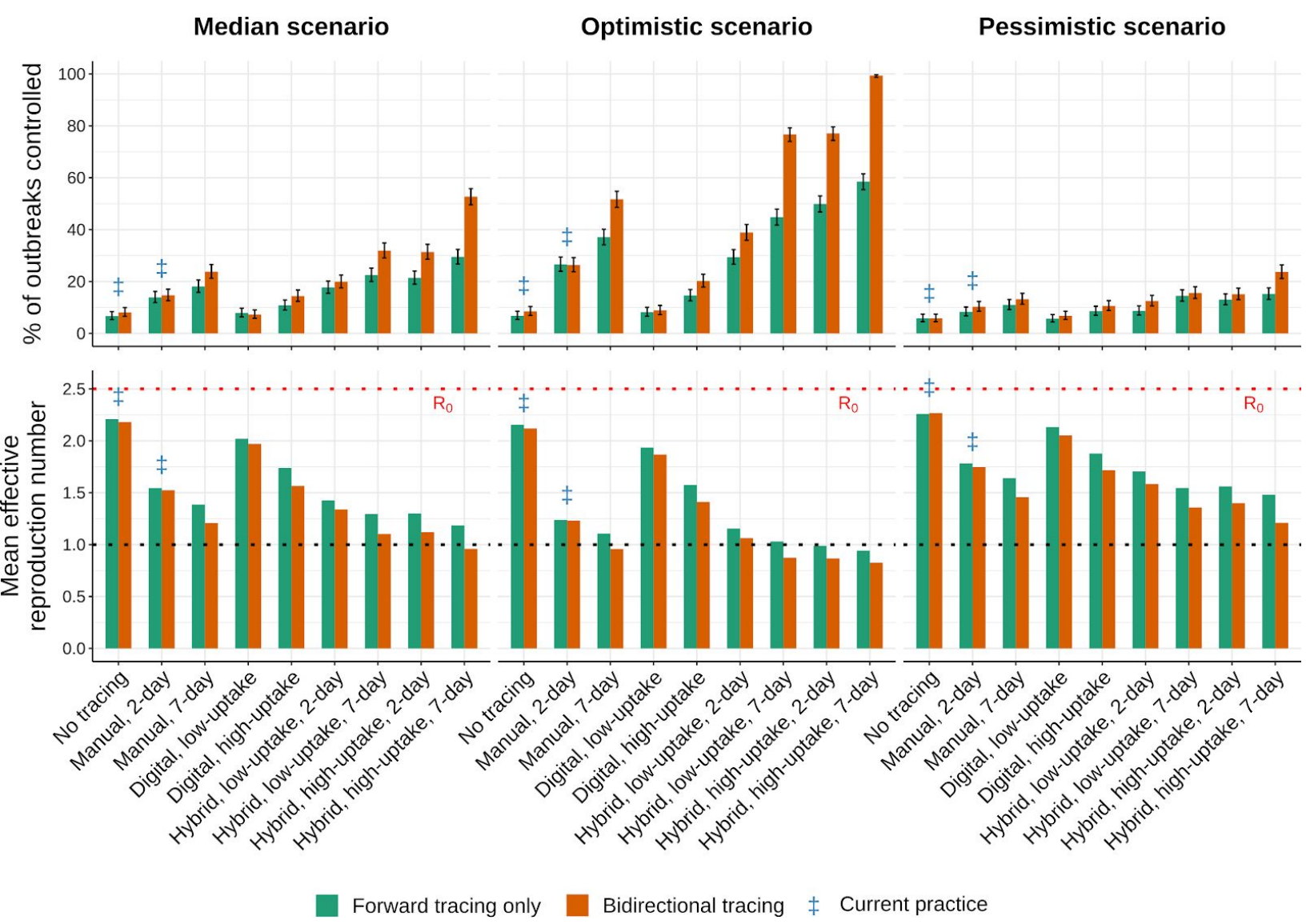

Figure 5. Performance of different tracing strategies relative to current practice. (top row) Percentage of outbreaks controlled, and (bottom row) mean effective reproduction number obtained under (left) median, (middle) optimistic, and (right) pessimistic scenarios (Table $\mathrm{S} 1$ ), assuming an $R_{0}$ of 2.5, 90\% of non-environmental contacts traced, 2- or 7-day manual trace windows, and immediate (pre-test) tracing of symptomatic cases. Blue $\$$ symbols indicate current practice in most regions. Low and high uptake correspond to $53 \%$ and $80 \%$ of cases, respectively, having chirp-enabled smartphones. Error bars in the top row represent 95\% credible intervals across 1000 runs under a uniform beta prior. Without tracing, forward and bidirectional are equivalent.

We stress-tested these conclusions with a wide range of plausible parameter combinations and possible values of $R_{0}$. Notably, our "optimistic" scenario is more pessimistic than some earlier studies due to recent studies reporting higher values for both the rate and relative infectiousness of asymptomatic carriers $^{5,9,23,25,26}$. Whether hybrid bidirectional tracing alone was sufficient to reliably control the pandemic was dependent on epidemiological parameters; however, if other low-cost precautions ${ }^{27}$ could reduce $R_{\text {eff }}$ below 1.75, our model predicts that this strategy would bring transmission under control with high probability even under our pessimistic scenario.

Despite this stress-testing, our conclusions must be considered in the context of our model, which, while less idealized than its predecessors, has limitations. It makes no distinction between mild and severe symptoms, and does not consider demographic, geospatial or behavioural variation between cases. Since only true cases are included in the model, only the sensitivity of testing is considered; in reality, the 
balance between test sensitivity and specificity is a crucial trade-off, and high rates of false positives will severely impede response effectiveness and the credibility of the tracing system.

These limitations aside, there is considerable evidence that bidirectional tracing can be feasibly implemented in practice. Locales such as Singapore ${ }^{13,14}$ and Washington State $^{28}$ have employed bidirectional tracing to determine whether community transmission is occurring, while Japan's protocol explicitly aims to identify sources of infection ${ }^{12}$. The primary practical difference between contact with an infector and an infectee is the time at which the contact occurred; as such, the core obstacle to implementation in other areas is the cost of expanding the tracing window. Health authorities could accomplish this by expanding the workforce of contact tracers, leveraging the lightened workload afforded by a high-uptake digital system, or focusing limited resources on clusters as is done in Japan. Digital systems, which already track exposures for 14 days, can trace bidirectionally at no additional cost.

In addition to effective implementation of bidirectional tracing, a successful control program will also depend on the availability of timely COVID-19 testing ${ }^{15}$, high adherence to quarantine requests ${ }^{4,17,29,30}$, and scaling of manual contact tracing, while digital systems will require efficient algorithms with acceptable sensitivity and specificity. These caveats notwithstanding, our results indicate that bidirectional contact tracing could play an essential and potentially decisive role in controlling COVID-19 and preventing future pandemics.

\section{Acknowledgments}

We thank Aaron Bucher of the COVID-19 HPC Consortium and Amazon Web Services for granting us extra cloud compute credits.

Funding: This work was supported by gifts from the Reid Hoffman Foundation and the Open Philanthropy Project (to K.M.E.) and cluster time granted by the COVID-19 HPC consortium (MCB20071 to K.M.E.). E.C.A. was supported by a fellowship from the Open Philanthropy Project. A.L.L. is supported by the Drexel Endowment (NC State University). The funders had no role in the research, writing, or decision to publish.

Author Contributions: K.M.E. conceived the study. J.H.H. and A.L.L. identified a suitable model framework. W.J.B. designed and programmed the adapted model, advised by the other authors. All authors independently estimated key model parameters based on the literature. W.J.B. ran all simulations and generated figures with assistance from E.C.A. All authors jointly wrote and edited the manuscript.

Data and Code Availability: Code for configuring and running the model is publicly available at https://github.com/willbradshaw/covid-bidirectional-tracing. 
medRxiv preprint doi: https://doi.org/10.1101/2020.05.06.20093369; this version posted July 14, 2020. The copyright holder for this preprint (which was not certified by peer review) is the author/funder, who has granted medRxiv a license to display the preprint in perpetuity.

It is made available under a CC-BY 4.0 International license .

\section{References}

1 Cohen J, Kupferschmidt K. Countries test tactics in 'war' against COVID-19. Science 2020; 367: $1287-8$.

2 European Centre for Disease Prevention. Contact tracing: Public health management of persons, including healthcare workers, having had contact with COVID-19 cases in the European Union second update. 2020

https://www.ecdc.europa.eu/en/covid-19-contact-tracing-public-health-management (accessed April 27, 2020).

3 World Health Organization. Contact tracing in the context of COVID-19. 2020 https://www.who.int/publications-detail/contact-tracing-in-the-context-of-covid-19 (accessed June 1, 2020).

4 Ferretti L, Wymant C, Kendall M, et al. Quantifying SARS-CoV-2 transmission suggests epidemic control with digital contact tracing. Science 2020; published online March 31.

DOI:10.1126/science.abb6936.

5 Zou L, Ruan F, Huang M, et al. SARS-CoV-2 Viral Load in Upper Respiratory Specimens of Infected Patients. N Engl J Med 2020; 382: 1177-9.

6 Mizumoto K, Kagaya K, Zarebski A, Chowell G. Estimating the asymptomatic proportion of coronavirus disease 2019 (COVID-19) cases on board the Diamond Princess cruise ship, Yokohama, Japan, 2020. Euro Surveill 2020; 25. DOI:10.2807/1560-7917.ES.2020.25.10.2000180.

7 Sutton D, Fuchs K, D'Alton M, Goffman D. Universal Screening for SARS-CoV-2 in Women Admitted for Delivery. N Engl J Med 2020; published online April 13.

DOI:10.1056/NEJMc2009316.

8 Gudbjartsson DF, Helgason A, Jonsson H, et al. Spread of SARS-CoV-2 in the Icelandic Population. N Engl J Med 2020; published online April 14. DOI:10.1056/NEJMoa2006100.

9 Lavezzo E, Franchin E, Ciavarella C, et al. Suppression of COVID-19 outbreak in the municipality of Vo, Italy. medRxiv. 2020; published online April 18. DOI:10.1101/2020.04.17.20053157.

10 Ma S, Zhang J, Zeng M, et al. Epidemiological parameters of coronavirus disease 2019: a pooled analysis of publicly reported individual data of 1155 cases from seven countries. medRxiv. 2020; published online March 24. DOI:10.1101/2020.03.21.20040329.

11 Google. Exposure Notification FAQ v1.0. Google, 2020

https://www.blog.google/documents/63/Exposure_Notification_-_FAQ_v1.0.pdf.

12 Ministry of Health, Labor, and Welfare, Japan. Preventing the spread of COVID-19 by targeting disease clusters. 25 February, 2020 https://www.mhlw.go.jp/content/10906000/000599837.pdf.

13 Jo YS. A guide to Singapore's Covid-19 contact-tracing system, Multimedia. The Straits Times. 2020; published online March 28.

https:/www.straitstimes.com/multimedia/a-guide-to-singapores-covid-19-contact-tracing-system 
medRxiv preprint doi: https://doi.org/10.1101/2020.05.06.20093369; this version posted July 14, 2020. The copyright holder for this preprint (which was not certified by peer review) is the author/funder, who has granted medRxiv a license to display the preprint in perpetuity.

(accessed June 1, 2020).

14 Yong SEF, Anderson DE, Wei WE, et al. Connecting clusters of COVID-19: an epidemiological and serological investigation. Lancet Infect Dis 2020; published online April 21.

DOI:10.1016/S1473-3099(20)30273-5.

15 Müller J, Koopmann B. The effect of delay on contact tracing. Math Biosci 2016; 282: 204-14.

$16 \mathrm{DP}^{\wedge} 3 \mathrm{~T}$ Consortium. Decentralized Privacy-Preserving Contact Tracing. Github. https://github.com/DP-3T (accessed May 6, 2020).

17 Hellewell J, Abbott S, Gimma A, et al. Feasibility of controlling COVID-19 outbreaks by isolation of cases and contacts. Lancet Glob Health 2020; 8: e488-96.

18 Rivest R, Weitzner D, Kalai Y, Raskar R, Gruber J, Esvelt KM, Vepakomma P, Zeldovich N, Abelson H. A simple proximity-based approach to contact tracing. 2020; published online March 23. https://epic.org/privacy/covid/Rivest-Contact-Tracing.pdf.

19 KFF Health Tracking Poll - Late April 2020: Coronavirus, Social Distancing, and Contact Tracing. The Henry J. Kaiser Family Foundation. 2020; published online April 24.

https://www.kff.org/global-health-policy/issue-brief/kff-health-tracking-poll-late-april-2020/ (accessed April 27, 2020).

20 Hargittai E, Redmiles E. Will Americans Be Willing to Install COVID-19 Tracking Apps? Scientific American Blog Network.

https://blogs.scientificamerican.com/observations/will-americans-be-willing-to-install-covid-19-trac king-apps/ (accessed May 4, 2020).

21 Hinch R, Probert W, Nurtay A, Kendall M, Wymant C, Hall M, Lythgoe K, Bulas Cruz A, Zhao L, Stewart A, Ferretti L, Parker M, Meroueh A, Mathias B, Stevenson S, Montero D, Warren J, Mather NK, Finkelstein A, Abeler-Dorner L, Bonsall D, Fraser C. Effective configurations of a digtal contact tracing app: A report to NHSX. 2020; published online April.

https://github.com/BDI-pathogens/covid-19_instant_tracing (accessed May 3, 2020).

22 Kucharski AJ, Klepac P, Conlan A, et al. Effectiveness of isolation, testing, contact tracing and physical distancing on reducing transmission of SARS-CoV-2 in different settings. medRxiv. 2020; published online April 29. DOI:10.1101/2020.04.23.20077024.

23 Li R, Pei S, Chen B, et al. Substantial undocumented infection facilitates the rapid dissemination of novel coronavirus (SARS-CoV-2). Science 2020; 368: 489-93.

24 Riccardo F, Ajelli M, Andrianou X, et al. Epidemiological characteristics of COVID-19 cases in Italy and estimates of the reproductive numbers one month into the epidemic. medRxiv. 2020; published online April 11. DOI:10.1101/2020.04.08.20056861.

25 Cao B, Wang Y, Wen D, et al. A Trial of Lopinavir-Ritonavir in Adults Hospitalized with Severe Covid-19. N Engl J Med 2020; published online March 18. DOI:10.1056/NEJMoa2001282.

26 Chau NVV, Lam VT, Dung NT, et al. The natural history and transmission potential of asymptomatic SARS-CoV-2 infection. medRxiv. 2020; published online April 29.

DOI:10.1101/2020.04.27.20082347.

27 Zhang J, Litvinova M, Liang Y, et al. Changes in contact patterns shape the dynamics of the 
COVID-19 outbreak in China. Science 2020; published online April 29.

DOI:10.1126/science.abb8001.

28 Hamner L, Dubbel P, Capron I, et al. High SARS-CoV-2 Attack Rate Following Exposure at a Choir Practice - Skagit County, Washington, March 2020. MMWR Morb Mortal Wkly Rep 2020; 69: 606-10.

29 Kretzschmar M, Rozhnova G, van Boven M. Effectiveness of Isolation and Contact Tracing for Containment and Slowing Down a COVID-19 Epidemic: A Modelling Study. 2020; published online March.

30 Peak CM, Kahn R, Grad YH, et al. Comparative Impact of Individual Quarantine vs. Active Monitoring of Contacts for the Mitigation of COVID-19: a modelling study. medRxiv. 2020; published online March 8. DOI:10.1101/2020.03.05.20031088. 
medRxiv preprint doi: https://doi.org/10.1101/2020.05.06.20093369; this version posted July 14, 2020. The copyright holder for this preprint (which was not certified by peer review) is the author/funder, who has granted medRxiv a license to display the preprint in perpetuity.

It is made available under a CC-BY 4.0 International license .

\section{Supplementary References}

31 Rivett L, Sridhar S, Sparkes D, et al. Screening of healthcare workers for SARS-CoV-2 highlights the role of asymptomatic carriage in COVID-19 transmission. Elife 2020; 9: e58728.

$32 \mathrm{Hu} \mathrm{Z}$, Song C, Xu C, et al. Clinical characteristics of 24 asymptomatic infections with COVID-19 screened among close contacts in Nanjing, China. Sci China Life Sci 2020; 63: 706-11.

33 Jing Cai, Wenjie Sun, Jianping Huang, Michelle Gamber, Jing Wu, Guiqing He. Indirect Virus Transmission in Cluster of COVID-19 Cases, Wenzhou, China, 2020. Emerging Infectious Disease journal 2020; 26. DOI:10.3201/eid2606.200412.

34 Cheng H-Y, Jian S-W, Liu D-P, et al. Contact Tracing Assessment of COVID-19 Transmission Dynamics in Taiwan and Risk at Different Exposure Periods Before and After Symptom Onset. JAMA Intern Med 2020; published online May 1. DOI:10.1001/jamainternmed.2020.2020.

35 He X, Lau EHY, Wu P, et al. Temporal dynamics in viral shedding and transmissibility of COVID-19. Nat Med 2020; published online April 15. DOI:10.1038/s41591-020-0869-5.

36 Jing Q-L, Liu M-J, Yuan J, et al. Household Secondary Attack Rate of COVID-19 and Associated Determinants. medRxiv. 2020; published online April 15. DOI:10.1101/2020.04.11.20056010.

37 Zhanwei Du, Xiaoke Xu, Ye Wu, Lin Wang, Benjamin J. Cowling, Lauren Ancel Meyers. Serial Interval of COVID-19 among Publicly Reported Confirmed Cases. Emerging Infectious Disease journal 2020; 26. DOI:10.3201/eid2606.200357.

38 Wei WE, Li Z, Chiew CJ, Yong SE, Toh MP, Lee VJ. Presymptomatic Transmission of SARS-CoV-2 - Singapore, January 23-March 16, 2020. MMWR Morb Mortal Wkly Rep 2020; 69: $411-5$.

39 Ganyani T, Kremer C, Chen D, et al. Estimating the generation interval for coronavirus disease (COVID-19) based on symptom onset data, March 2020. Eurosurveillance 2020; 25: 2000257.

40 Demographics of Mobile Device Ownership and Adoption in the United States. Pew Research Center: Internet, Science \& Tech. https://www.pewresearch.org/internet/fact-sheet/mobile/ (accessed April 28, 2020).

41 Harmon A. Inside the Race to Contain America's First Coronavirus Case. The New York Times. 2020; published online Feb 5.

https://www.nytimes.com/2020/02/05/us/corona-virus-washington-state.html (accessed May 4, 2020).

42 Zhao J, Yuan Q, Wang H, et al. Antibody responses to SARS-CoV-2 in patients of novel coronavirus disease 2019. Clin Infect Dis 2020; published online March 28.

DOI:10.1093/cid/ciaa344.

43 Whitman JD, Hiatt J, Mowery CT, et al. Test performance evaluation of SARS-CoV-2 serological assays. medRxiv. 2020; published online April 29. DOI:10.1101/2020.04.25.20074856.

44 Li Q, Guan X, Wu P, et al. Early Transmission Dynamics in Wuhan, China, of Novel 
Coronavirus-Infected Pneumonia. N Engl J Med 2020; 382: 1199-207.

45 Endo A, Centre for the Mathematical Modelling of Infectious Diseases COVID-19 Working Group, Abbott S, Kucharski AJ, Funk S. Estimating the overdispersion in COVID-19 transmission using outbreak sizes outside China. Wellcome Open Res 2020; 5: 67.

46 Keyword Team. Apple and Google partner on COVID-19 contact tracing technology. Google. 2020; published online April 10.

https://blog.google/inside-google/company-announcements/apple-and-google-partner-covid-19-conta ct-tracing-technology/ (accessed April 27, 2020).

47 Lauer SA, Grantz KH, Bi Q, et al. The incubation period of 2019-nCoV from publicly reported confirmed cases: estimation and application. medRxiv 2020. DOI:10.1101/2020.02.02.20020016.

48 McCann L, Allan W, Read P, McNulty A. Contact tracing using provider referral: how difficult is it? Sex Health 2013; 10: 472-3. 


\section{Methods}

\section{Structure of the model - Infection dynamics}

A new case is infected at some exposure time, equal to zero if the case is an index case and otherwise drawn from the generation time distribution of its parent case (see below). If not asymptomatic, the case develops symptoms at some onset time drawn from an incubation time distribution. Asymptomatic cases do not develop symptoms, but are still assigned an onset time for the purpose of determining their generation-time distribution (see below).

The number of child cases infected by the case is drawn from a negative binomial distribution, with mean equal to the appropriate reproduction number (see below) and heterogeneity determined by the overdispersion parameter $k$. The exposure times of these child cases are drawn from a skewed-normal generation time distribution centered on the symptom onset of their parent ${ }^{17}$, with a skew parameter chosen to give a pre-specified probability of pre-symptomatic transmission (for a symptomatic parent) and an SD parameter of 2. The generation time distribution for an asymptomatic parent is centered on its "effective" onset time (see above). The shape of the generation-time distribution is the same for all cases.

The average number of children produced by a case depends on its symptomatic status, and is determined by the overall $R_{0}$ value, the proportion of asymptomatic carriers $p_{\text {asym }}$, and the relative infectiousness $x_{\text {asym }}$ of asymptomatic carriers (expressed as a fraction of $R_{0}$ ). Given a reproduction number for asymptomatics of $R_{\text {asym }}=R_{0} \cdot x_{\text {asym }}$, the reproduction number of symptomatic cases that produces the desired overall $R_{0}$ is given by $R_{\text {sym }}=R_{\text {asym }} \cdot \frac{p_{\text {asym }}}{1-p_{\text {asym }}}$.

\section{Structure of the model - Infection control}

Once symptoms develop, a case is identified by public health authorities with probability $p_{i s o l}$, with the delay from onset to identification drawn from a delay distribution. Identified cases are instructed to isolate, and each case complies with that order with probability $p_{\text {comply }}$. Cases that comply with isolation generate no further child cases after their time of identification. Asymptomatic cases cannot be identified from symptoms, but may be identified via contact tracing from other cases (see below); once identified, they are instructed to isolate as above. Tracing can also cause symptomatic cases to be isolated earlier than they would be from symptoms alone. 
An identified case is tested, which takes time drawn from a test time distribution and returns a positive result with probability equal to the sensitivity of the test (since the model does not consider uninfected individuals, the specificity of the test is also not considered). For asymptomatic cases, or symptomatic cases identified prior to symptom onset, a positive test result is required to initiate contact tracing; symptomatic cases that have already developed symptoms can either be traced immediately upon identification, or require a positive test result prior to tracing, depending on model settings.

Whether before or after a test result is obtained, the contacts of an identified case can also be traced. Tracing can only proceed outward from a case if they share their contact history, either via a contact-tracing app or with a manual contact tracer (see below). Tracing can identify the children of the traced case (forward tracing), and may also be able to identify its parent (reverse/backward tracing), depending on model settings. The speed and success probability of tracing depend upon whether tracing is conducted digitally or manually, which in turn depends on several factors:

- If the contact between the trace originator and the tracee occurred environmentally (determined with probability $\left.p_{\text {env }}\right)$, tracing cannot take place.

- If transmission was not environmental, the contact can be traced digitally if:

- Both the trace originator and the tracee possess chirp-enabled smartphones (determined independently for each individual case with probability $p_{\text {smartphone }}$ );

- The trace originator shares their data with the tracing app (determined independently for each individual case with probability $\left.p_{\text {share_digital }}\right)$;

- The time of between contact (equal to the exposure time of the child case, i.e. of the trace in forward tracing and the trace initiator in reverse tracing) and trace initiation is less than the data-retention window of the digital tracing system;

- The contact between the two cases was recorded by the tracing app of the trace originator (determined independently for each individual case with probability $p_{\text {trace_digital }}$ ).

- If any of the above conditions are not met, but transmission was not environmental, the contact might still be traced manually if:

- The trace originator shares their contact history with a manual contact tracer (determined independently for each individual case with probability $p_{\text {share_manual }}$ );

- The time between contact (as above) and the identification time or symptom onset of the trace initiator (whichever came first) is less than the contact-tracing window of the manual tracing system; 
medRxiv preprint doi: https://doi.org/10.1101/2020.05.06.20093369; this version posted July 14, 2020. The copyright holder for this preprint

- The tracee is successfully traced by the contact tracer (determined independently for each individual case with probability $p_{\text {trace_manual }}$ ).

- If neither digital nor manual tracing succeeds, then the trace fails and the tracee is not traced.

Cases that are successfully traced are identified at a time equal to the trace initiation time of the trace originator plus a delay time drawn from the appropriate trace delay distribution (which will differ between digital and manual tracing). Cases identified through tracing can then be isolated, tested, and traced as described above. If a case is isolated through tracing earlier than they would have been otherwise, child cases whose exposure time would be later than their parent's new isolation time are eliminated, as are their descendents.

\section{Run initiation and termination}

A simulation of an outbreak under the branching-process model is initialised with a given number of index cases (by default 20, in order to reduce the probability of stochastic elimination) and proceeds generation by generation until either no further child cases are generated (extinction) or the run exceeds one of:

1. A cumulative case limit of 10,000 cases, reached if the total number of cases ever exceeded that number, or

2. A time limit of 52 weeks, reached if the latest exposure time across all cases ever exceeded that number.

In practice, virtually all runs either went extinct or reached the cumulative case limit; across all scenarios tested for all datasets used in Figures 2-4, the overall percentage of runs that terminated as a result of exceeding the time limit was less than $0.02 \%$, and the highest percentage observed for any single scenario was $1.3 \%$. The cumulative case limit, meanwhile, was selected to minimise the chance of a run that would otherwise go extinct being terminated prematurely while preserving computational tractability; in test runs with a cumulative case limit of 100,000 cases, fewer than $2 \%$ of extinct runs in any scenario had a cumulative case count of over 10,000 .

A terminated run was deemed "controlled" if it reached extinction, and uncontrolled otherwise. The control rate for a scenario was computed as the proportion of runs for that scenario that were controlled. 95\% credible intervals on the control rate were computed by beta-binomial conjugacy under a $\operatorname{Beta}(1,1)$ uniform prior, as the 2.5th and 97.5th percentiles of the beta distribution $\operatorname{Beta}(1+k, 1+n-k)$, where $n$ 
medRxiv preprint doi: https://doi.org/10.1101/2020.05.06.20093369; this version posted July 14, 2020. The copyright holder for this preprint (which was not certified by peer review) is the author/funder, who has granted medRxiv a license to display the preprint in perpetuity.

It is made available under a CC-BY 4.0 International license .

is the total number of runs for that scenario and $k$ is the number of controlled runs. Effective reproduction numbers were computed as the average number of child cases produced across all cases in a run, averaged across all runs in the scenario. For main figures, 1000 runs were performed per scenario; for figures, either 500 or 1000 runs were performed, as specified in the figure captions. 


\section{Supplementary tables}

Table S1: Parameters of the branching-process model.

\begin{tabular}{|c|c|c|c|c|}
\hline \multirow[t]{2}{*}{ Parameter } & \multicolumn{3}{|l|}{ Value } & \multirow[t]{2}{*}{ Sources and Notes } \\
\hline & Median & Optimistic & Pessimistic & \\
\hline$\%$ asymptomatic carriers & $45 \%$ & $40 \%$ & $55 \%$ & $8-10,31$ \\
\hline $\begin{array}{l}\text { Relative infectiousness of } \\
\text { asymptomatic carriers }\end{array}$ & $50 \%$ & $45 \%$ & $60 \%$ & $\begin{array}{l}\text { Informed by viral loads and tracing } \\
\text { results described in } 5,9,23,25,26,32\end{array}$ \\
\hline$\%$ environmental transmission & $10 \%$ & $5 \%$ & $15 \%$ & 4,33 \\
\hline $\begin{array}{l}\text { Proportion of pre-symptomatic } \\
\text { transmission }\end{array}$ & $48 \%$ & $38 \%$ & $53 \%$ & $\begin{array}{l}\text { Informed by viral load measurements, } \\
\text { tracing results, and negative serial } \\
\text { intervals described in }{ }_{5,23,26,34-39}\end{array}$ \\
\hline $\begin{array}{l}\% \text { of symptomatic cases identified } \\
\text { without tracing }\end{array}$ & \multicolumn{3}{|l|}{$90 \%$} & Assumed \\
\hline $\begin{array}{l}\% \text { of cases with chirping smartphones } \\
\text { (high-uptake case) }\end{array}$ & \multicolumn{3}{|c|}{$53 \%$ (low-uptake) / 80\% (high-uptake) } & $\begin{array}{l}\text { Survey data on phone ownership and } \\
\text { attitudes to exposure notification }{ }^{19,20,40}\end{array}$ \\
\hline $\begin{array}{l}\% \text { of cases with smartphones who } \\
\text { upload data when diagnosed }\end{array}$ & \multicolumn{3}{|l|}{$90 \%$} & Assumed \\
\hline $\begin{array}{l}\% \text { of cases who share data with } \\
\text { manual contact tracers }\end{array}$ & \multicolumn{3}{|l|}{$98 \%$} & Non-cooperation reportedly rare ${ }^{41}$ \\
\hline Test sensitivity & \multicolumn{3}{|l|}{$80 \%$} & 42,43 \\
\hline$R_{0}$ (default) & \multicolumn{3}{|l|}{2.5} & $\begin{array}{l}\text { Most estimates cluster between } 2.0 \\
\text { and 3.0: }\end{array}$ \\
\hline Overdispersion & \multicolumn{3}{|l|}{0.11} & 45 \\
\hline Number of initial cases & \multicolumn{3}{|l|}{20} & Assumed \\
\hline $\begin{array}{l}\text { Data retention window for digital } \\
\text { tracing (days) }\end{array}$ & \multicolumn{3}{|l|}{14 days } & 46 \\
\hline Incubation period & \multicolumn{3}{|c|}{$5.5 \pm 2.1$ days (lognormal distribution) } & 47 \\
\hline Delay from onset to isolation & \multicolumn{3}{|c|}{$3.8 \pm 2.4$ days (Weibull distribution) } & 17 \\
\hline Delay for testing & \multicolumn{3}{|c|}{$1 \pm 0.3$ days (gamma distribution) } & Assumed \\
\hline Delay for manual tracing & \multicolumn{3}{|c|}{$\begin{array}{l}1.5 \pm 4.8 \text { days (lognormal distribution); } \\
\text { median } 0.5 \text { days }\end{array}$} & $\begin{array}{l}\text { Previous reports suggest most contacts } \\
\text { can be traced within one day, but some } \\
\text { take much longer }{ }^{48}\end{array}$ \\
\hline Delay for digital tracing & \multicolumn{3}{|l|}{0 days } & Assumed \\
\hline
\end{tabular}




\section{Supplementary figures}

a

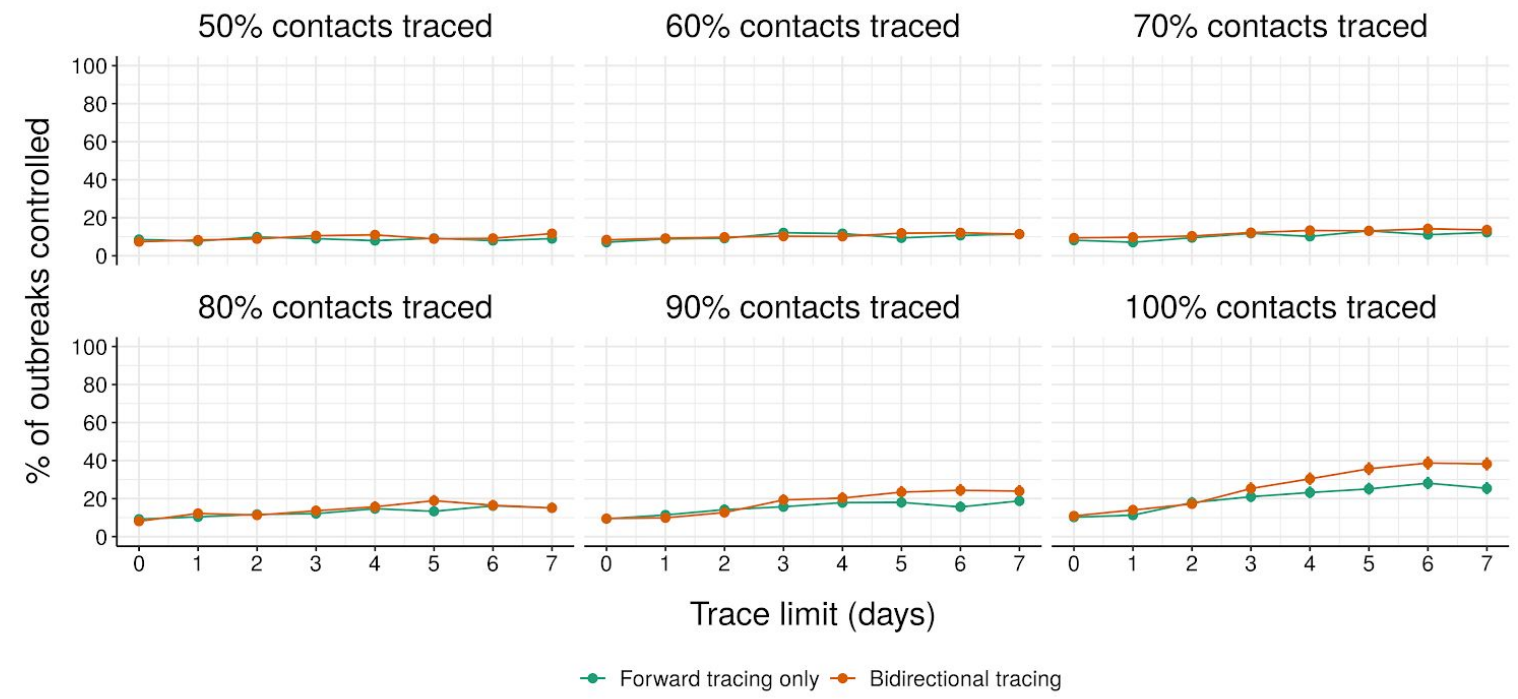

b

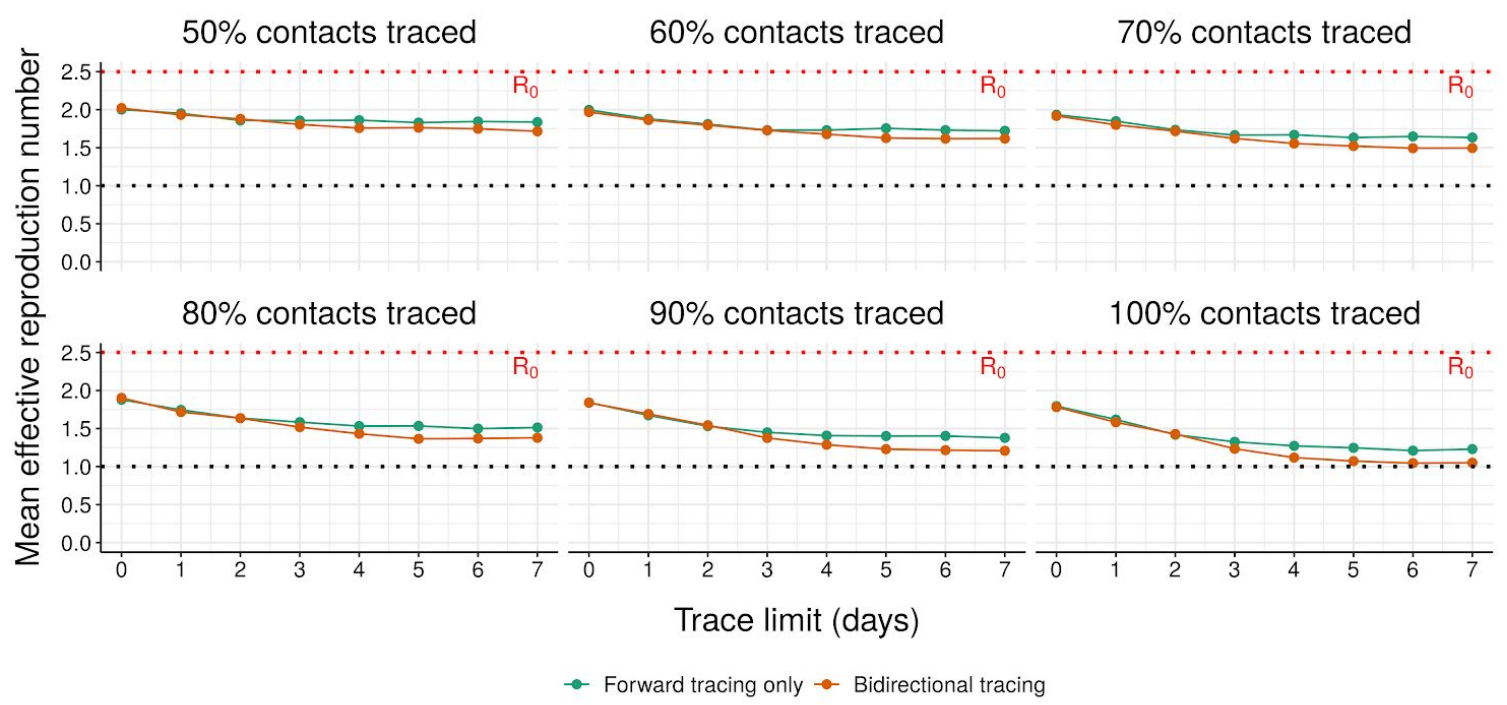

Figure S1: Effect of contact-tracing window size on performance of manual tracing. (a) Control rate and (b) average effective reproduction number of manual tracing under median parameters (Table S1) when contacts are traced for varying periods prior to symptom onset (for symptomatic cases) or case identification (for presymptomatic and asymptomatic cases). Panel headers indicate the percentage of non-environmental contacts traced. Error bars in (a) represent 95\% credible intervals across 1000 runs under a uniform beta prior; points in (b) represent average values over the same. 
a

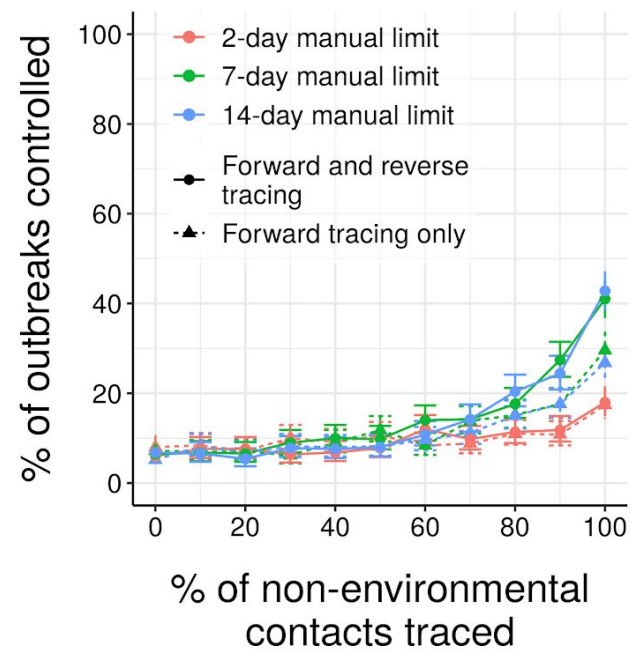

b

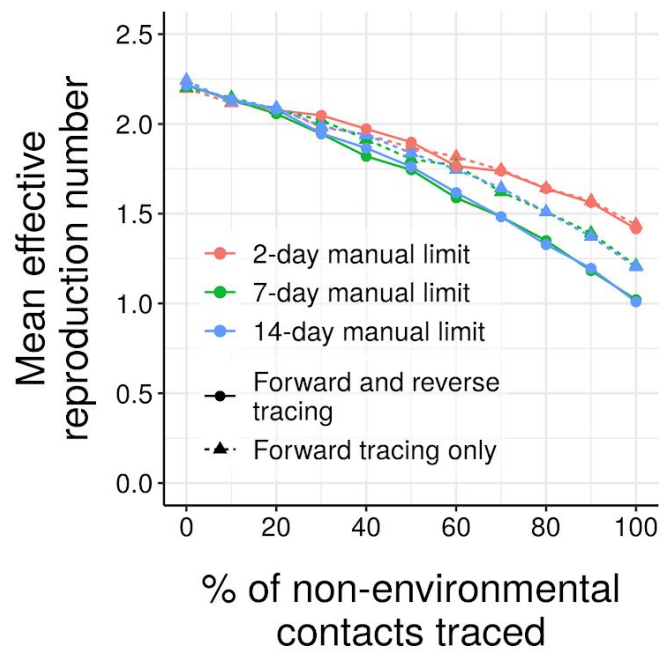

Figure S2: Effect of increased contact-tracing window size on performance of manual tracing. (a) Control rate and (b) average effective reproduction number of manual tracing under median disease parameters (Table S1) when contacts are traced up to 2, 7, or 14 days prior to symptom onset (for symptomatic cases) or case identification (for presymptomatic and asymptomatic cases). Error bars in (a) represent $95 \%$ credible intervals across 500 runs under a uniform beta prior; points in (b) represent average values over the same. 
a

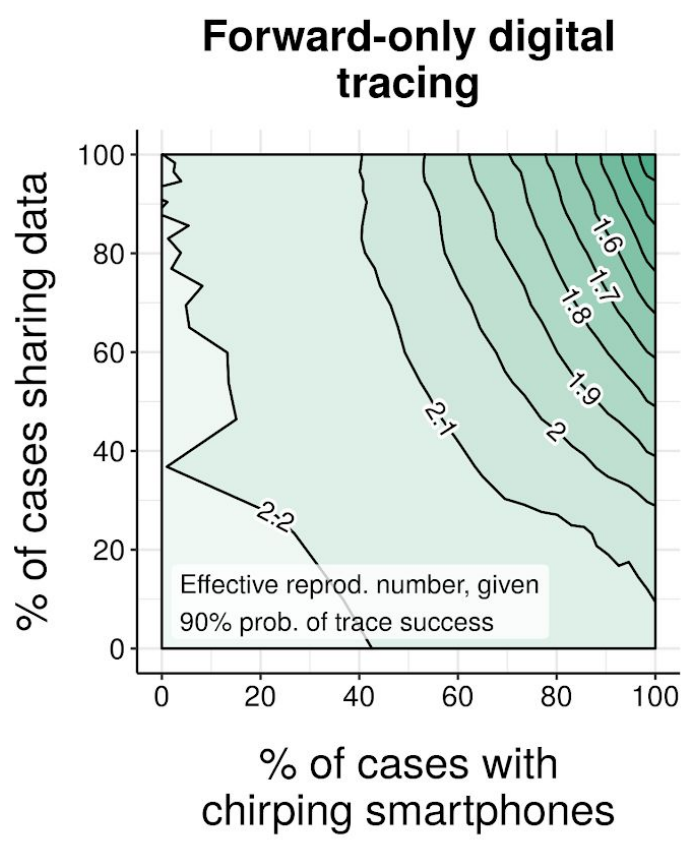

b

\section{Forward-only hybrid tracing (7-day manual window)}

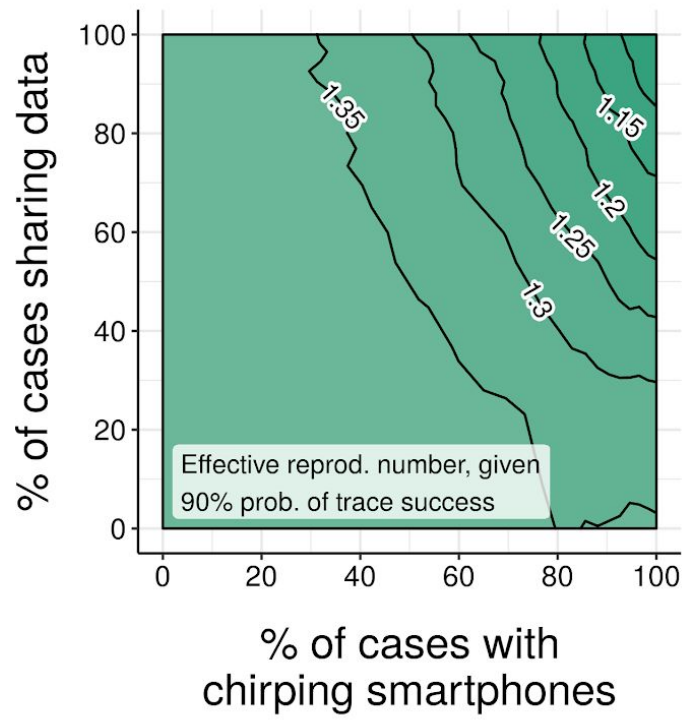

Figure S3: Effect of network fragmentation on performance of forward-only tracing.

Neighbour-averaged contour plot of effective reproduction number achieved under (a) digital-only and (b) hybrid forward-only tracing, over 1000 runs per scenario, for different levels of smartphone coverage and data-sharing, assuming median disease parameters (Table S1) and a 90\% probability of trace success. 
medRxiv preprint doi: https://doi.org/10.1101/2020.05.06.20093369; this version posted July 14, 2020. The copyright holder for this preprint (which was not certified by peer review) is the author/funder, who has granted medRxiv a license to display the preprint in perpetuity.

It is made available under a CC-BY 4.0 International license.

a

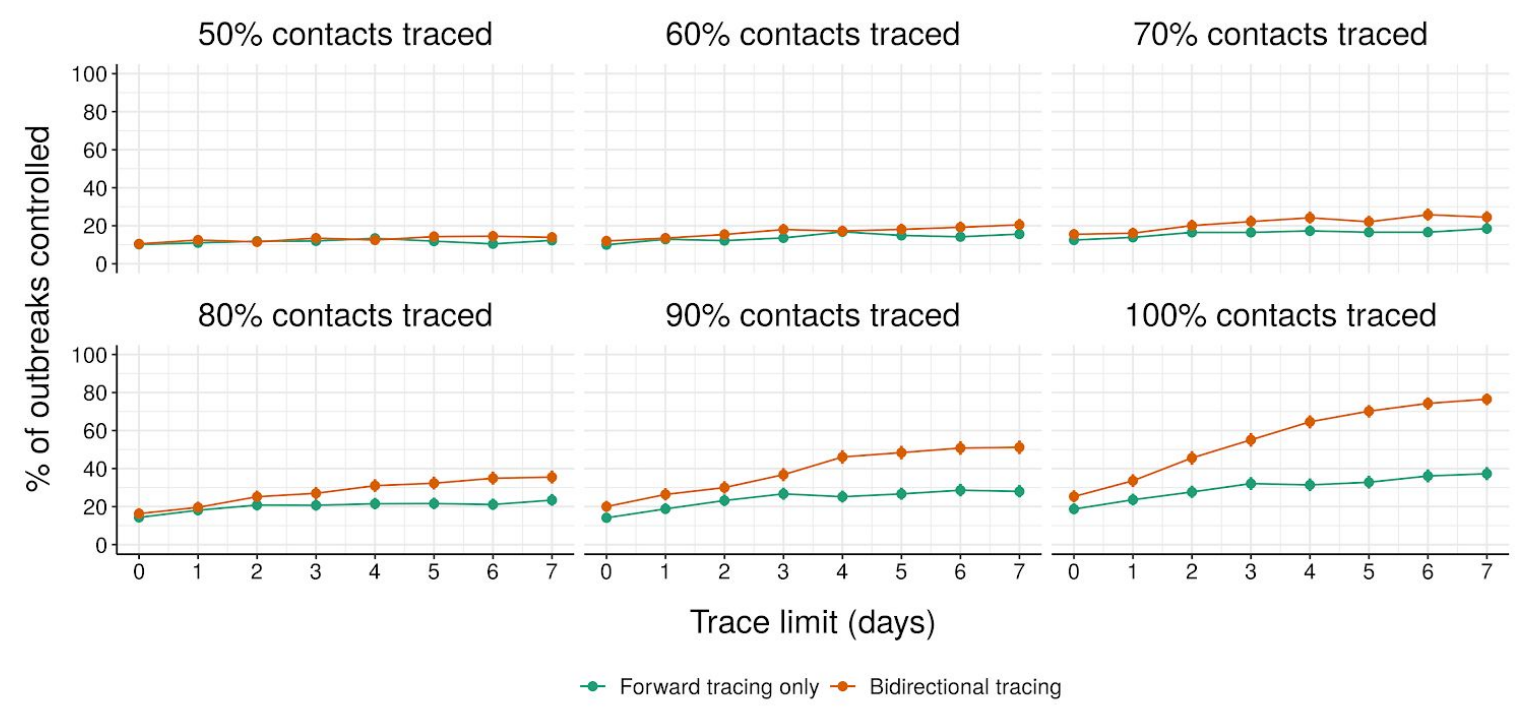

b

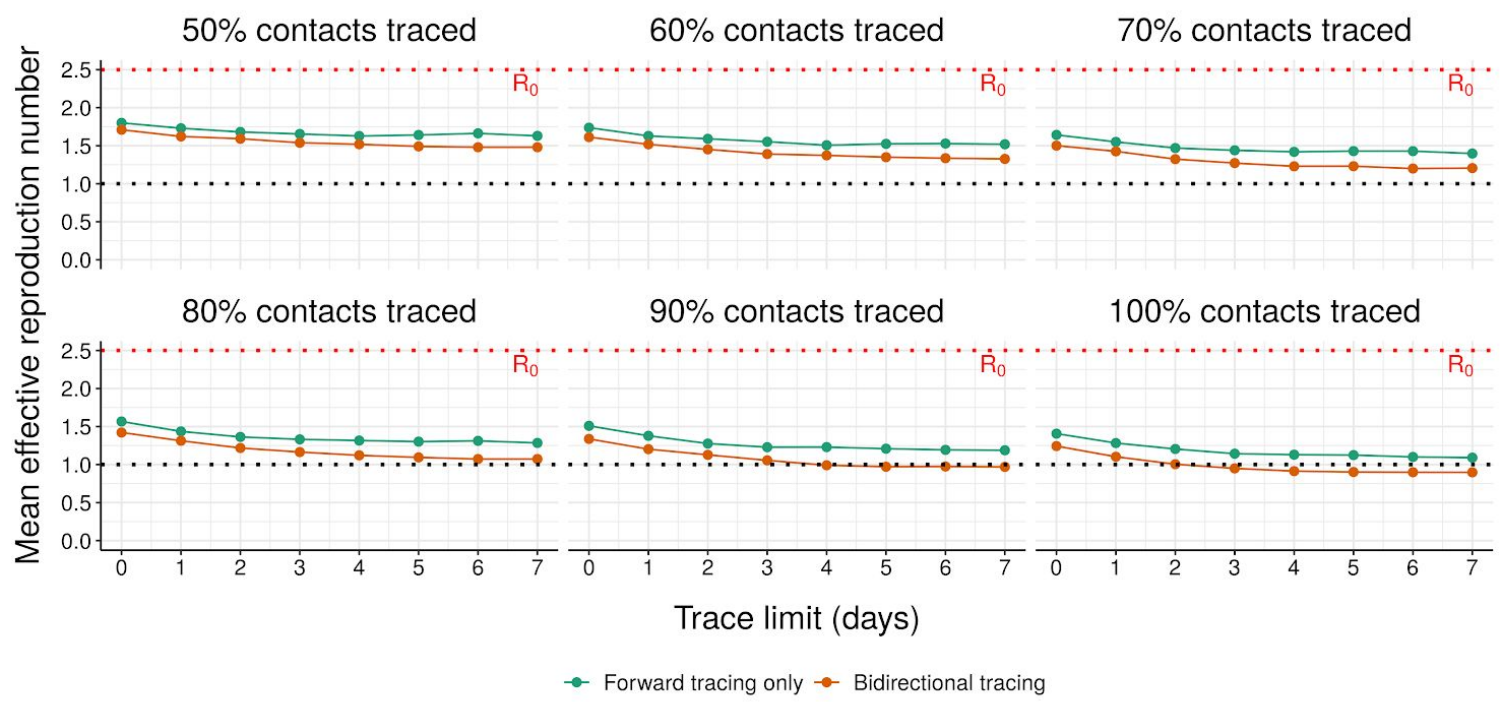

Figure S4: Effect of contact-tracing window size on performance of hybrid tracing. (a) Control rate and (b) average effective reproduction number of hybrid tracing under median parameters (Table S1) when contacts are manually traced for varying periods prior to symptom onset (for symptomatic cases) or case identification (for presymptomatic and asymptomatic cases). Data for digital contact tracing is assumed to be retained for 14 days after contact. Panel headers indicate the percentage of non-environmental contacts traced. Error bars in (a) represent $95 \%$ credible intervals across 1000 runs under a uniform beta prior; points in (b) represent average values over the same. 
a

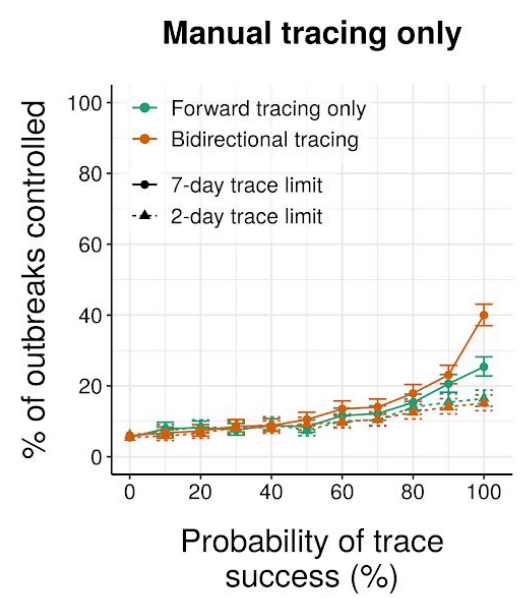

b

Digital tracing only (universal coverage)

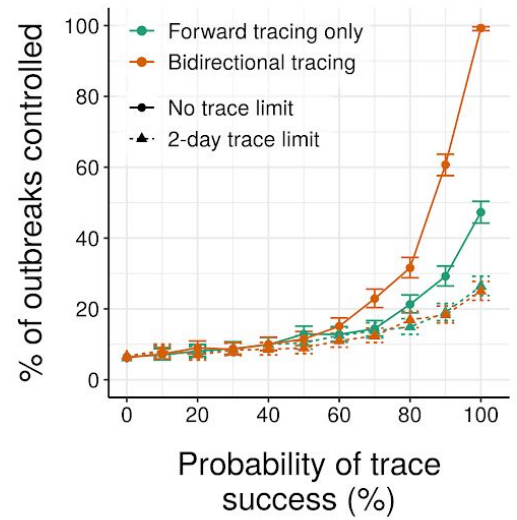

C

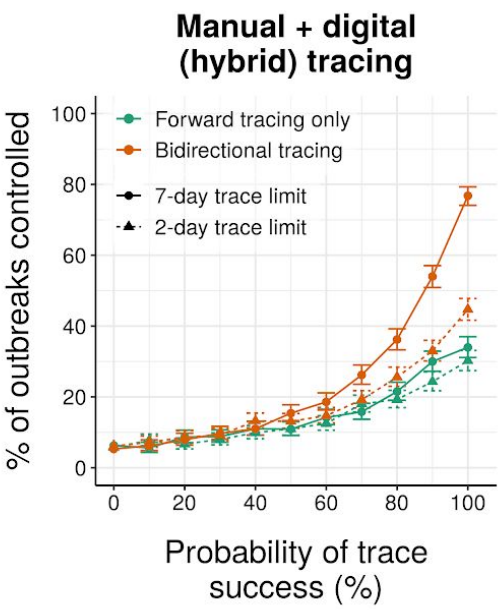

Figure S5: Outbreak control under manual, digital and hybrid tracing tracing. As Fig. 2a,b,d, but showing \% outbreaks controlled rather than effective reproduction number. Points represent average values over 1000 runs. 
a

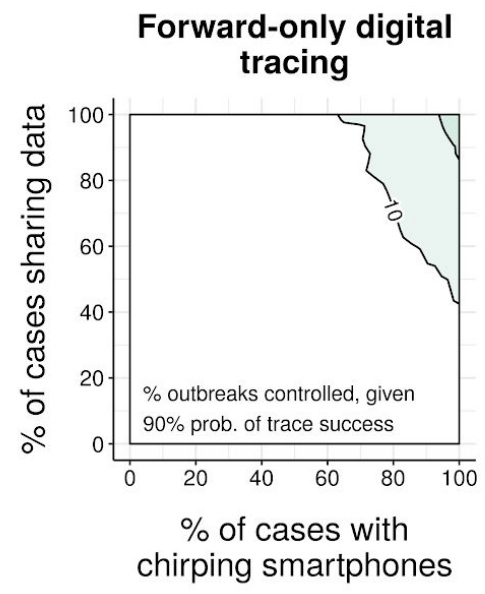

d

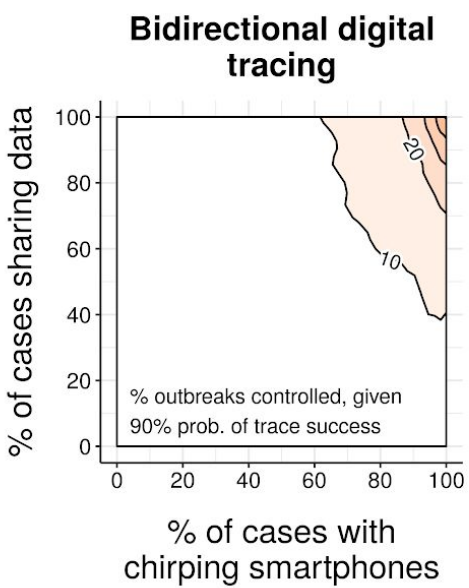

b

Forward-only hybrid tracing (2-day manual limit)

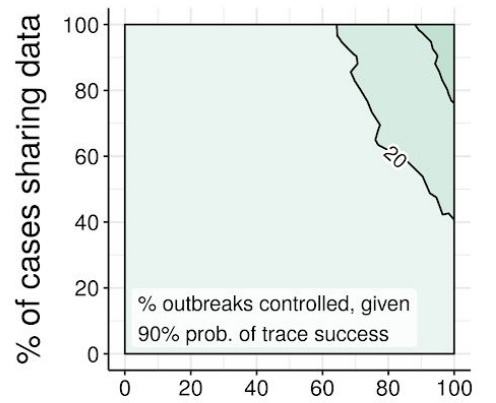

$\%$ of cases with chirping smartphones

e

Bidirectional hybrid tracing (2-day manual limit)

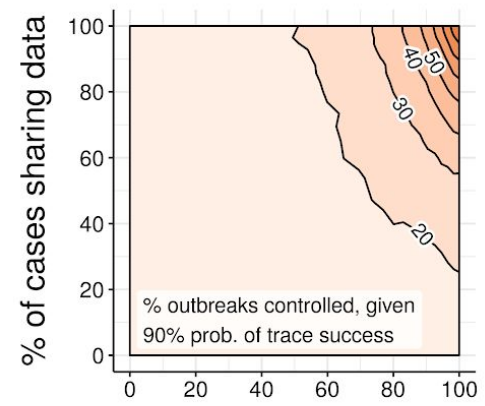

$\%$ of cases with chirping smartphones
C

Forward-only hybrid tracing (7-day manual limit)

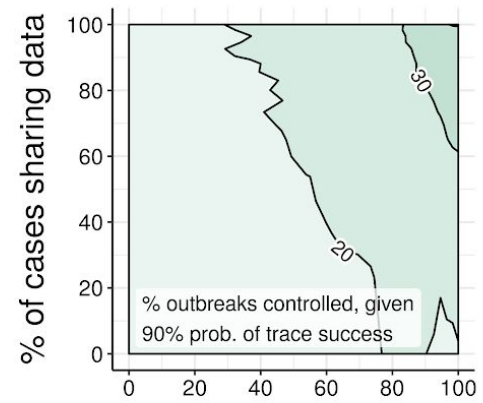

$\%$ of cases with chirping smartphones

f

Bidirectional hybrid tracing (7-day manual limit)

Figure S6: Effect of network fragmentation on effective reproduction number (\% outbreaks controlled). Neighbour-averaged contour plots of \% outbreaks controlled (over 1000 runs per scenario) under (a-c) forward-only and (d-f) bidirectional tracing, assuming median disease parameters (Table S1) and a $90 \%$ probability of trace success. 
a

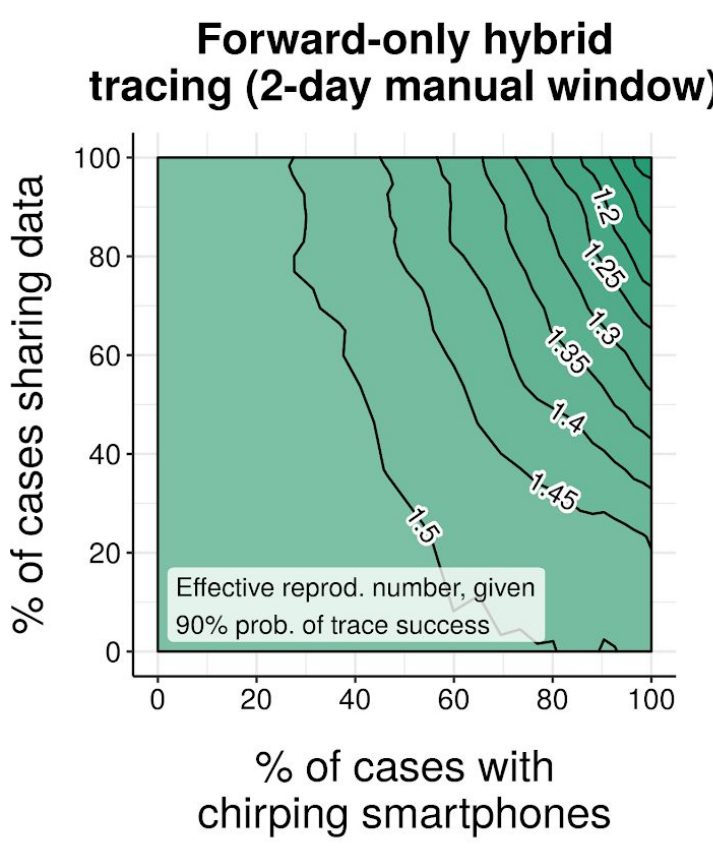

b

\section{Bidirectional hybrid tracing (2-day manual window)}

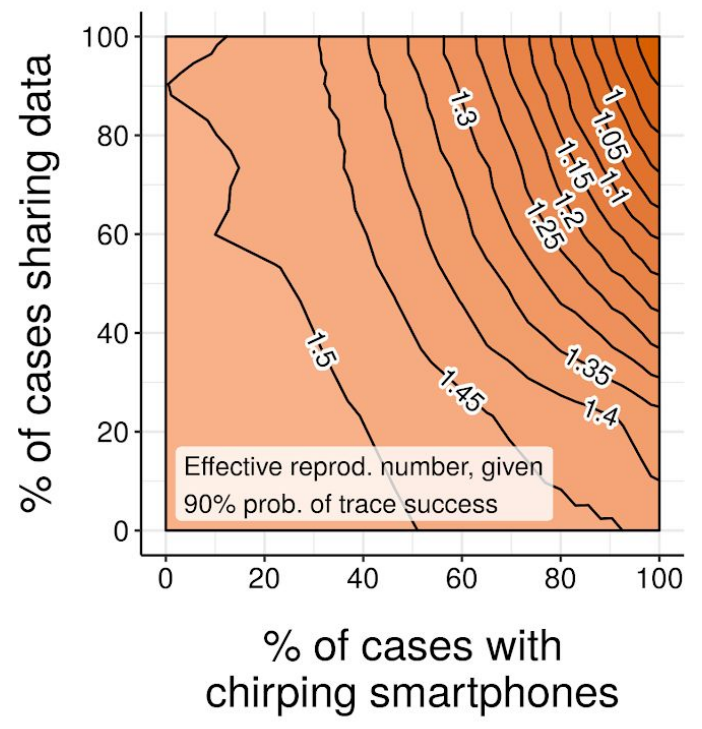

Figure S7: Effect of network fragmentation on control rates under a 2-day manual tracing window.

Neighbour-averaged contour plots of effective reproduction number achieved (over 1000 runs per scenario) under (a) bidirectional and (b) forward-only hybrid (manual+digital) tracing with a 2-day manual tracing window, assuming median disease parameters (Table S1) and a 90\% probability of trace success. 
a

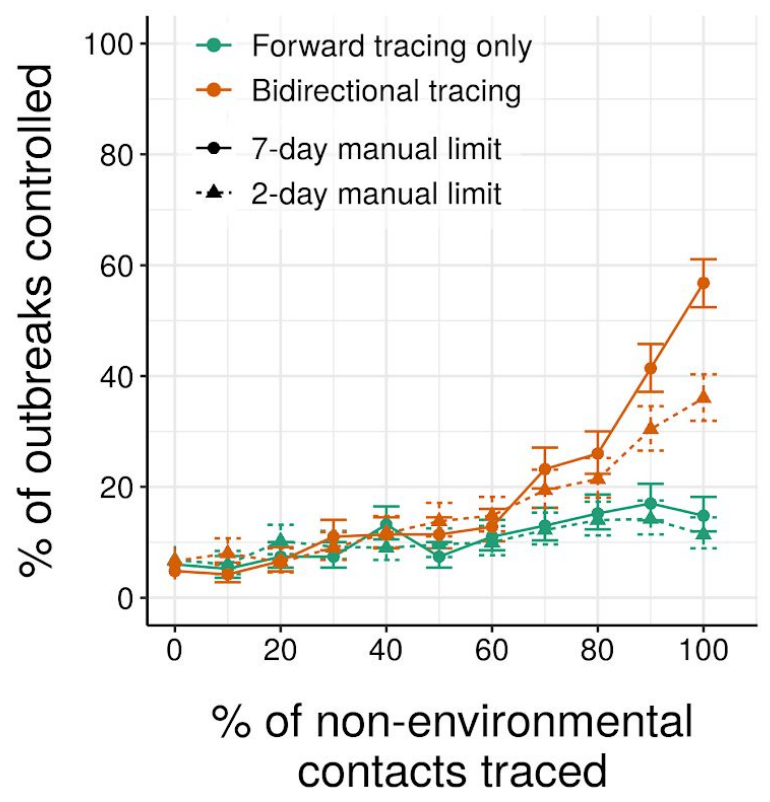

b

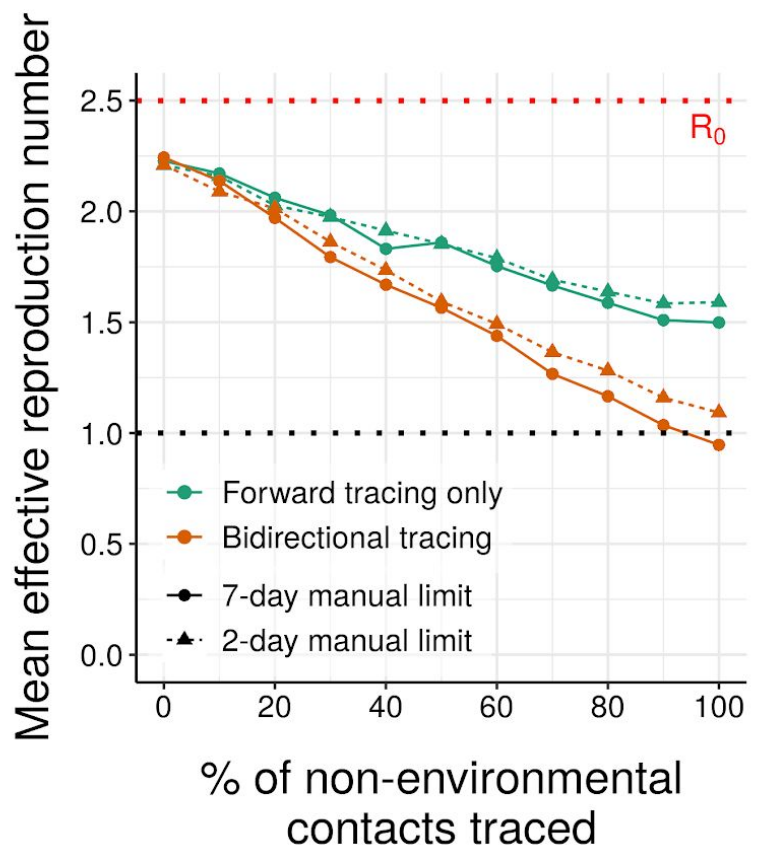

Figure S8: Effect of requiring pre-trace testing on hybrid tracing performance. As Fig. 3e-f, but requiring a positive test result before initiating contact tracing from a symptomatic case. Error bars in (a) represent $95 \%$ credible intervals across 500 runs under a uniform beta prior; points in (b) represent average values over the same. 
a

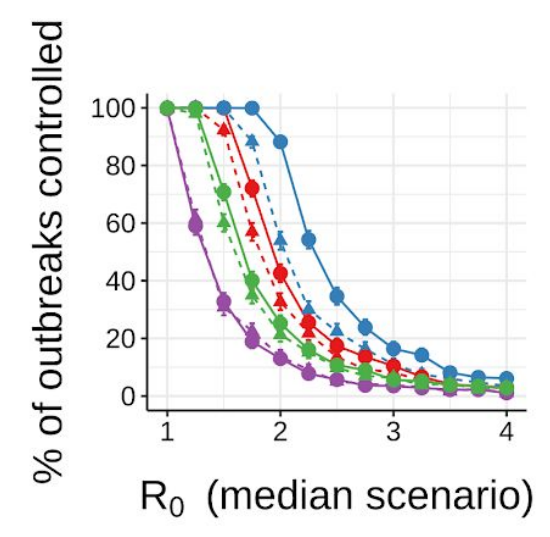

C

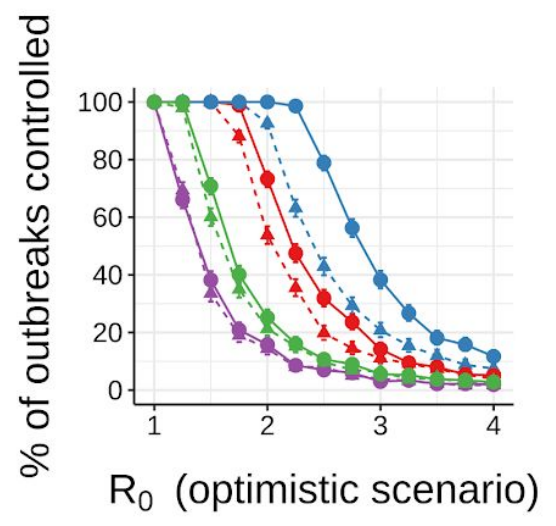

e

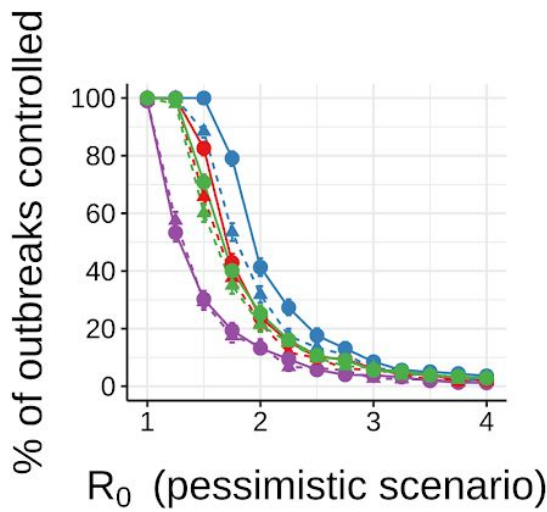

b

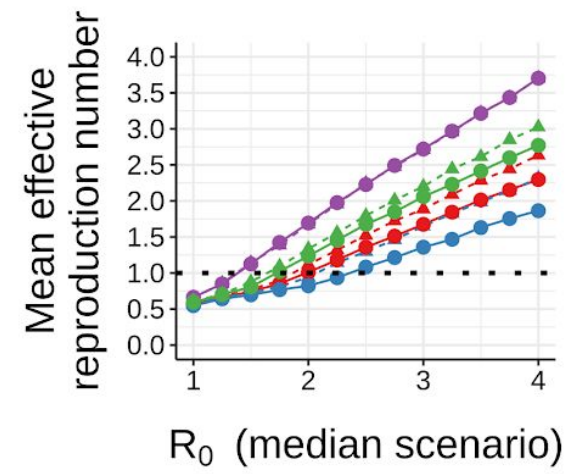

d

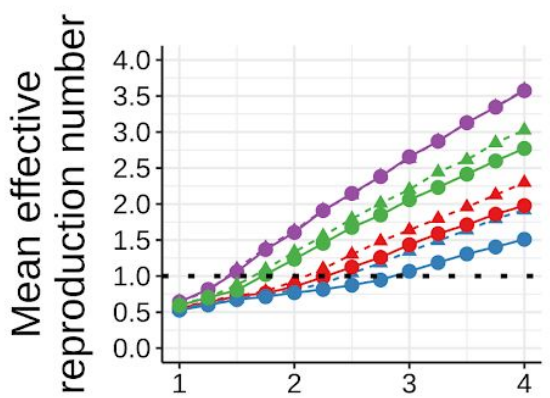

$\mathrm{R}_{0}$ (optimistic scenario)

f

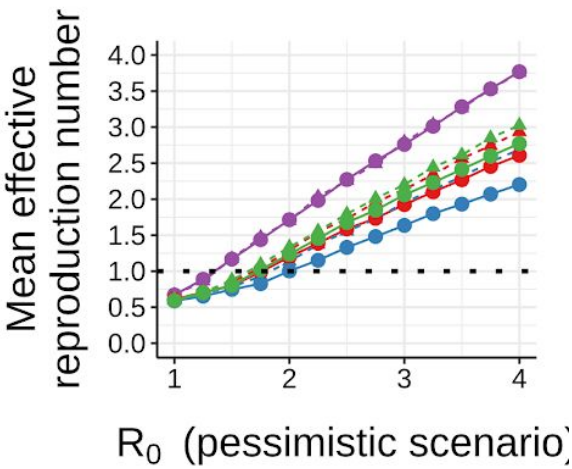

\section{Trace type}

- Manual only

- Digital only

- No tracing

- Bidirectional

-4- Forward only

Figure S9: Effect of $\mathbf{R}_{\mathbf{0}}$ and disease parameters on tracing performance ( $80 \%$ trace rate). As Figure 3, but assuming $80 \%$ of non-environmental contacts are traced. Error bars in (a,c,e) represent $95 \%$ credible intervals across 1000 runs under a uniform beta prior; points in (b) represent average values over the same. 
a

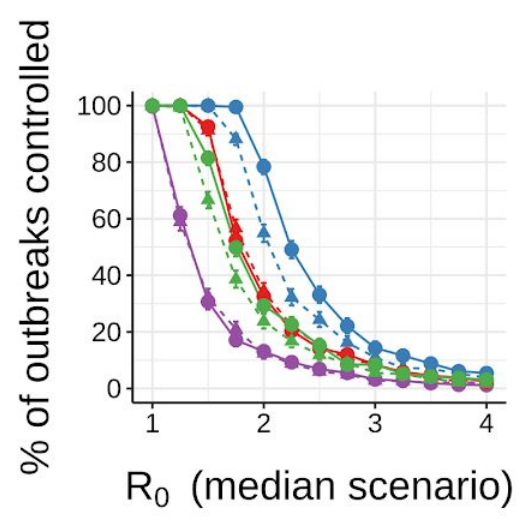

C

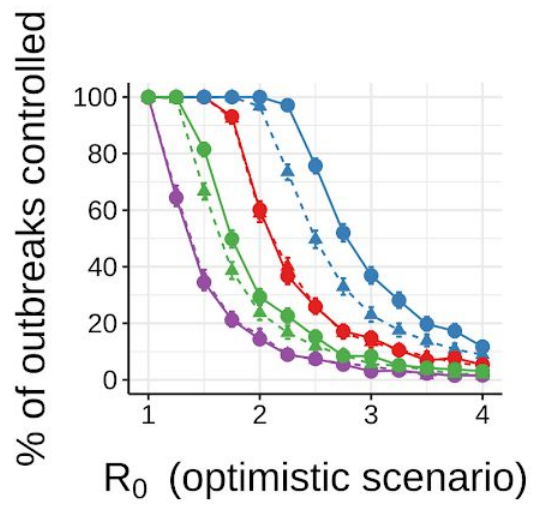

e

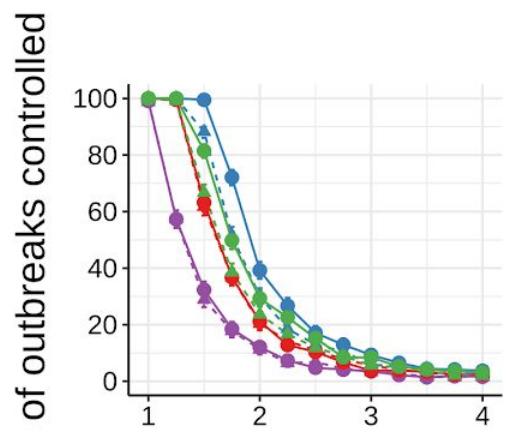

ㅇํㅇ b

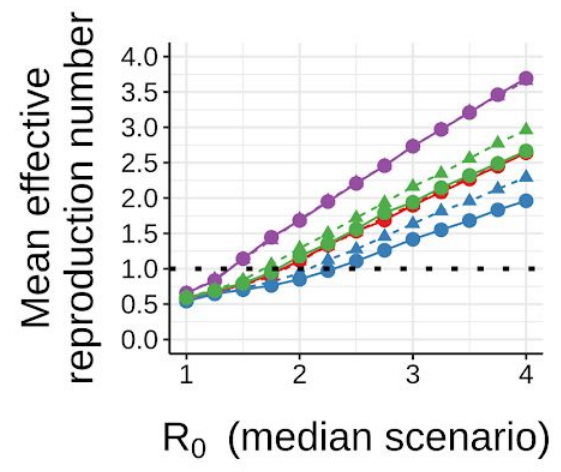

d

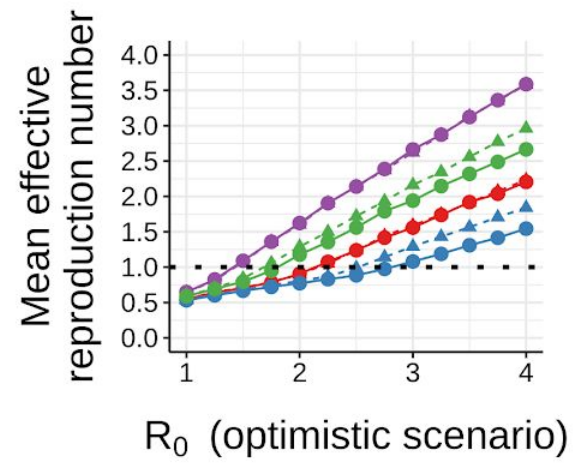

f

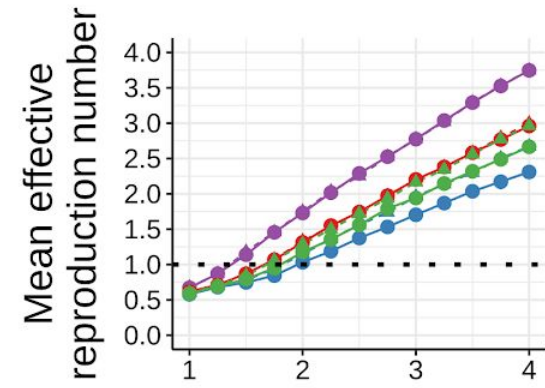

$\mathrm{R}_{0}$ (pessimistic scenario'

$R_{0}$ (pessimistic scenario)

\section{Trace type}

- Manual only

- Digital only

- Bidirectional

- Manual + digital

- No tracing

-^- Forward only

\section{Figure S10: Effect of $\mathbf{R}_{\mathbf{0}}$ and disease parameters on tracing performance (2-day manual trace}

window). As Figure 3, but assuming a 2-day manual trace window. Error bars in (a,c,e) represent 95\% credible intervals across 1000 runs under a uniform beta prior; points in $(b, d, f)$ represent average values over the same. 
a

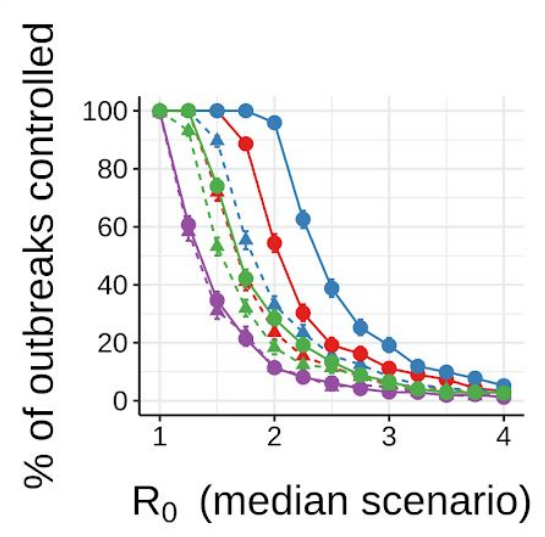

C

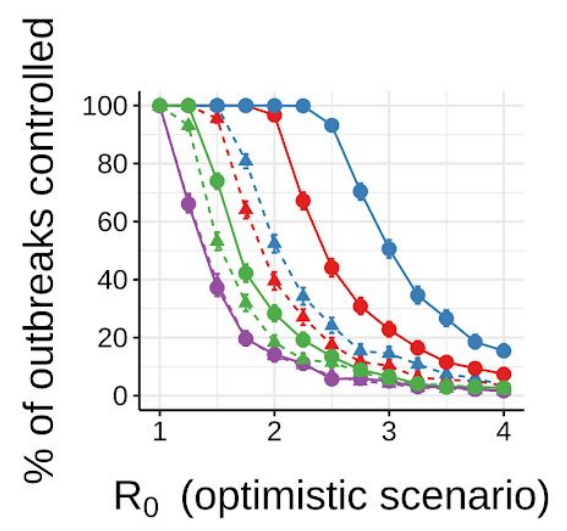

e

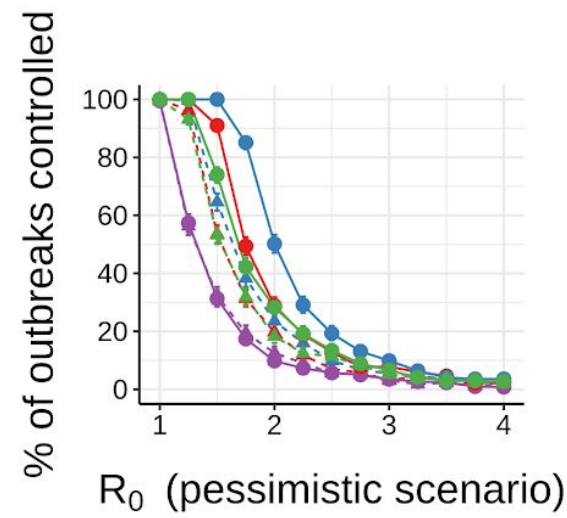

b

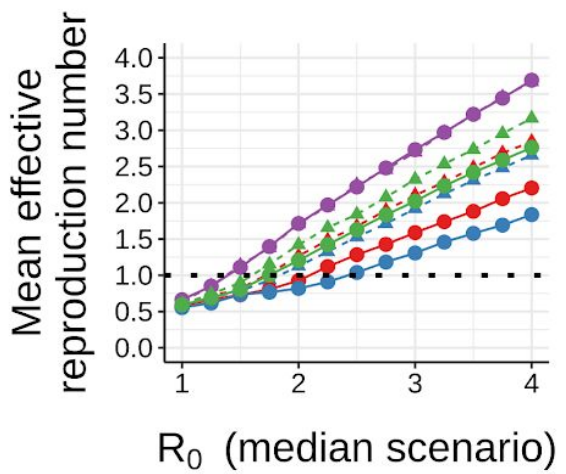

d

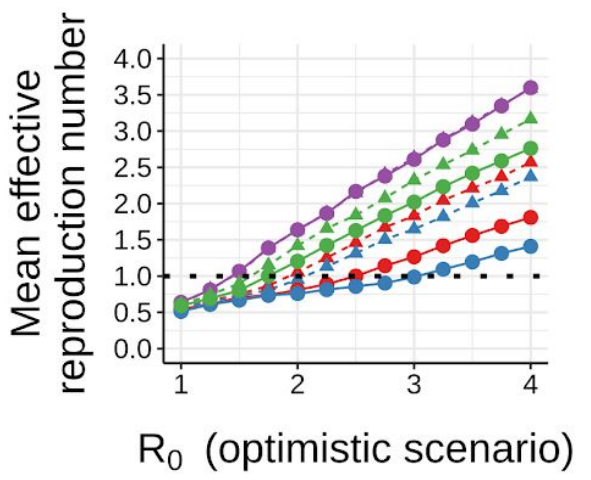

f

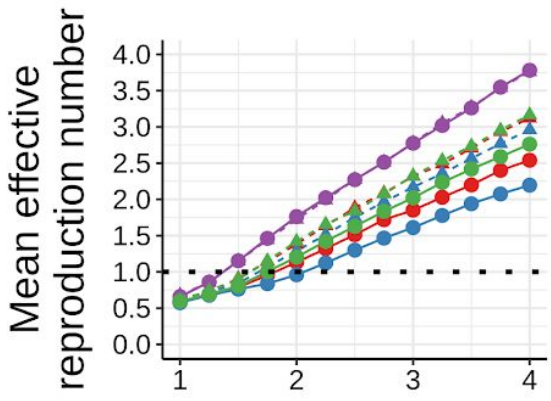

$\mathrm{R}_{0}$ (pessimistic scenario'

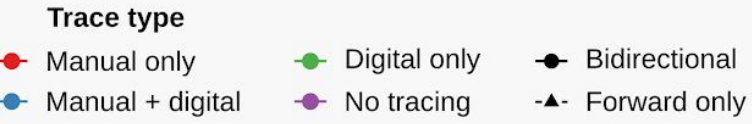

Figure S11: Effect of $\mathbf{R}_{0}$ and disease parameters on tracing performance (pre-emptive testing). As Figure 3, but requiring a positive test result before tracing symptomatic cases. Error bars in (a,c,e) represent $95 \%$ credible intervals across 1000 runs under a uniform beta prior; points in $(b, d, f)$ represent average values over the same. 
a

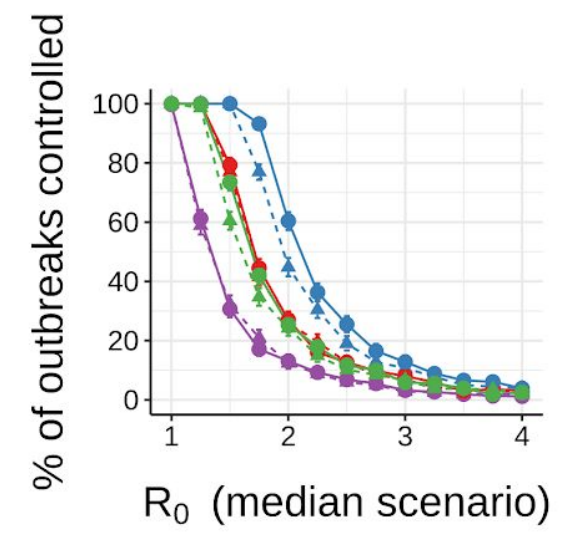

C

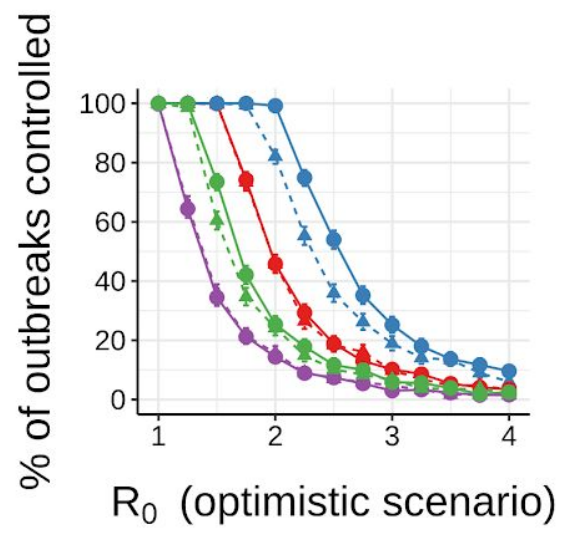

e

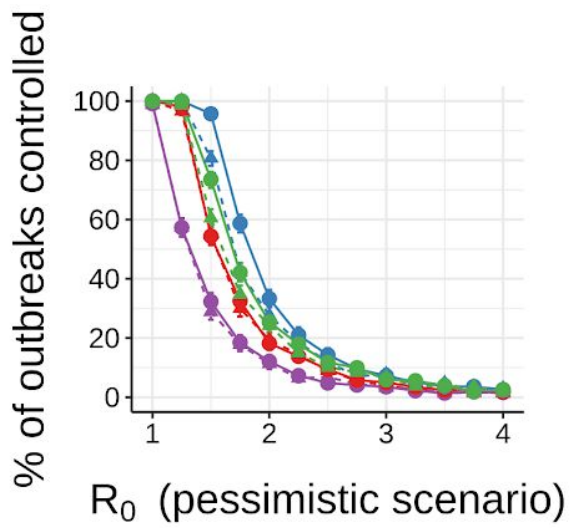

b

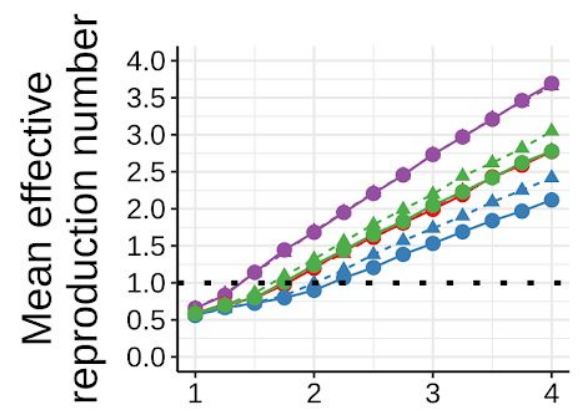

$\mathrm{R}_{0}$ (median scenario)

d

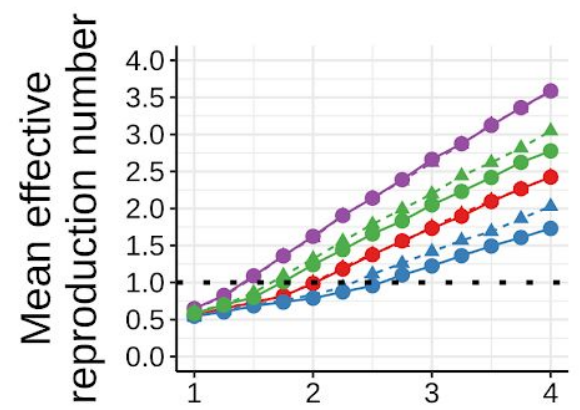

$\mathrm{R}_{0}$ (optimistic scenario)

f

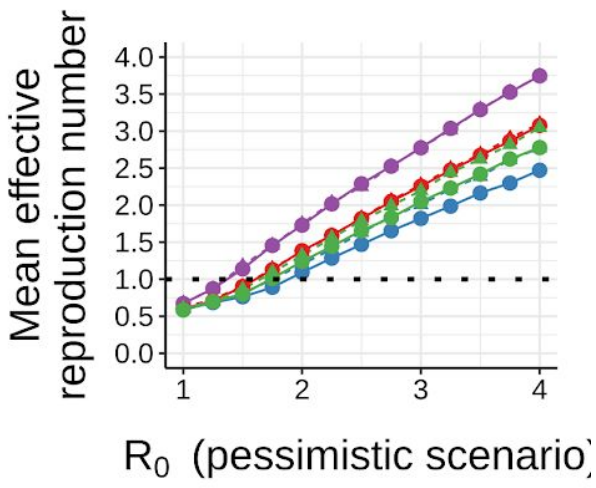

\section{Trace type}

- Manual only

- Digital only

- Bidirectional

- Manual + digital

No tracing

Figure S12: Effect of $R_{0}$ and disease parameters on tracing performance ( $80 \%$ trace rate, 2 -day manual trace window). As Figure 3, but assuming $80 \%$ of non-environmental contacts traced and a 2-day manual trace window. Error bars in (a,c,e) represent 95\% credible intervals across 1000 runs under a uniform beta prior; points in $(b, d, f)$ represent average values over the same. 
a

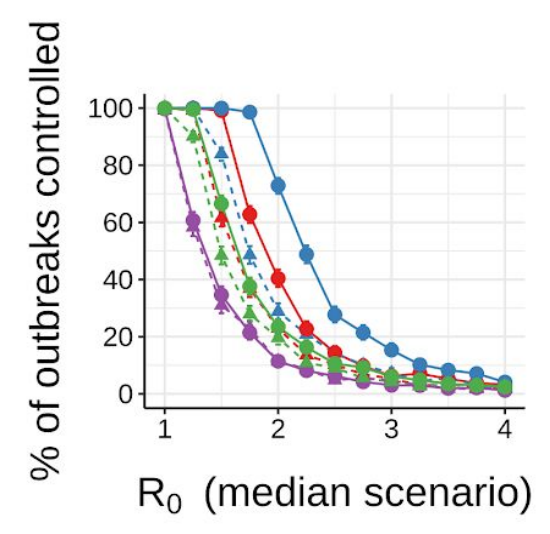

C

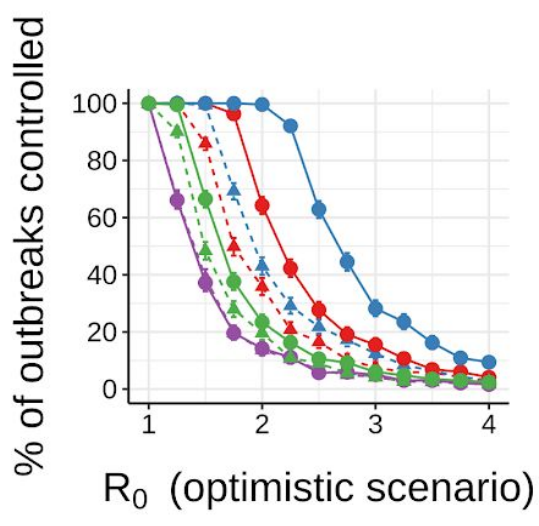

e

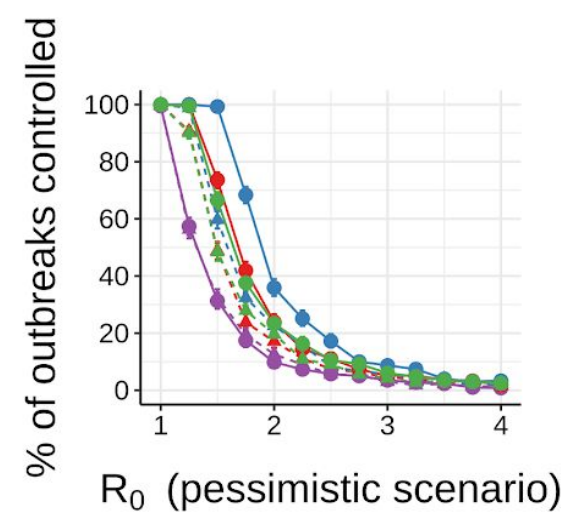

b

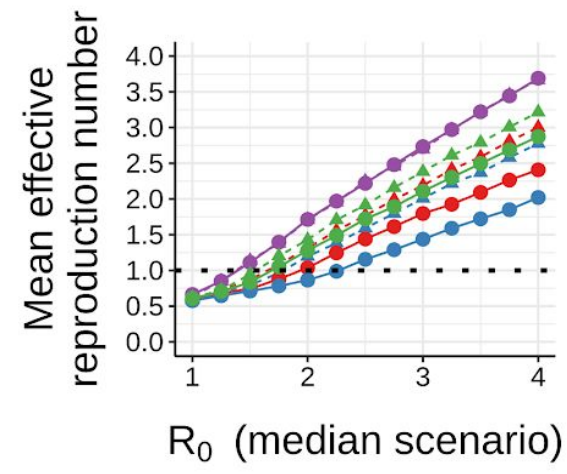

d

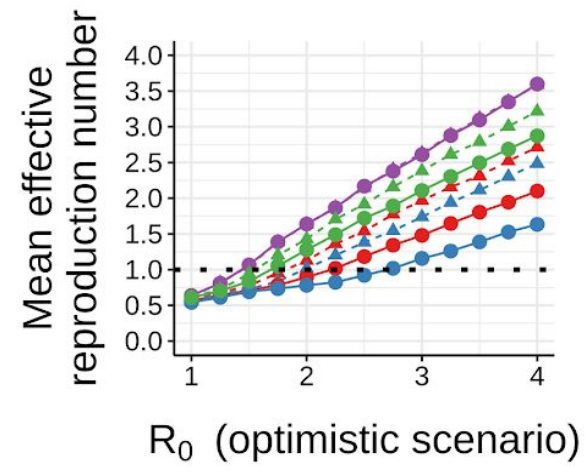

$\mathbf{f}$

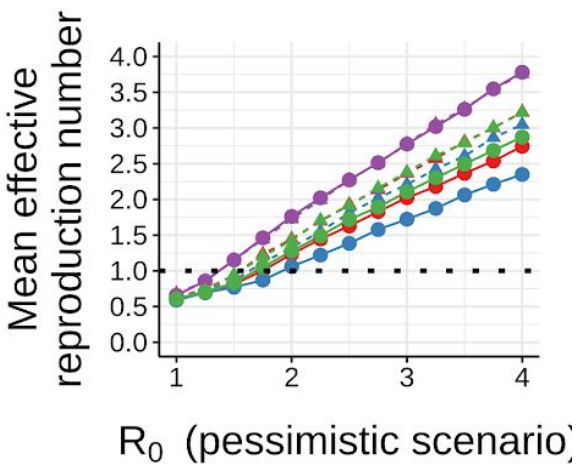

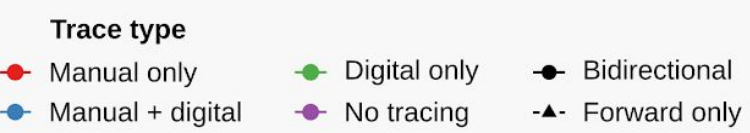

Figure S13: Effect of $\mathbf{R}_{\mathbf{0}}$ and disease parameters on tracing performance (pre-emptive testing, $80 \%$

trace rate). As Figure 3, but requiring a positive test result before tracing symptomatic cases and assuming $80 \%$ of non-environmental contacts traced and a 2-day manual trace window. Error bars in $(\mathrm{a}, \mathrm{c}, \mathrm{e})$ represent $95 \%$ credible intervals across 1000 runs under a uniform beta prior; points in $(\mathrm{b}, \mathrm{d}, \mathrm{f})$ represent average values over the same. 
a

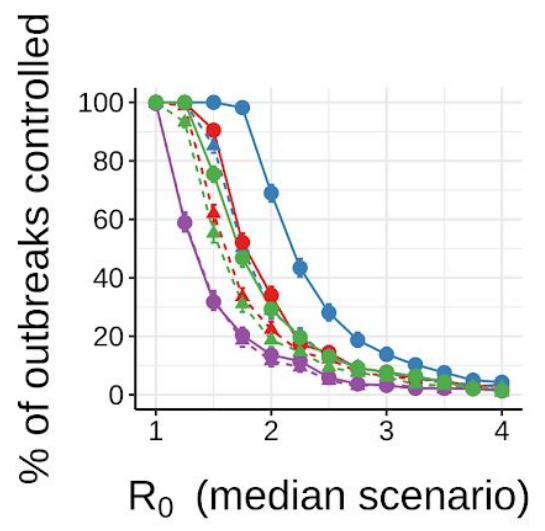

C

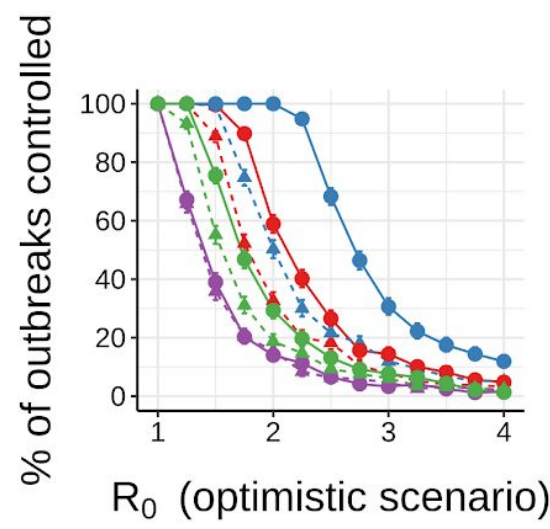

e

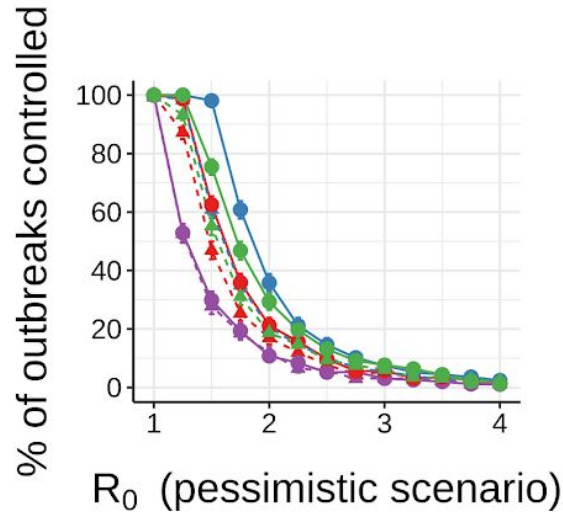

b

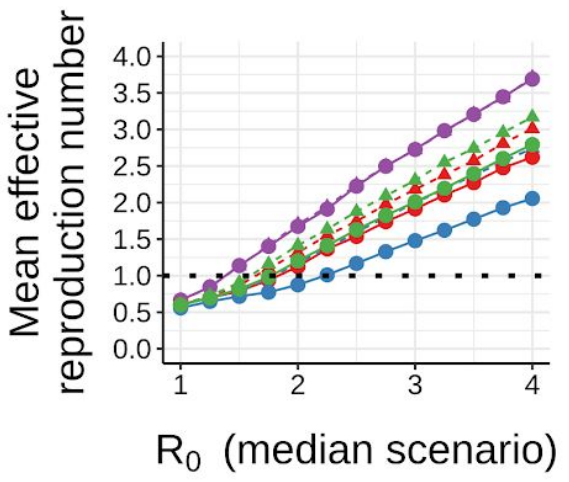

d

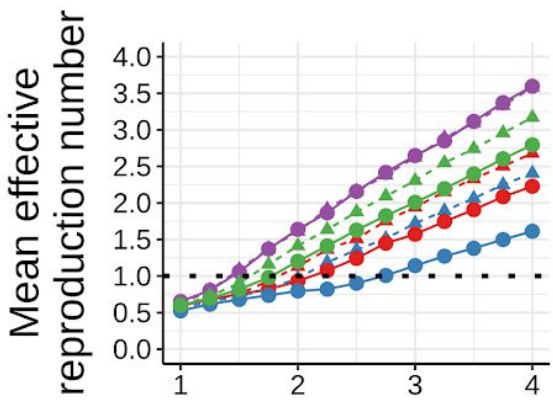

$\mathrm{R}_{0}$ (optimistic scenario)

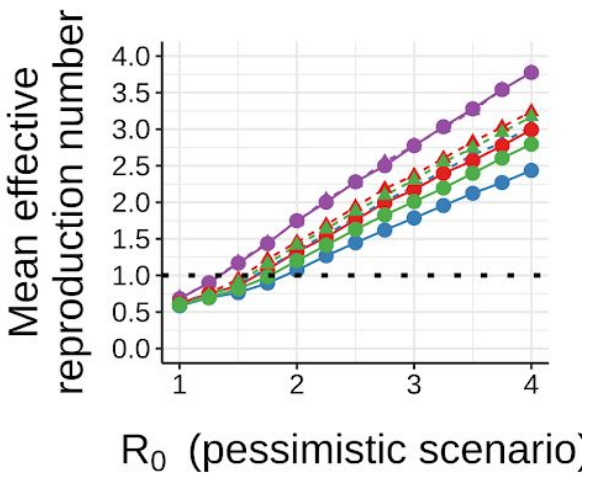

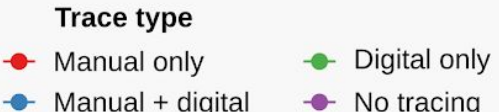

Figure S14: Effect of $R_{0}$ and disease parameters on tracing performance (pre-emptive testing, 2-day manual trace window). As Figure 3, but requiring a positive test result before tracing symptomatic cases and assuming a 2-day manual trace window. Error bars in (a,c,e) represent $95 \%$ credible intervals across 1000 runs under a uniform beta prior; points in $(\mathrm{b}, \mathrm{d}, \mathrm{f})$ represent average values over the same. 
a

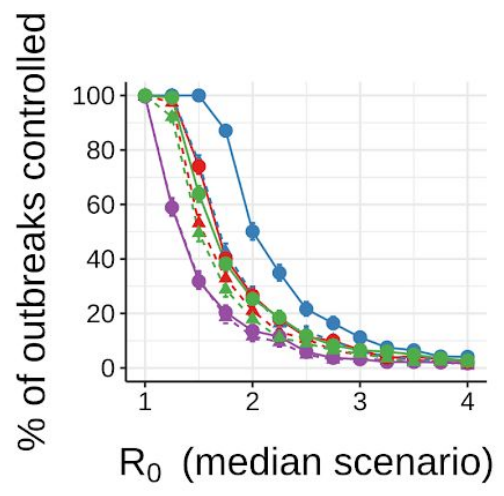

C

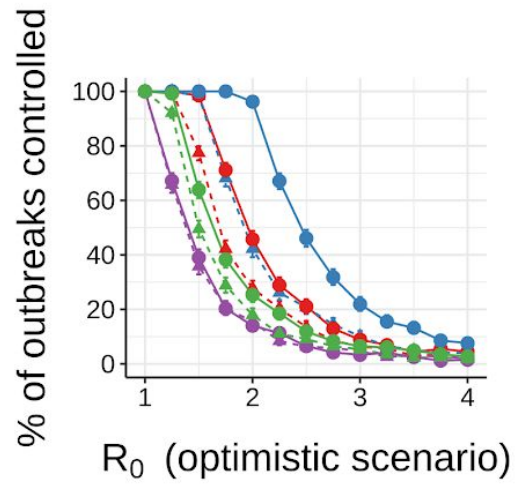

e

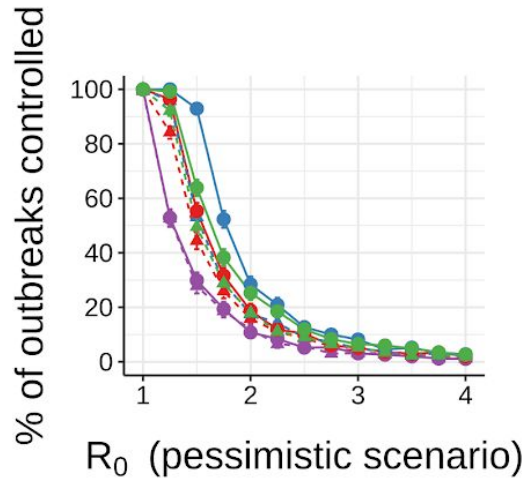

b

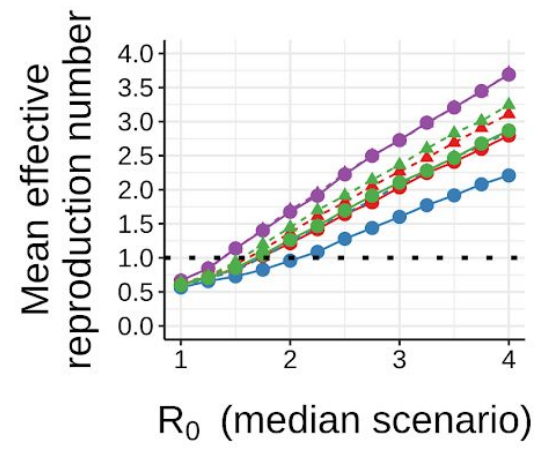

d

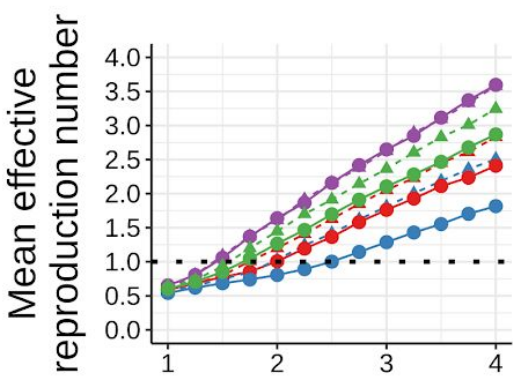

$\mathrm{R}_{0}$ (optimistic scenario)

f

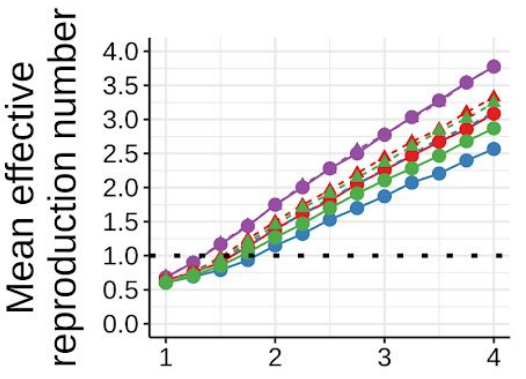

$\mathrm{R}_{0}$ (pessimistic scenario'

Figure S15: Effect of $R_{0}$ and disease parameters on tracing performance (pre-emptive testing, $80 \%$ trace rate, 2-day manual trace window). As Figure 3, but requiring a positive test result before tracing symptomatic cases, and assuming $80 \%$ of non-environmental contacts traced and a 2 -day manual trace window. Error bars in $(\mathrm{a}, \mathrm{c}, \mathrm{e})$ represent $95 \%$ credible intervals across 1000 runs under a uniform beta prior; points in $(b, d, f)$ represent average values over the same. 
a

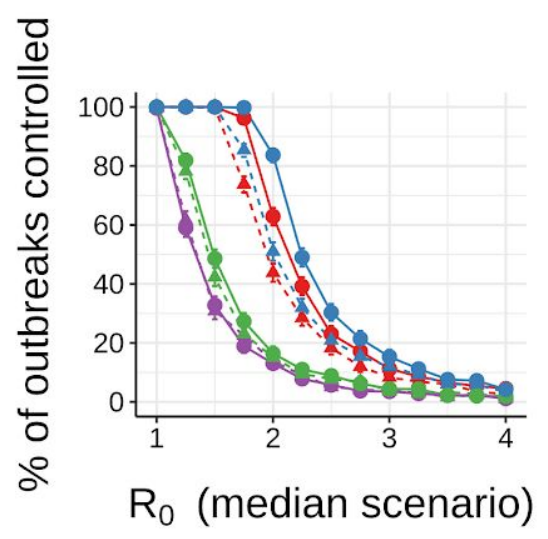

C

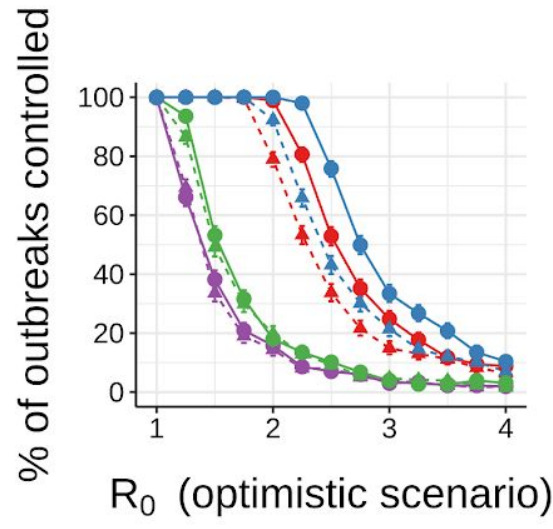

e

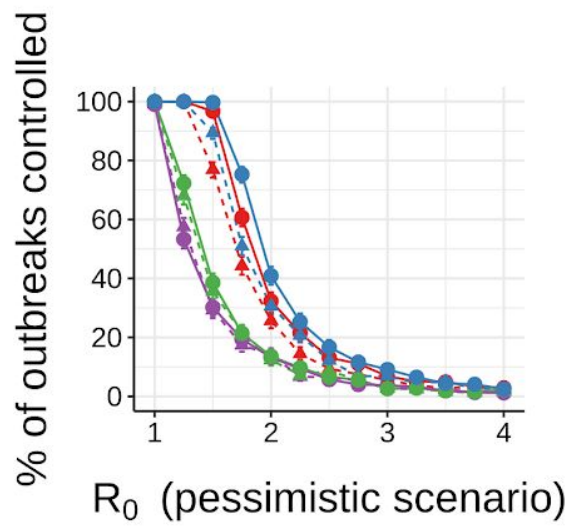

b

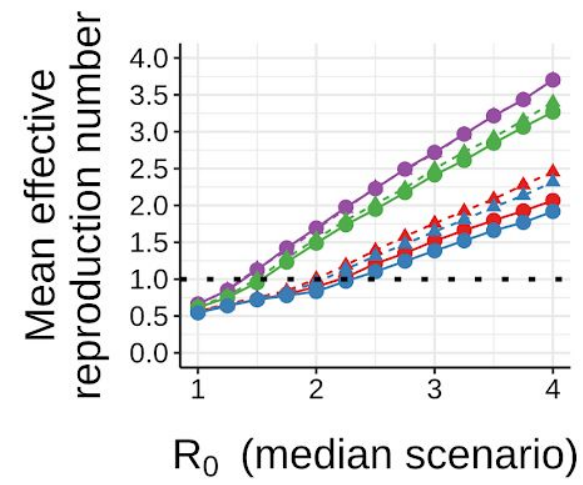

d

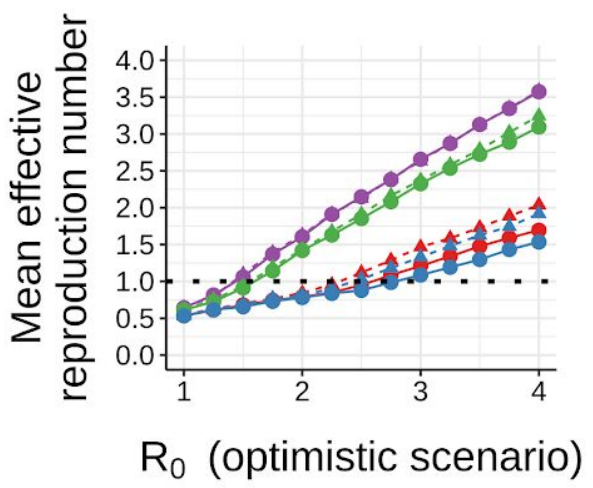

f

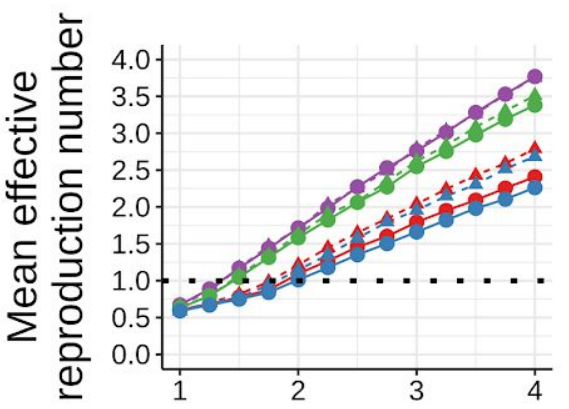

$\mathrm{R}_{0}$ (pessimistic scenario'
Trace type
- Manual only
- Digital only
- Bidirectional
- Manual + digital
- No tracing
-A- Forward only

Figure S16: Effect of $\mathbf{R}_{0}$ and disease parameters on tracing performance (low-uptake case). As

Figure 3, but assuming only 53\% of cases have chirp-enabled smartphones. Error bars in (a,c,e) represent 95\% credible intervals across 1000 runs under a uniform beta prior; points in (b,d,f) represent average values over the same. 
medRxiv preprint doi: https://doi.org/10.1101/2020.05.06.20093369; this version posted July 14, 2020. The copyright holder for this preprint (which was not certified by peer review) is the author/funder, who has granted medRxiv a license to display the preprint in perpetuity.

It is made available under a CC-BY 4.0 International license .

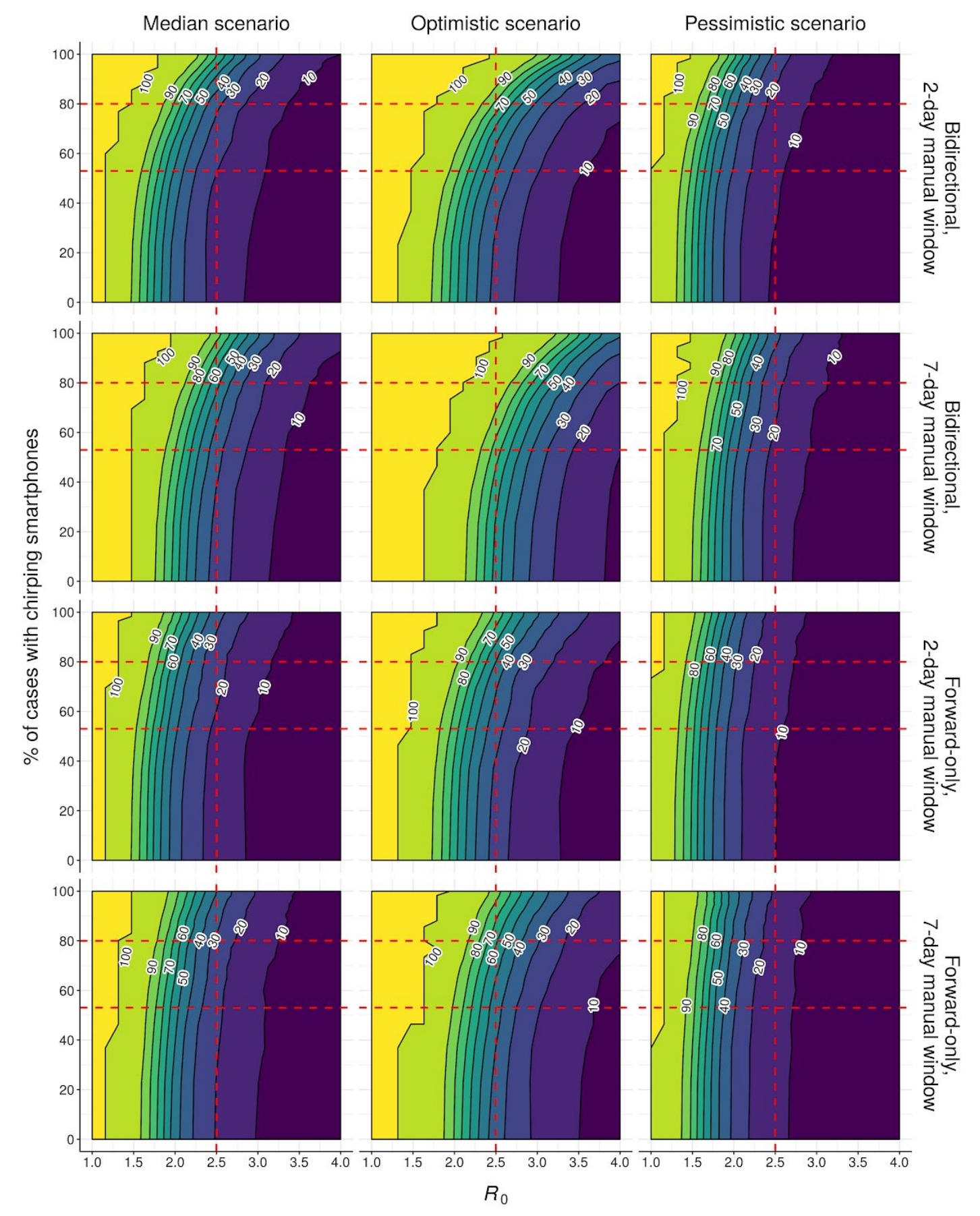

Figure S17: Effect of R0, network fragmentation, and disease parameters on hybrid tracing

performance . Neighbour-averaged contour plots showing $\%$ of outbreaks controlled (over 500 runs) under hybrid tracing for different disease scenarios (Table S1) and tracing strategies, assuming $90 \%$ of non-environmental contacts traced and immediate tracing of symptomatic cases. Horizontal red dashed lines indicate low- and high-uptake scenarios from the main text (Table S1); vertical red dashed line indicates the $R_{0}$ value used in Fig. $2 \& 4$. 


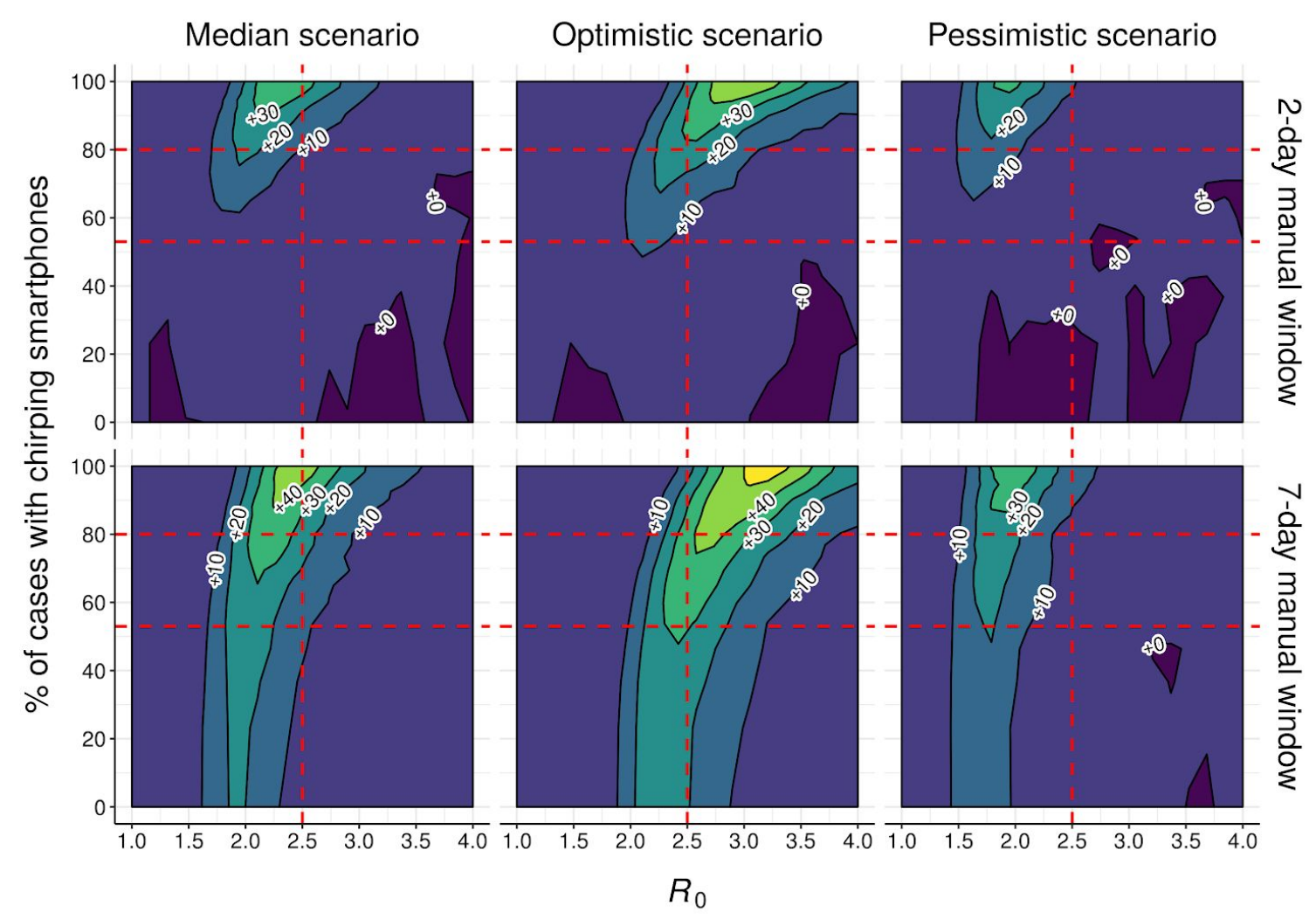

Figure S18: Effect of R0, network fragmentation, and disease parameters on outperformance of bidirectional tracing. Contour plot showing difference in \% of outbreaks controlled (over 500 runs) between bidirectional and forward-only hybrid tracing for different disease scenarios (Table S1) and tracing strategies, assuming $90 \%$ of non-environmental contacts traced and immediate tracing of symptomatic cases. Horizontal red dashed lines indicate low- and high-uptake scenarios from the main text (Table $\mathrm{S} 1$ ); vertical red dashed line indicates the $R_{0}$ value used in Fig. $2 \& 4$. 
medRxiv preprint doi: https://doi.org/10.1101/2020.05.06.20093369; this version posted July 14, 2020. The copyright holder for this preprint (which was not certified by peer review) is the author/funder, who has granted medRxiv a license to display the preprint in perpetuity.

It is made available under a CC-BY 4.0 International license.

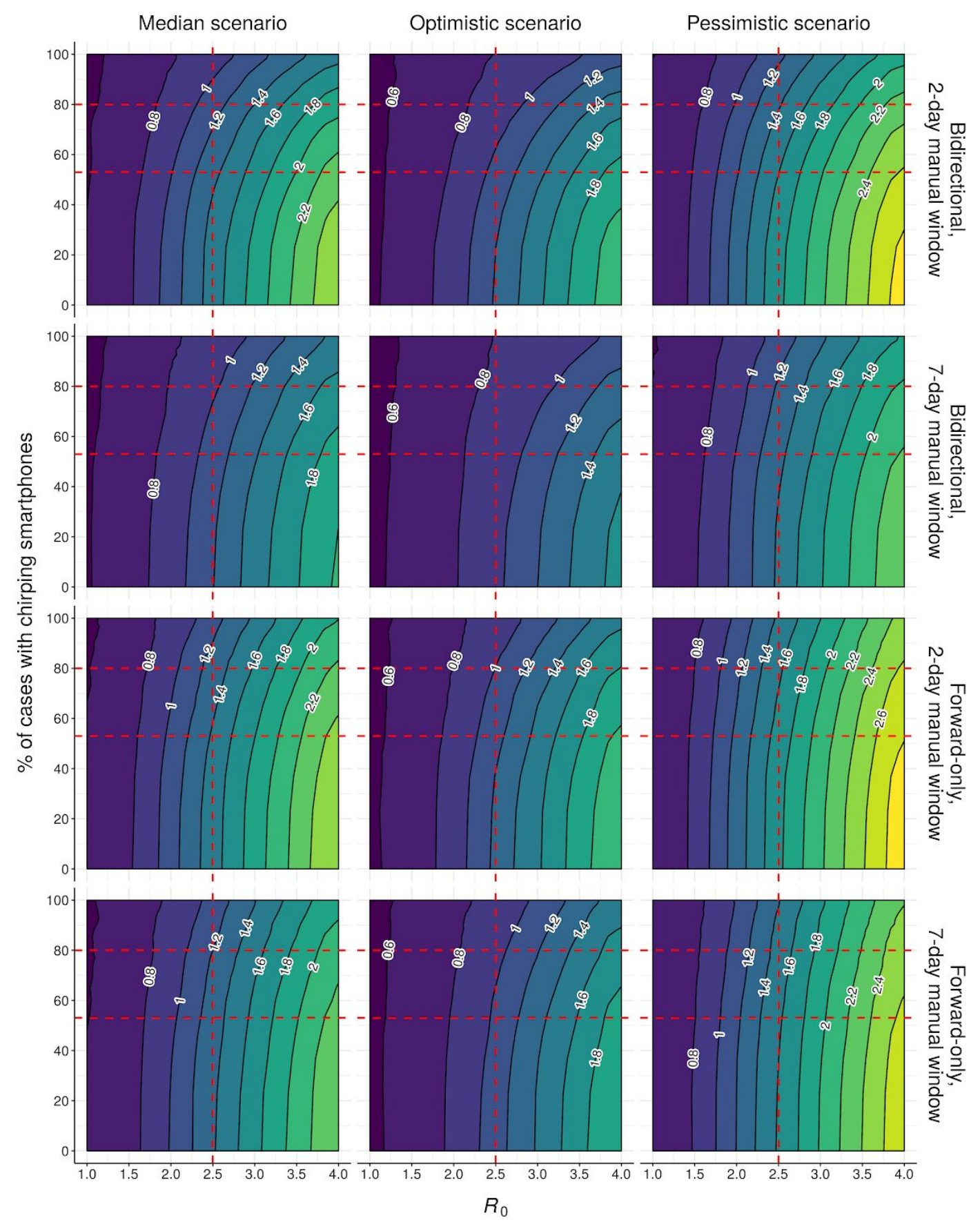

Figure S19: Effect of R0, network fragmentation, and disease parameters on hybrid tracing

performance $\left(\mathbf{R}_{\text {eff }}\right)$. Contour plot showing mean effective reproduction number (over 500 runs) under hybrid tracing for different disease scenarios (Table S1) and tracing strategies, assuming $90 \%$ of non-environmental contacts traced and immediate tracing of symptomatic cases. Horizontal red dashed lines indicate low- and high-uptake scenarios from the main text (Table S1); vertical red dashed line indicates the $R_{0}$ value used in Fig. $2 \& 4$. 
medRxiv preprint doi: https://doi.org/10.1101/2020.05.06.20093369; this version posted July 14, 2020. The copyright holder for this preprint (which was not certified by peer review) is the author/funder, who has granted medRxiv a license to display the preprint in perpetuity.

It is made available under a CC-BY 4.0 International license.

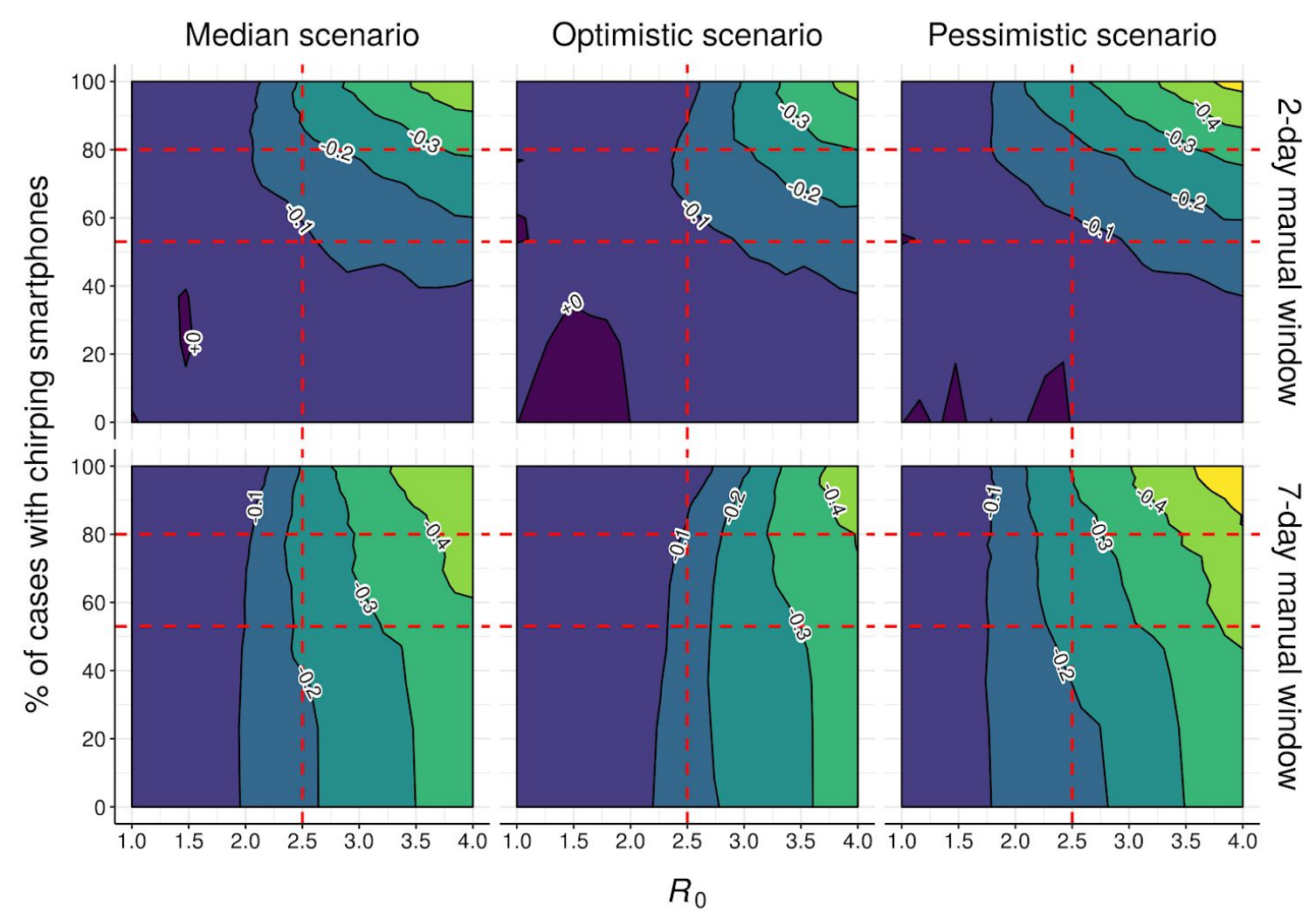

Figure S20: Effect of R0, network fragmentation, and disease parameters on outperformance of bidirectional tracing $\left(\mathbf{R}_{\text {eff }}\right)$. Contour plot showing difference in mean effective reproduction number (over 500 runs) between bidirectional and forward-only hybrid tracing for different disease scenarios (Table S1) and tracing strategies, assuming $90 \%$ of non-environmental contacts traced and immediate tracing of symptomatic cases. Horizontal red dashed lines indicate low- and high-uptake scenarios from the main text (Table S1); vertical red dashed line indicates the $R_{0}$ value used in Fig. $2 \& 4$. 
medRxiv preprint doi: https://doi.org/10.1101/2020.05.06.20093369; this version posted July 14, 2020. The copyright holder for this preprint (which was not certified by peer review) is the author/funder, who has granted medRxiv a license to display the preprint in perpetuity.

It is made available under a CC-BY 4.0 International license.

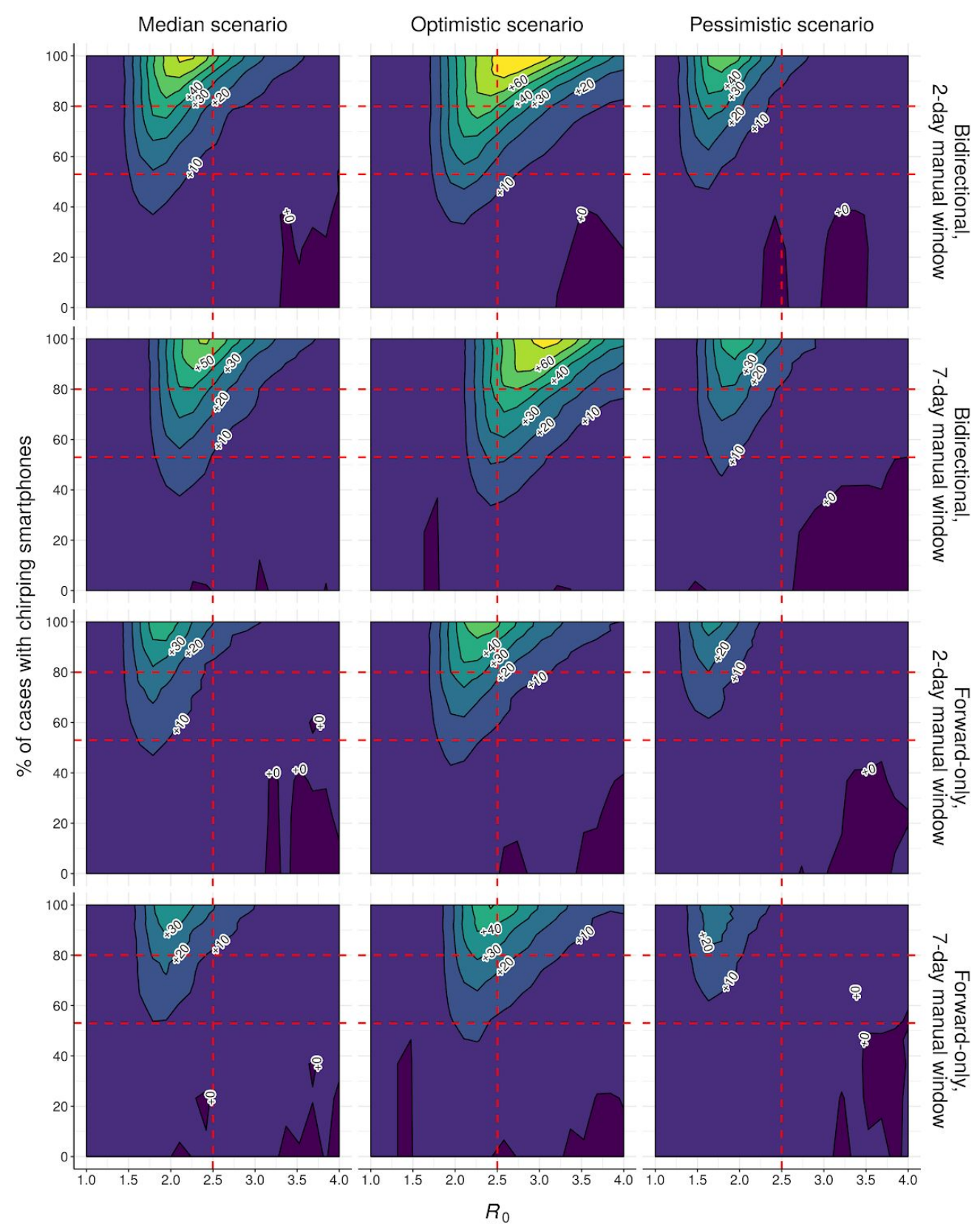

Figure S21: Effect of R0, network fragmentation, and disease parameters on outperformance of

hybrid vs manual tracing. Contour plot showing difference in \% outbreaks controlled (over 500 runs) between hybrid and manual-only hybrid tracing for different disease scenarios (Table S1) and tracing strategies, assuming $90 \%$ of non-environmental contacts traced and immediate tracing of symptomatic cases. Horizontal red dashed lines indicate low- and high-uptake scenarios from the main text (Table S1); vertical red dashed line indicates the $R_{0}$ value used in Fig. $2 \& 4$. Note that the data-retention limit for the digital system is 14 days in all cases. 
medRxiv preprint doi: https://doi.org/10.1101/2020.05.06.20093369; this version posted July 14, 2020. The copyright holder for this preprint (which was not certified by peer review) is the author/funder, who has granted medRxiv a license to display the preprint in perpetuity.

It is made available under a CC-BY 4.0 International license.

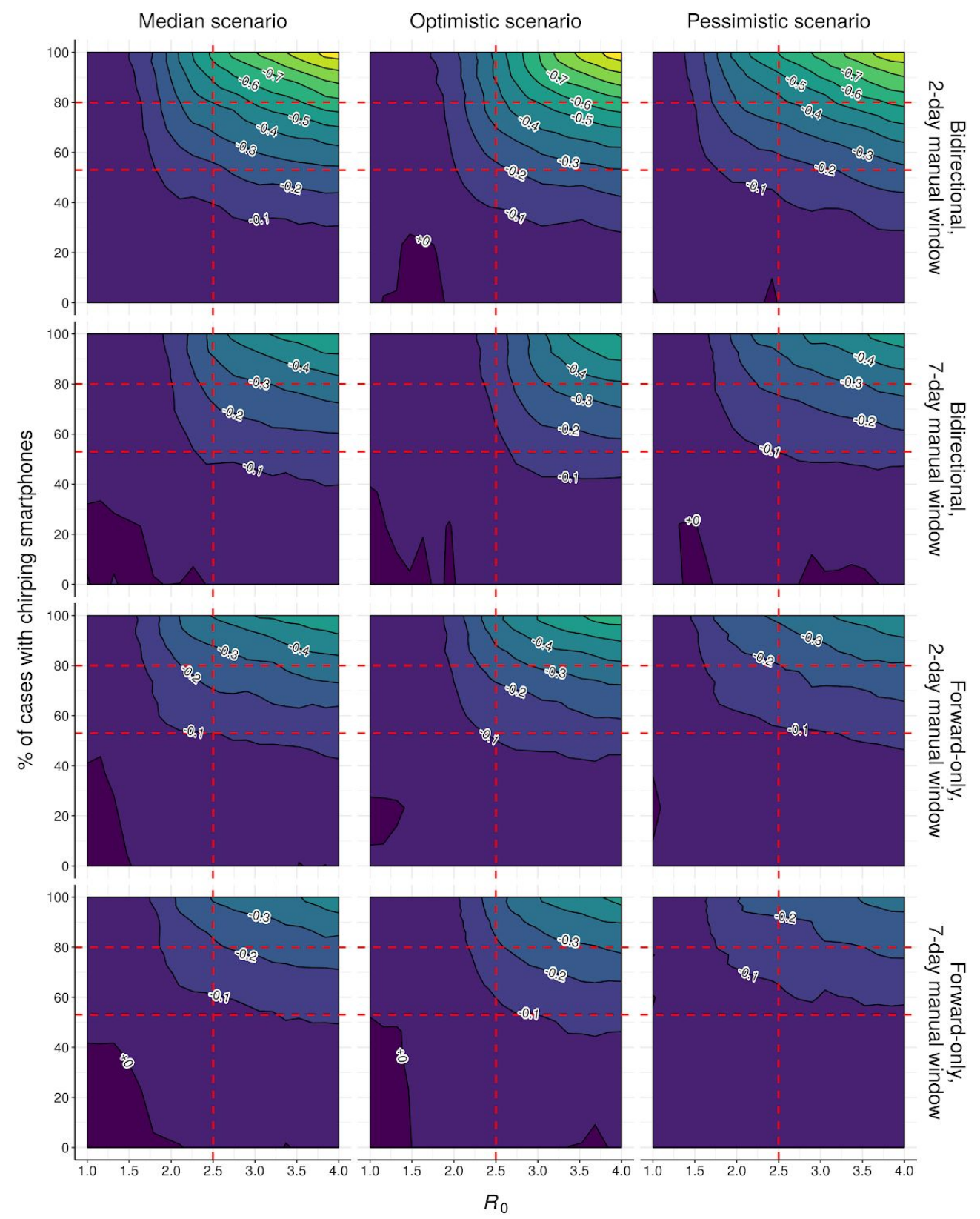

Figure S22: Effect of R0, network fragmentation, and disease parameters on outperformance of hybrid vs manual tracing $\left(\mathbf{R}_{\mathrm{eff}}\right)$. Contour plot showing difference in mean effective reproduction number (over 500 runs) between hybrid and manual-only hybrid tracing for different disease scenarios (Table S1) and tracing strategies, assuming $90 \%$ of non-environmental contacts traced and immediate tracing of symptomatic cases. Horizontal red dashed lines indicate low- and high-uptake scenarios from the main text (Table S1); vertical red dashed line indicates the $R_{0}$ value used in Fig. $2 \& 4$. Note that the data-retention limit for the digital system in 14 days in all cases. 
medRxiv preprint doi: https://doi.org/10.1101/2020.05.06.20093369; this version posted July 14, 2020. The copyright holder for this preprint (which was not certified by peer review) is the author/funder, who has granted medRxiv a license to display the preprint in perpetuity.

It is made available under a CC-BY 4.0 International license .

a

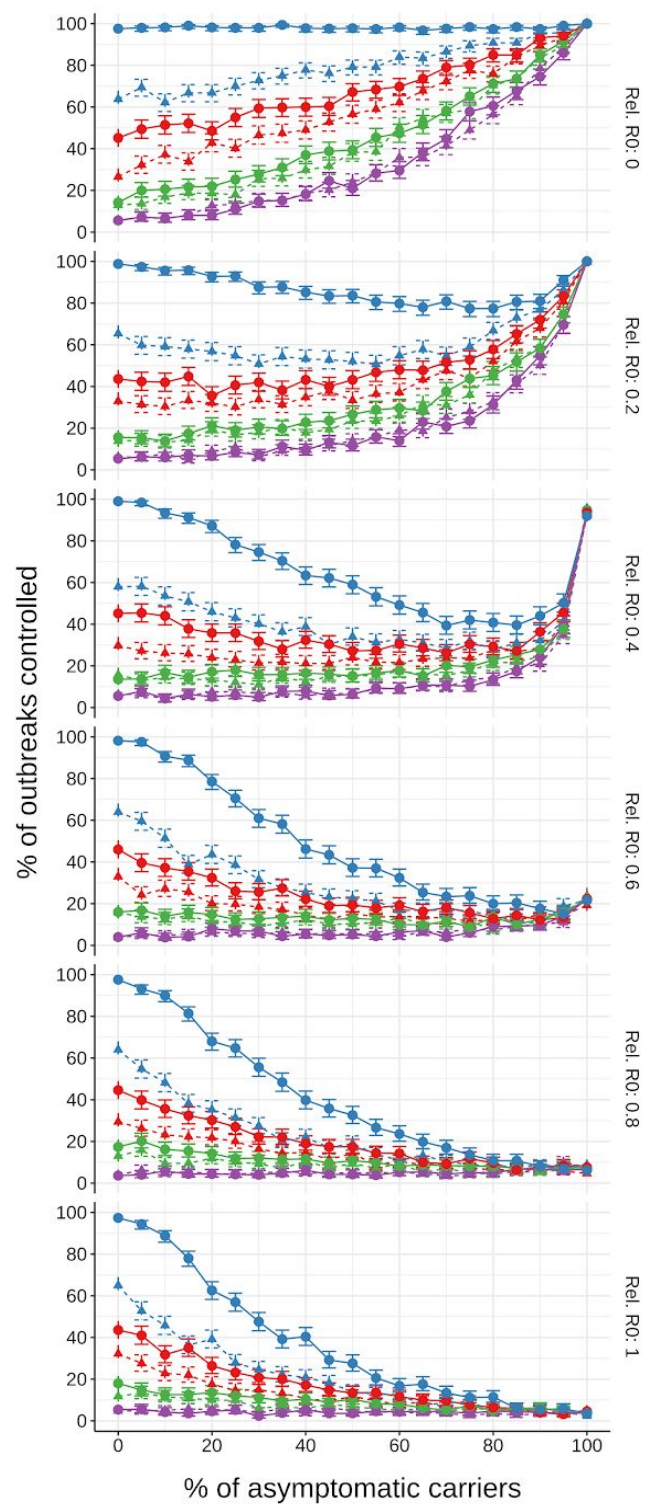

b

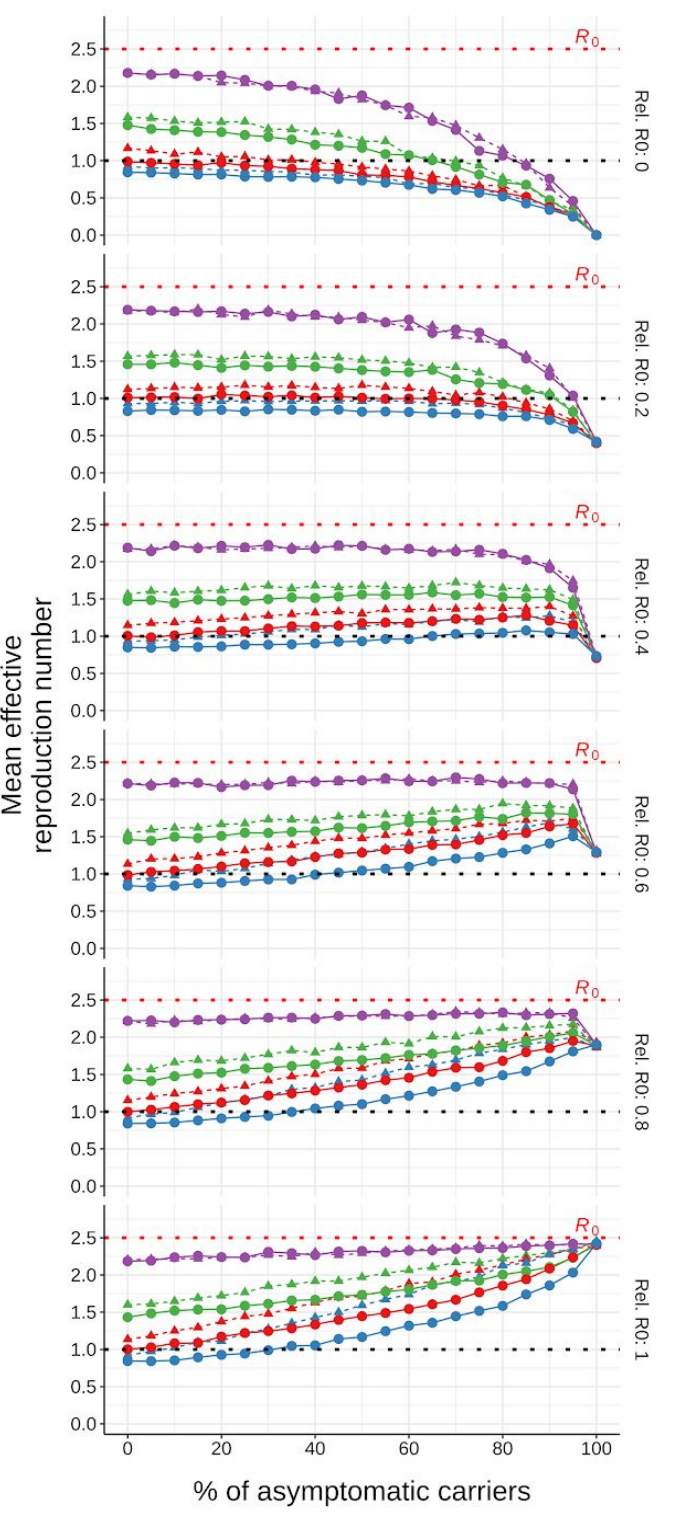

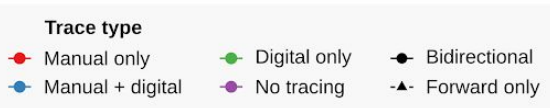

Figure S23: Effect of the rate and infectiousness of asymptomatic carriers on epidemic control

(7-day manual window). (a) Control rates and (b) Average effective reproduction number achieved under different combinations of the rate (\%) and relative infectiousness ("Rel. R0") of asymptomatic carriers, assuming otherwise median disease parameters (Table S1), 90\% of non-environmental contacts traced and a 7-day manual trace window. Error bars in (a) represent 95\% credible intervals across 500 runs under a uniform beta prior; points in (b) represent average values over the same. 
medRxiv preprint doi: https://doi.org/10.1101/2020.05.06.20093369; this version posted July 14, 2020. The copyright holder for this preprint (which was not certified by peer review) is the author/funder, who has granted medRxiv a license to display the preprint in perpetuity.

It is made available under a CC-BY 4.0 International license .

a

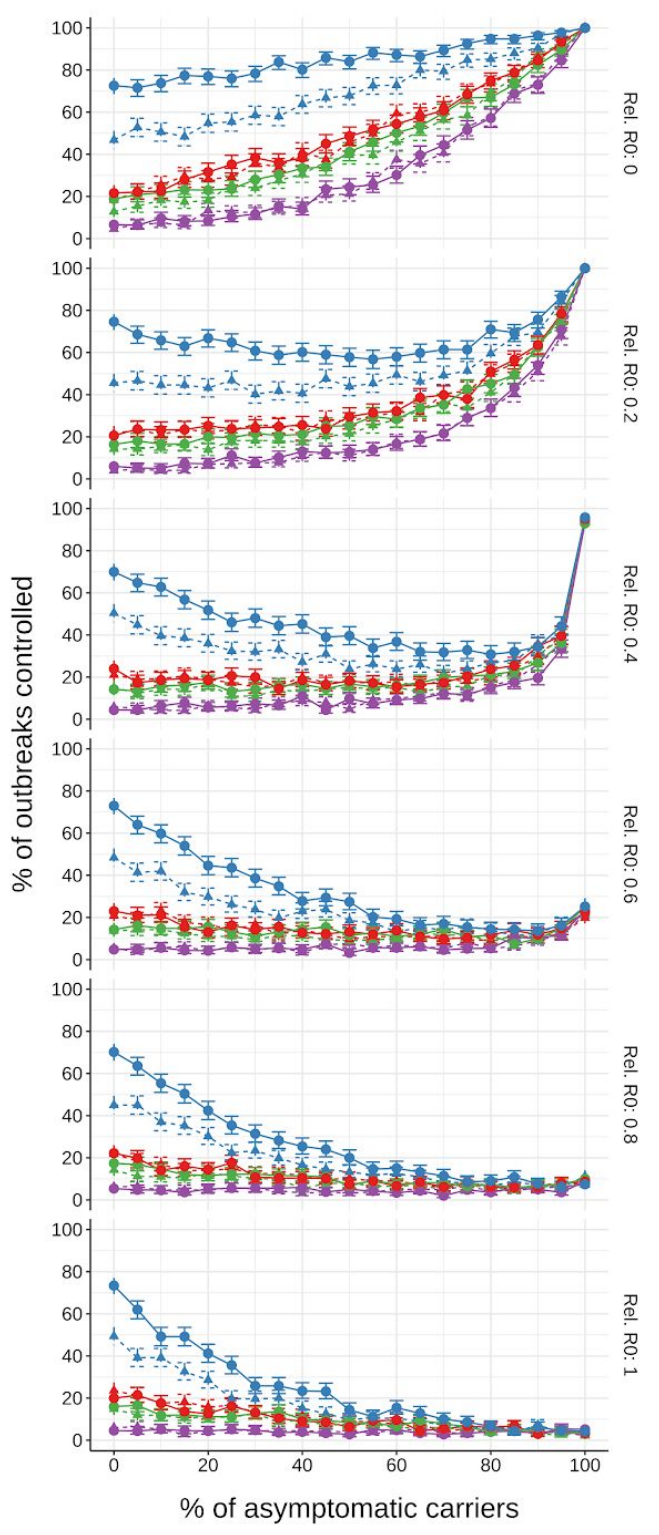

b

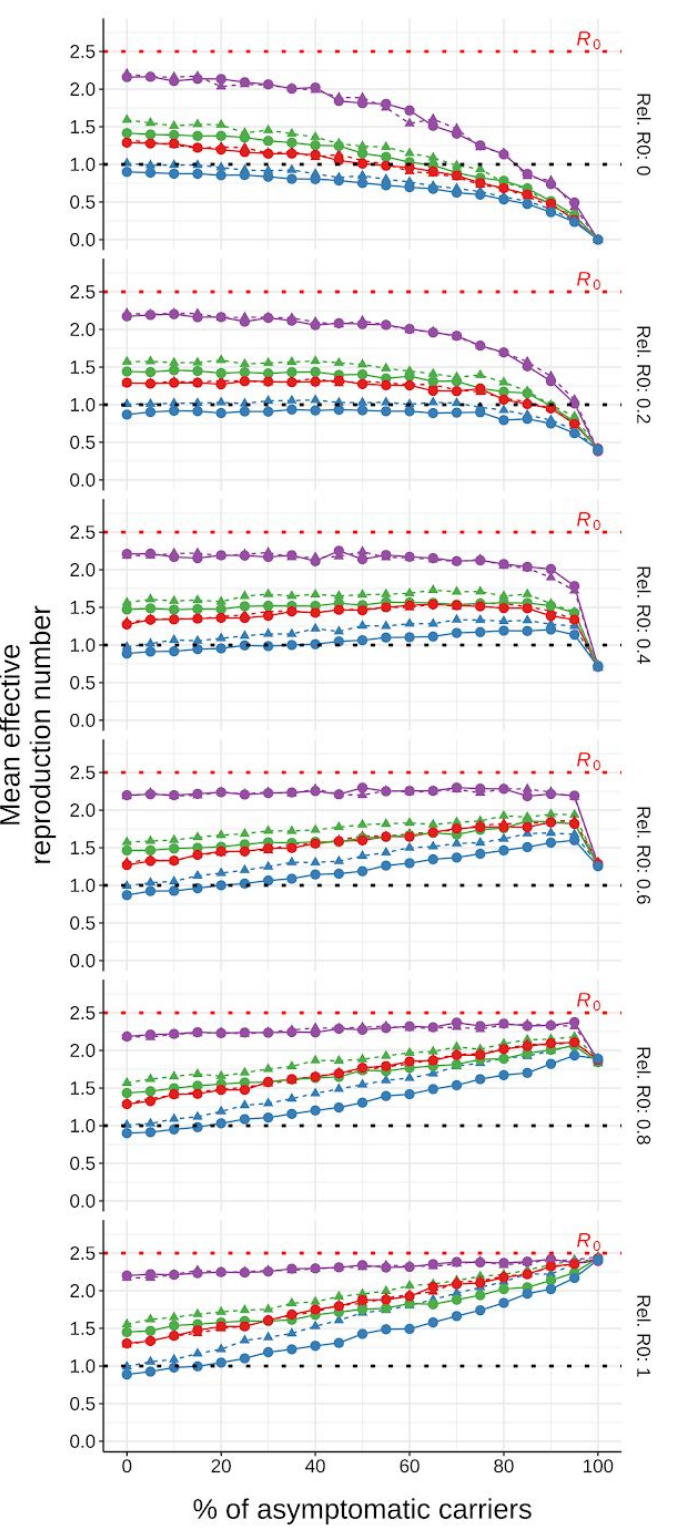

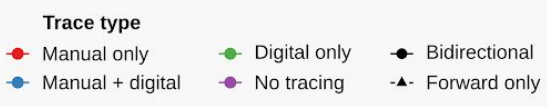

Figure S24: Effect of the rate and infectiousness of asymptomatic carriers on epidemic control

(2-day manual window). (a) Control rates and (b) Average effective reproduction number achieved under different combinations of the rate (\%) and relative infectiousness ("Rel. R0") of asymptomatic carriers, assuming otherwise median disease parameters (Table S1), 90\% of non-environmental contacts traced and a 2-day manual trace window. Error bars in (a) represent 95\% credible intervals across 500 runs under a uniform beta prior; points in (b) represent average values over the same. 
medRxiv preprint doi: https://doi.org/10.1101/2020.05.06.20093369; this version posted July 14, 2020. The copyright holder for this preprint (which was not certified by peer review) is the author/funder, who has granted medRxiv a license to display the preprint in perpetuity.

It is made available under a CC-BY 4.0 International license .

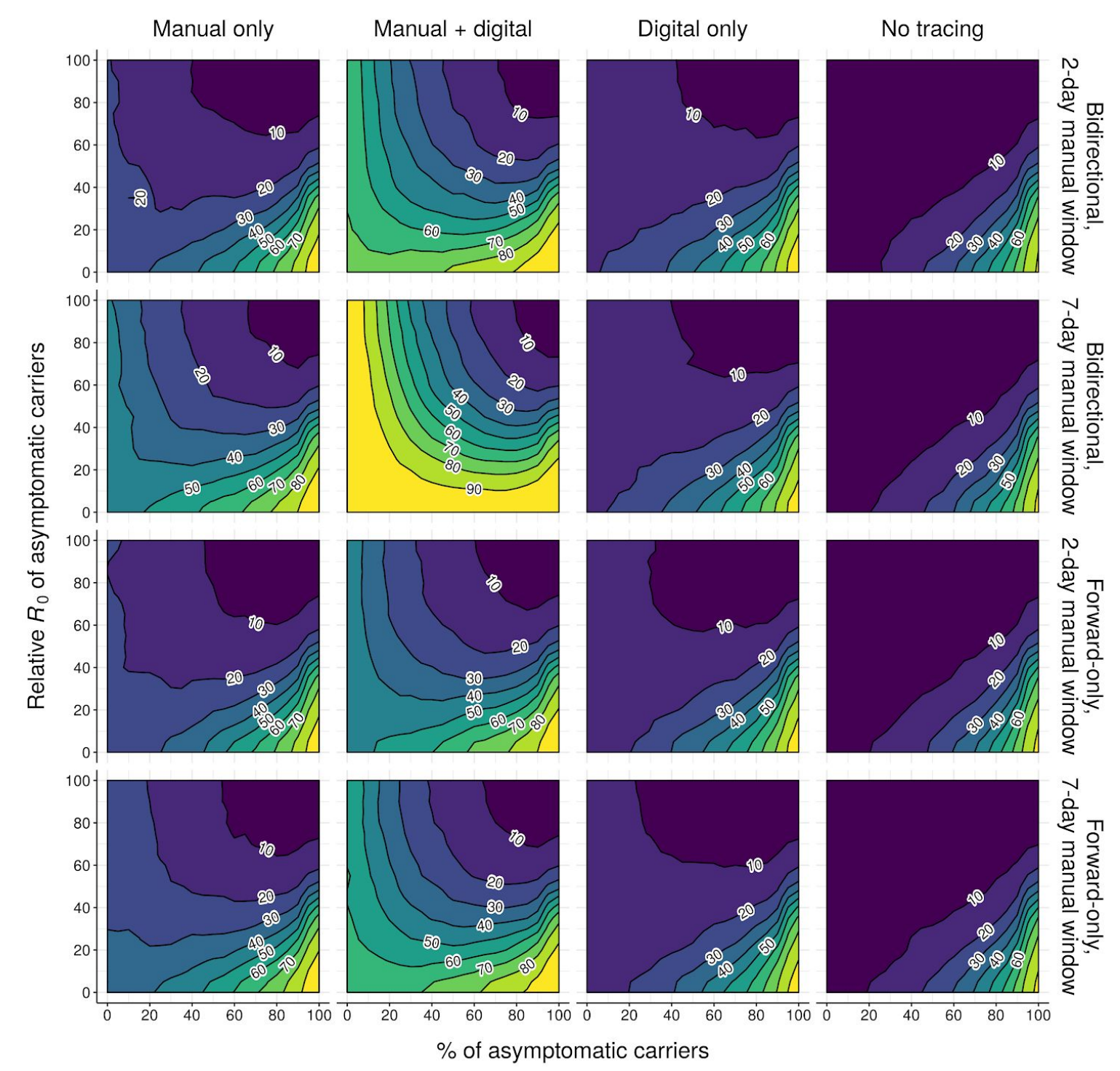

Figure S25: Effect of the rate and infectiousness of asymptomatic carriers on epidemic control

(contour plot, control rate). Neighbour-averaged contour plots showing \% of outbreaks controlled (over 500 runs) under different tracing strategies and different combinations of the rate (\%) and relative infectiousness ("Relative $R_{0}$ ") of asymptomatic carriers, assuming otherwise median disease parameters (Table S1) and that $90 \%$ of non-environmental contacts are traced. 
medRxiv preprint doi: https://doi.org/10.1101/2020.05.06.20093369; this version posted July 14, 2020. The copyright holder for this preprint (which was not certified by peer review) is the author/funder, who has granted medRxiv a license to display the preprint in perpetuity.

It is made available under a CC-BY 4.0 International license .

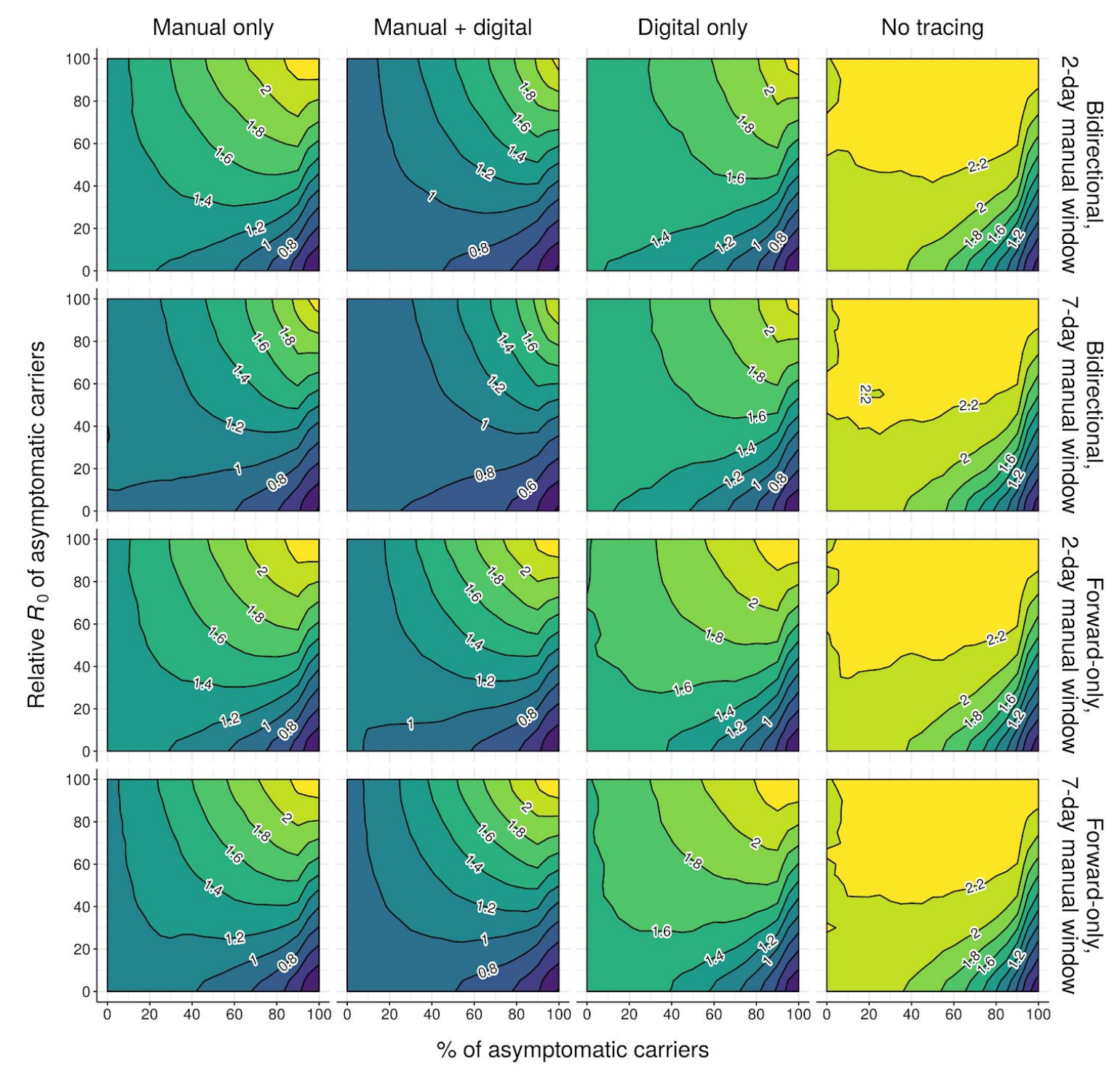

Figure S26: Effect of the rate and infectiousness of asymptomatic carriers on epidemic control

(contour plot, $\boldsymbol{R}_{\text {eff }}$ ). Neighbour-averaged contour plots showing mean effective reproduction number (over 500 runs) achieved under different tracing strategies and different combinations of the rate (\%) and relative infectiousness ("Relative $R_{0}$ ") of asymptomatic carriers, assuming otherwise median disease parameters (Table S1) and that $90 \%$ of non-environmental contacts are traced. 
a

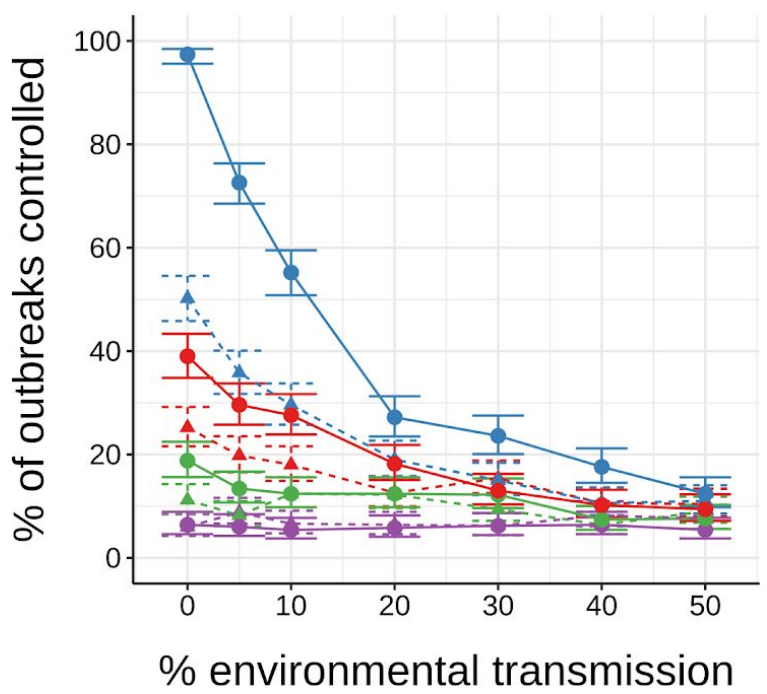

b

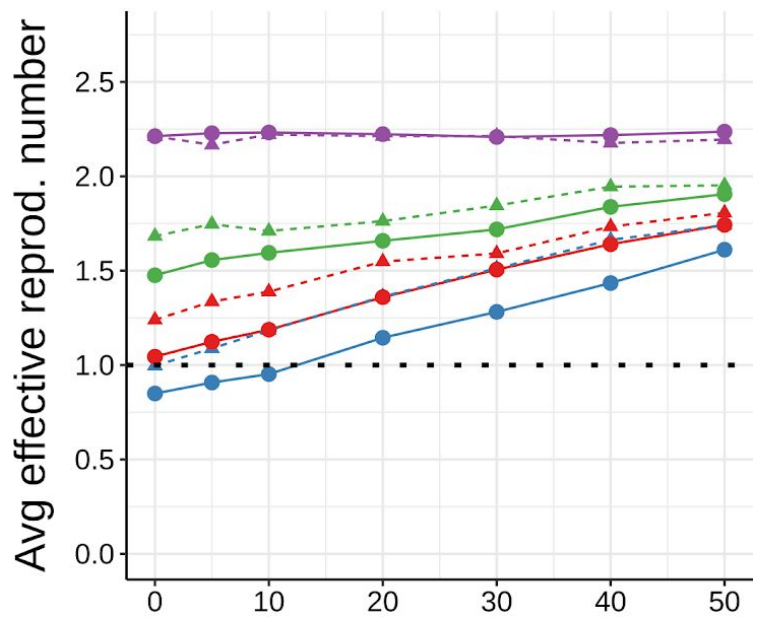

$\%$ environmental transmission

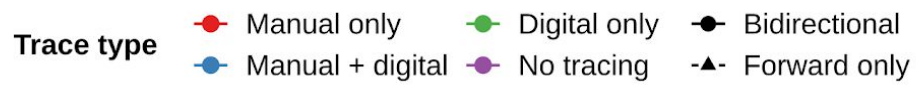

Figure S27: Effect of environmental transmission on epidemic control. (a) Control rates and (b)

Average effective reproduction numbers achieved under different rates of environmental transmission, assuming otherwise median disease parameters (Table S1), 90\% of non-environmental contacts traced and a 7-day manual trace window. Environmental transmission is assumed to be untraceable by either manual or digital contact tracing. Error bars in (a) represent $95 \%$ credible intervals across 500 runs under a uniform beta prior; points in (b) represent average values over the same. 
a

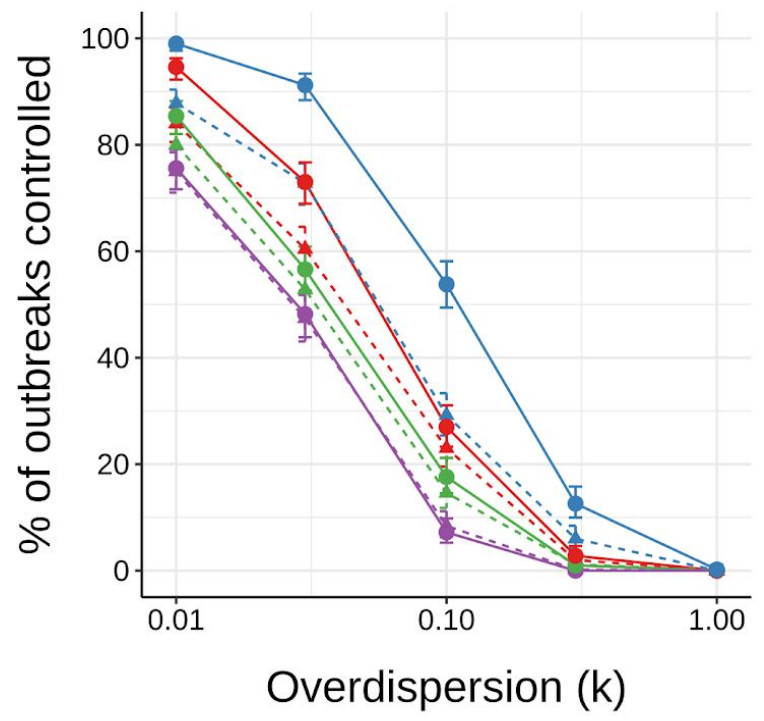

b

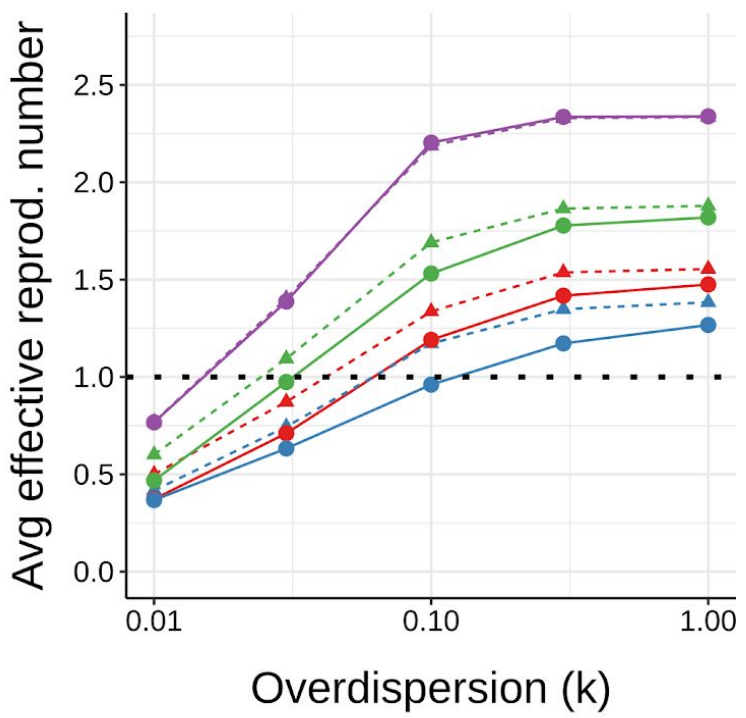

Digital only

No tracing - - - Forward only

Figure S28: Effect of overdispersion parameter on epidemic control. (a) Control rates and (b)

Average effective reproduction numbers achieved under different values of the overdispersion parameter $k$ (where lower values of $k$ denote higher variance in infectiousness among cases), assuming otherwise median disease parameters (Table S1), 90\% of non-environmental contacts traced and a 7-day manual trace window. Error bars in (a) represent 95\% credible intervals across 500 runs under a uniform beta prior; points in (b) represent average values over the same. 

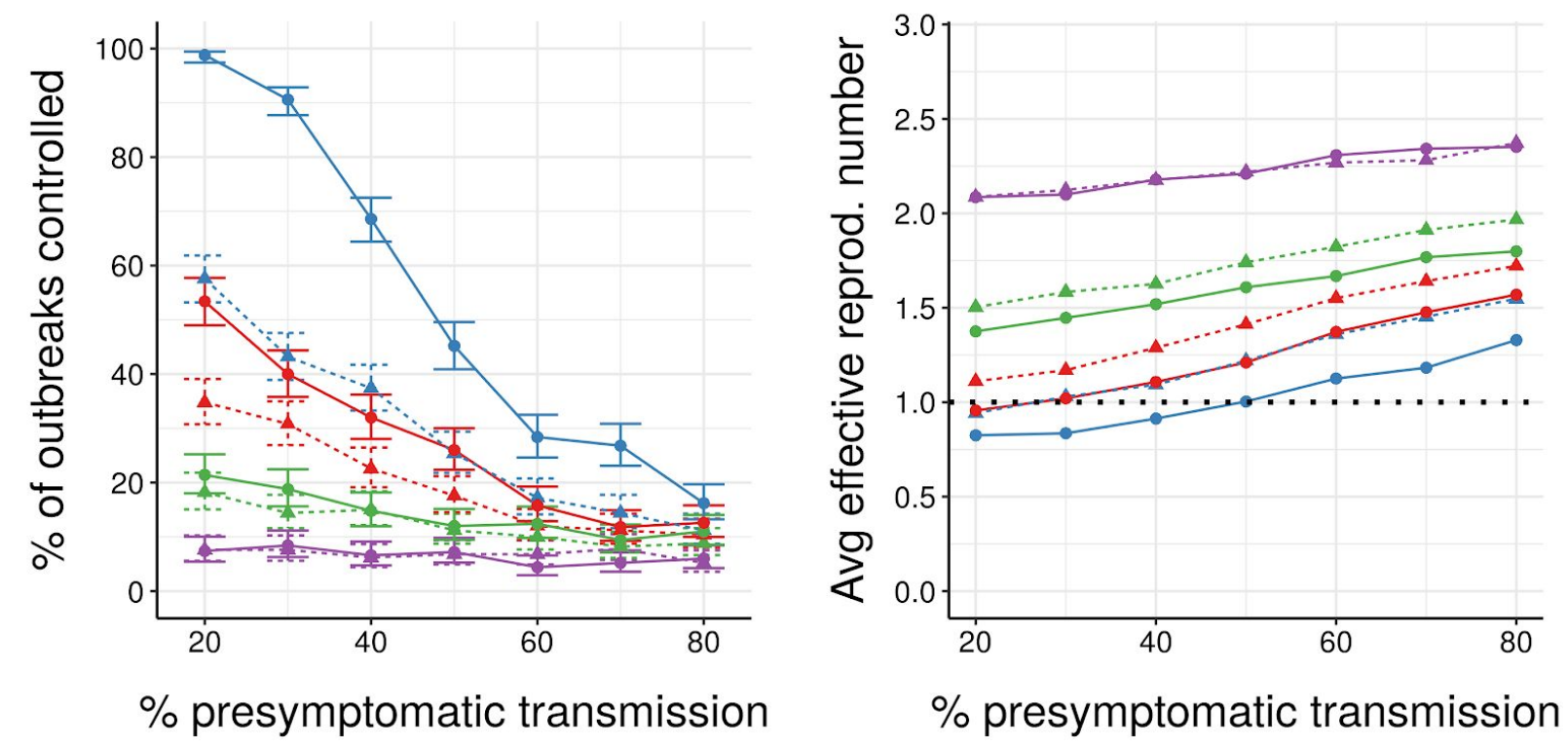

$\begin{array}{lll} & \rightarrow \text { Manual only } \rightarrow \text { Digital only } & \rightarrow \text { Bidirectional } \\ \text { Trace type } & \rightarrow \text { Manual + digital } \rightarrow \text { No tracing } & - \text { - }\end{array}$

Figure S29: Effect of pre-symptomatic transmission on epidemic control. (a) Control rates and (b) Average effective reproduction numbers achieved under different rates of pre-symptomatic transmission, assuming otherwise median disease parameters (Table S1), 90\% of non-environmental contacts traced and a 7-day manual trace window. Error bars in (a) represent 95\% credible intervals across 500 runs under a uniform beta prior; points in (b) represent average values over the same. 
a

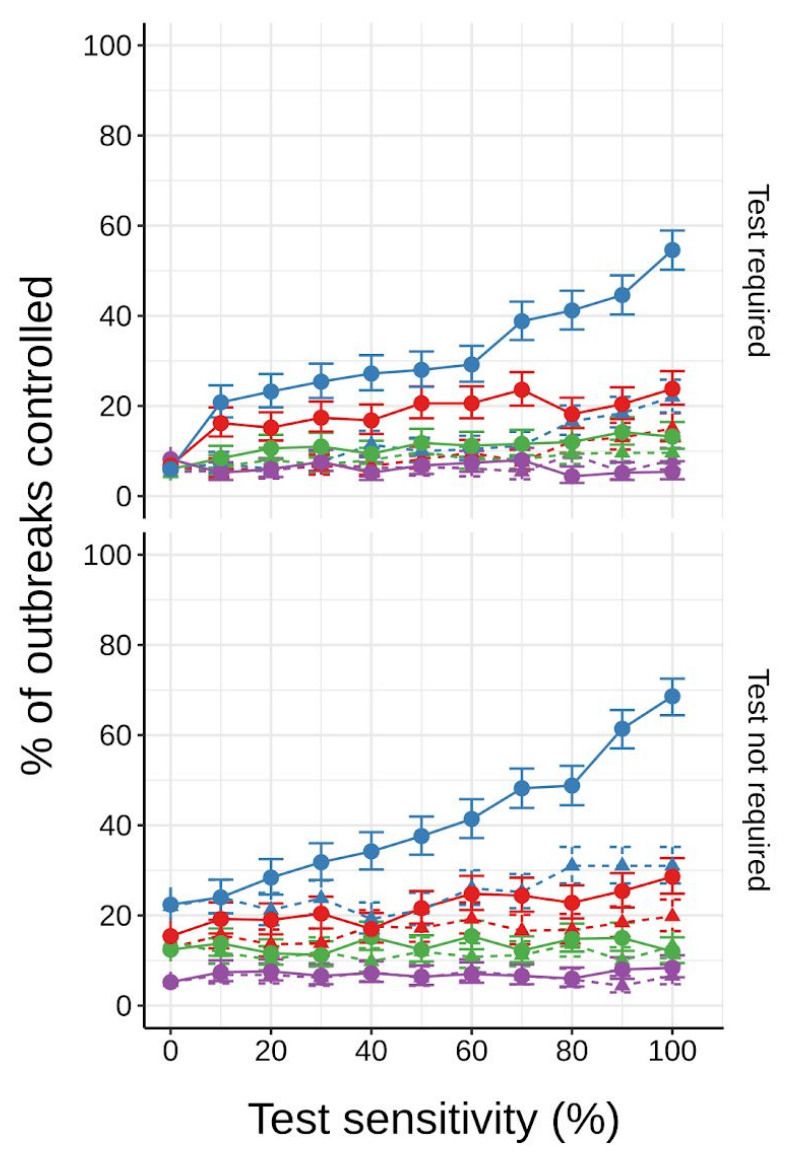

b

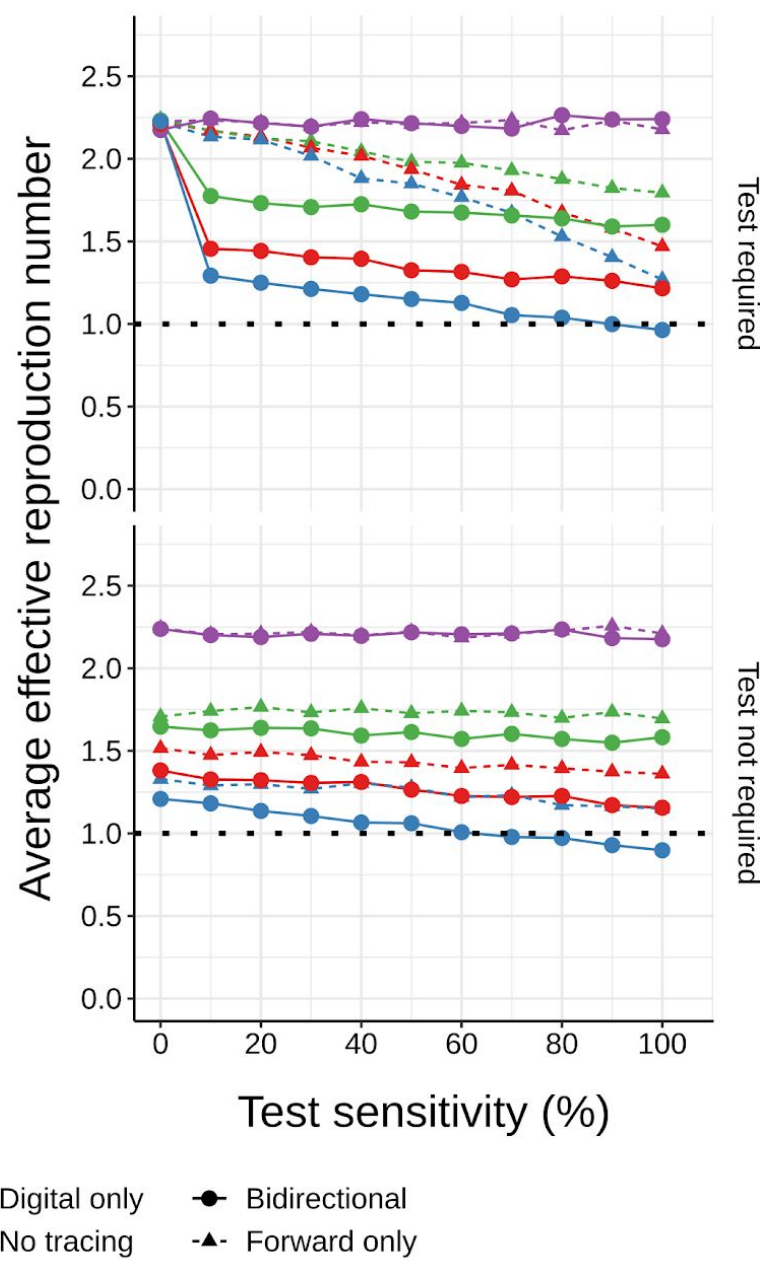

Figure S30: Effect of test sensitivity on epidemic control. (a) Control rates and (b) Average effective reproduction numbers achieved under different assumptions about test sensitivity (x-axis) and whether or not a positive test result is required before contact tracing from a symptomatic case (top/bottom panels), assuming otherwise median disease parameters (Table S1), 90\% of non-environmental contacts traced and a 7-day manual trace window. Error bars in (a) represent 95\% credible intervals across 500 runs under a uniform beta prior; points in (b) represent average values over the same. 
a

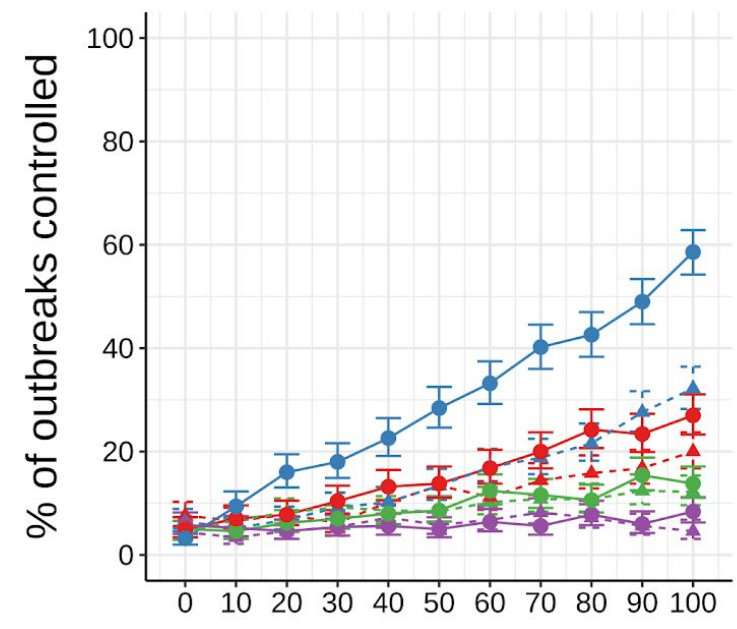

$\%$ symptomatic cases identified b

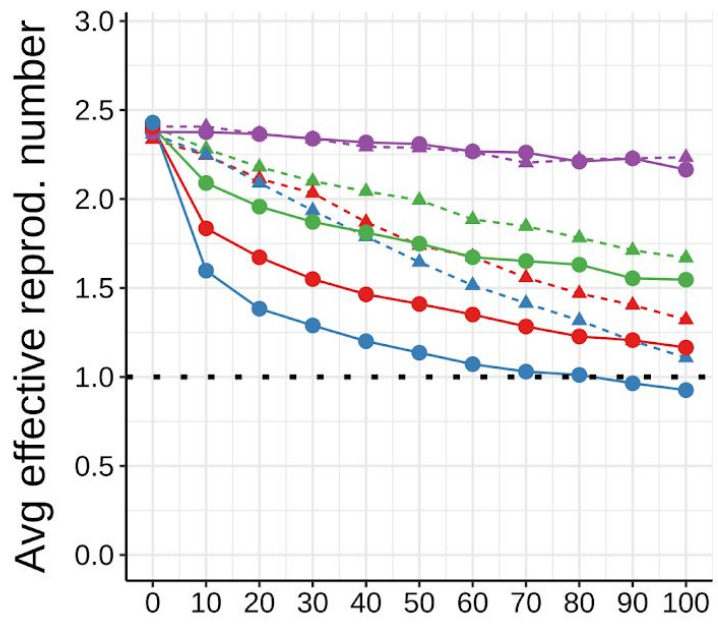

$\%$ symptomatic cases identified

$\begin{array}{llll} & - \text { Manual only } & - \text { Digital only } & - \text { Bidirectional } \\ & - \text { Manual + digital } & - \text { No tracing } & -\boldsymbol{\Delta} \text { - Forward only }\end{array}$

Figure S31: Effect of symptomatic case ascertainment on epidemic control. (a) Control rates and (b) average effective reproduction numbers achieved as a function of the probability of identifying symptomatic cases (based on symptoms alone), assuming otherwise median disease parameters (Table S1), $90 \%$ probability of trace success, and a 7-day manual trace window. Error bars in (a) represent 95\% credible intervals across 500 runs under a uniform beta prior; points in (b) represent average values over the same. Note that, since $45 \%$ of cases are asymptomatic (and thus never identified from symptoms), overall ascertainment when $x \%$ of symptomatic cases are identified is roughly $0.55 x \%$. 


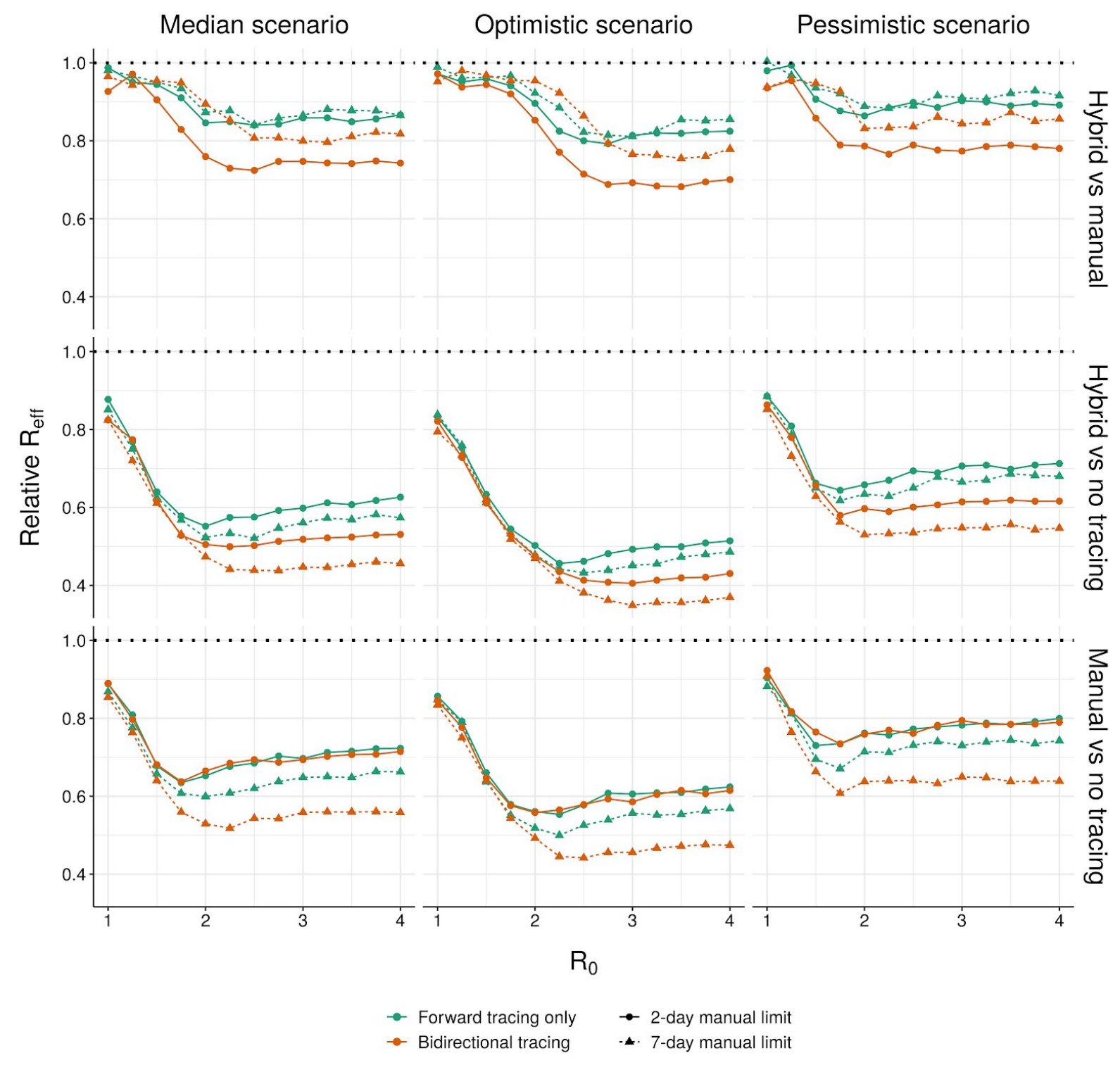

Figure S32: Relative effective reproduction numbers of hybrid, manual and no tracing. Ratio between the effective reproduction number (over 1000 runs per condition) achieved by (top row) hybrid and manual tracing, (middle row) hybrid and no tracing, (bottom row) manual and no tracing, under (left) median, (middle) optimistic and (right) pessimistic disease parameters (Table S1), given $90 \%$ of non-environmental contacts traced, high uptake of the digital system, and immediate tracing of symptomatic cases. 
a

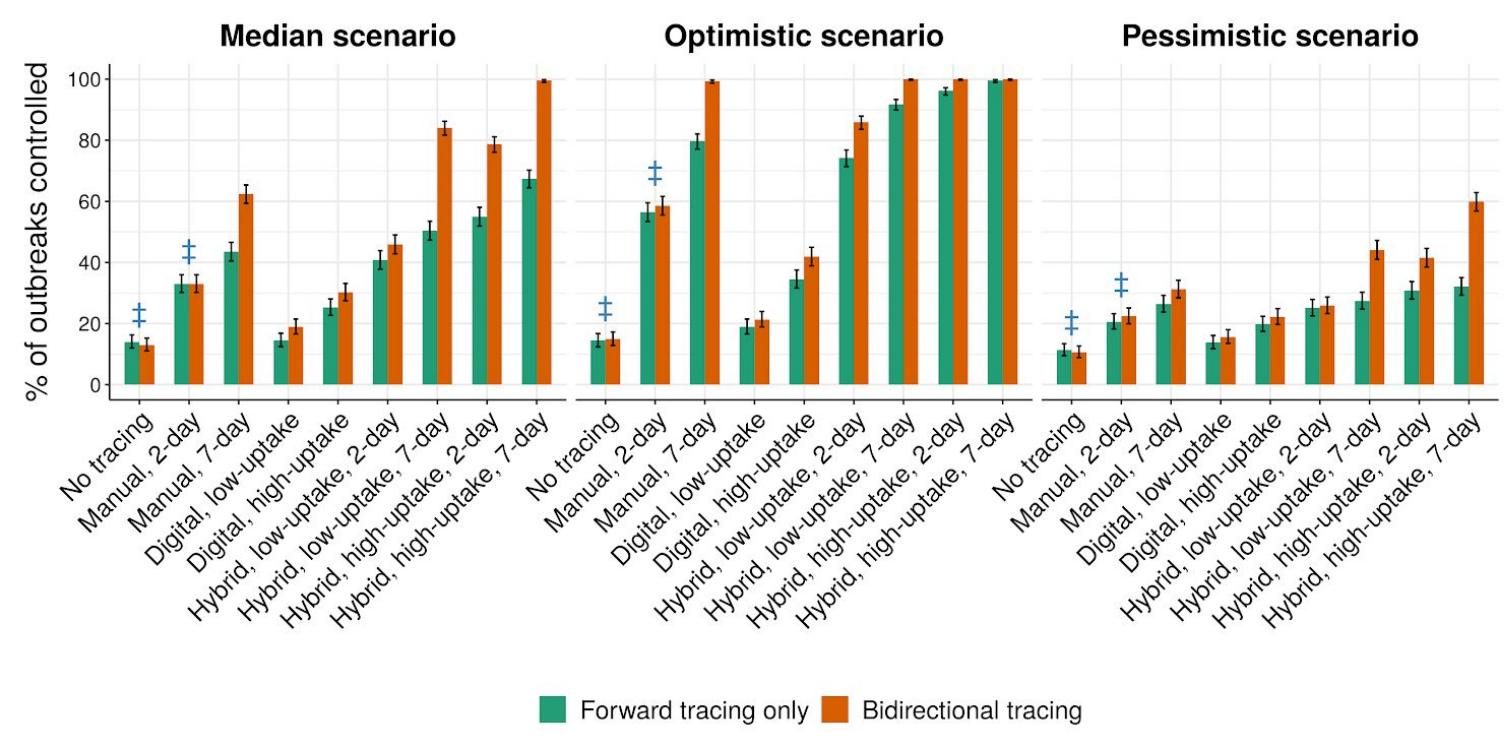

b

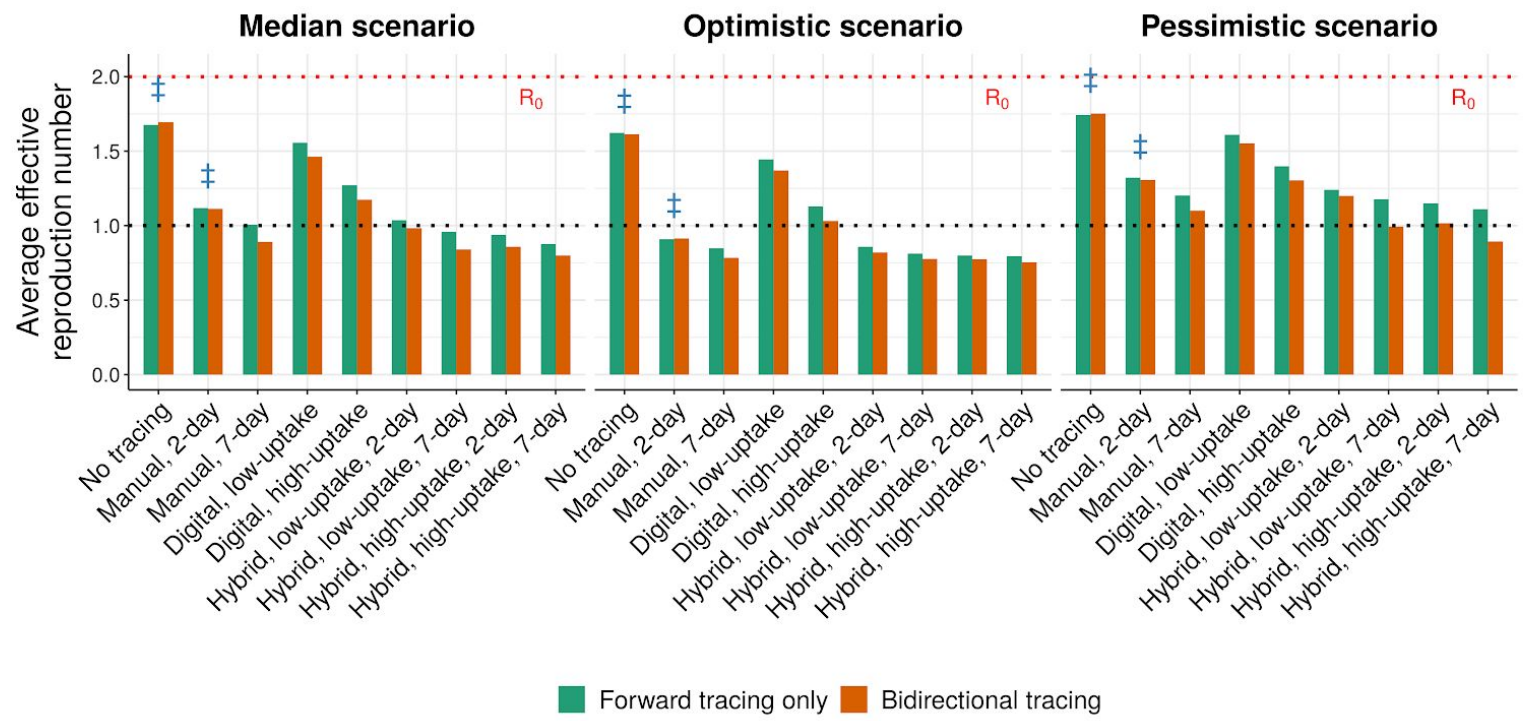

Figure S33. Tracing strategies for controlling COVID-19 $\left(\boldsymbol{R}_{\mathbf{0}}=\mathbf{2 . 0}\right)$. As Fig. 4 , but assuming an $R 0$ of

2.0. Blue $\ddagger$ symbols indicate current practice in most regions. Low and high uptake correspond to $53 \%$ and $80 \%$ of cases, respectively, having chirp-enabled smartphones. Error bars in (a) represent $95 \%$ credible intervals across 1000 runs under a uniform beta prior. Without tracing, forward and bidirectional are equivalent. 
medRxiv preprint doi: https://doi.org/10.1101/2020.05.06.20093369; this version posted July 14, 2020. The copyright holder for this preprint (which was not certified by peer review) is the author/funder, who has granted medRxiv a license to display the preprint in perpetuity.

It is made available under a CC-BY 4.0 International license .

a

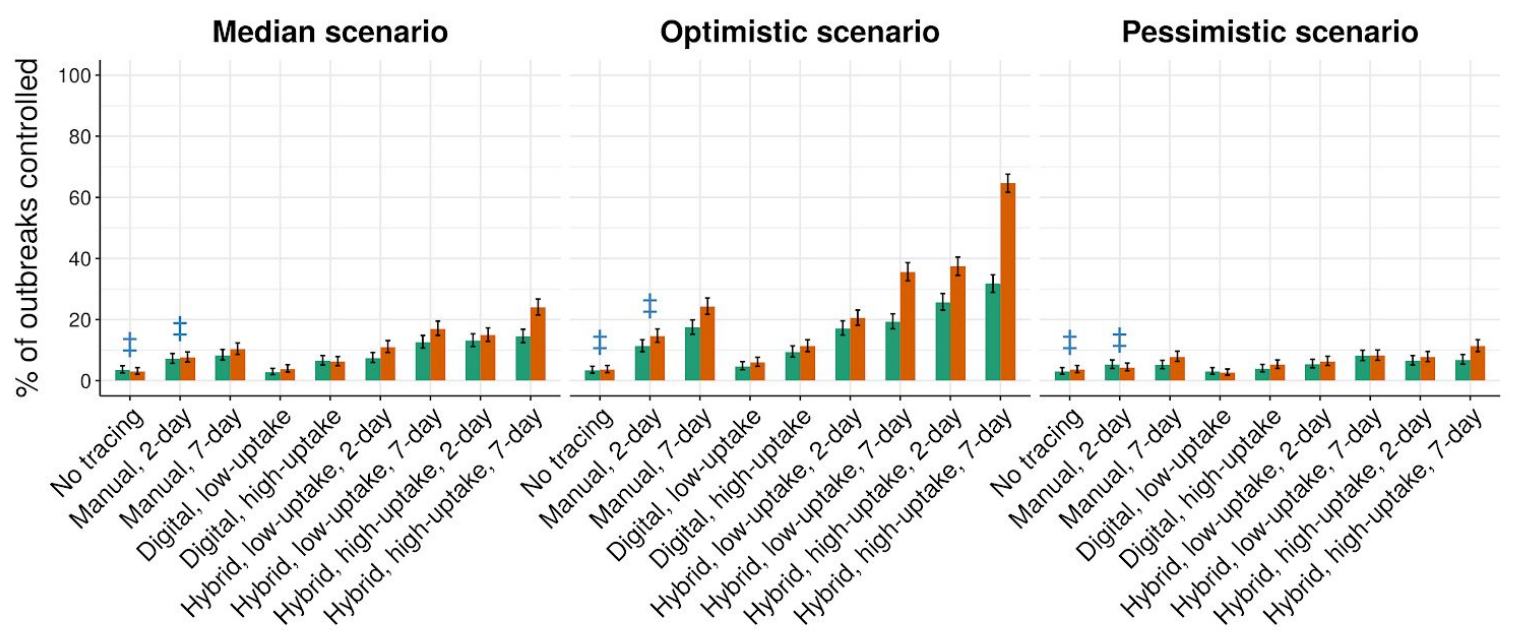

Forward tracing only $\square$ Bidirectional tracing

b

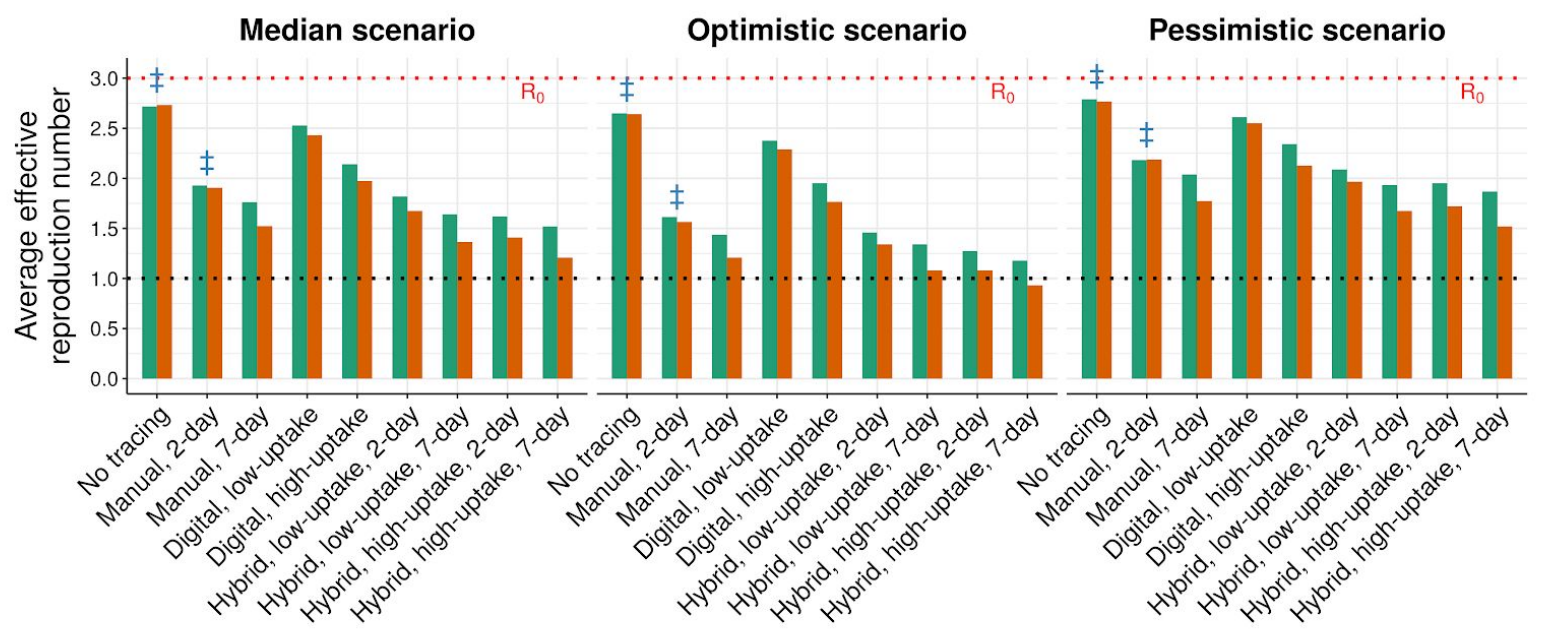

Forward tracing only $\square$ Bidirectional tracing

Figure S34. Tracing strategies for controlling COVID-19 $\left(\boldsymbol{R}_{\mathbf{0}}=\mathbf{3 . 0}\right)$. As Fig. 4 , but assuming an $R 0$ of

3.0. Blue + symbols indicate current practice in most regions. Low and high uptake correspond to 53\% and $80 \%$ of cases, respectively, having chirp-enabled smartphones. Error bars in (a) represent $95 \%$ credible intervals across 1000 runs under a uniform beta prior. Without tracing, forward and bidirectional are equivalent. 
medRxiv preprint doi: https://doi.org/10.1101/2020.05.06.20093369; this version posted July 14, 2020. The copyright holder for this preprint (which was not certified by peer review) is the author/funder, who has granted medRxiv a license to display the preprint in perpetuity.

It is made available under a CC-BY 4.0 International license.

a

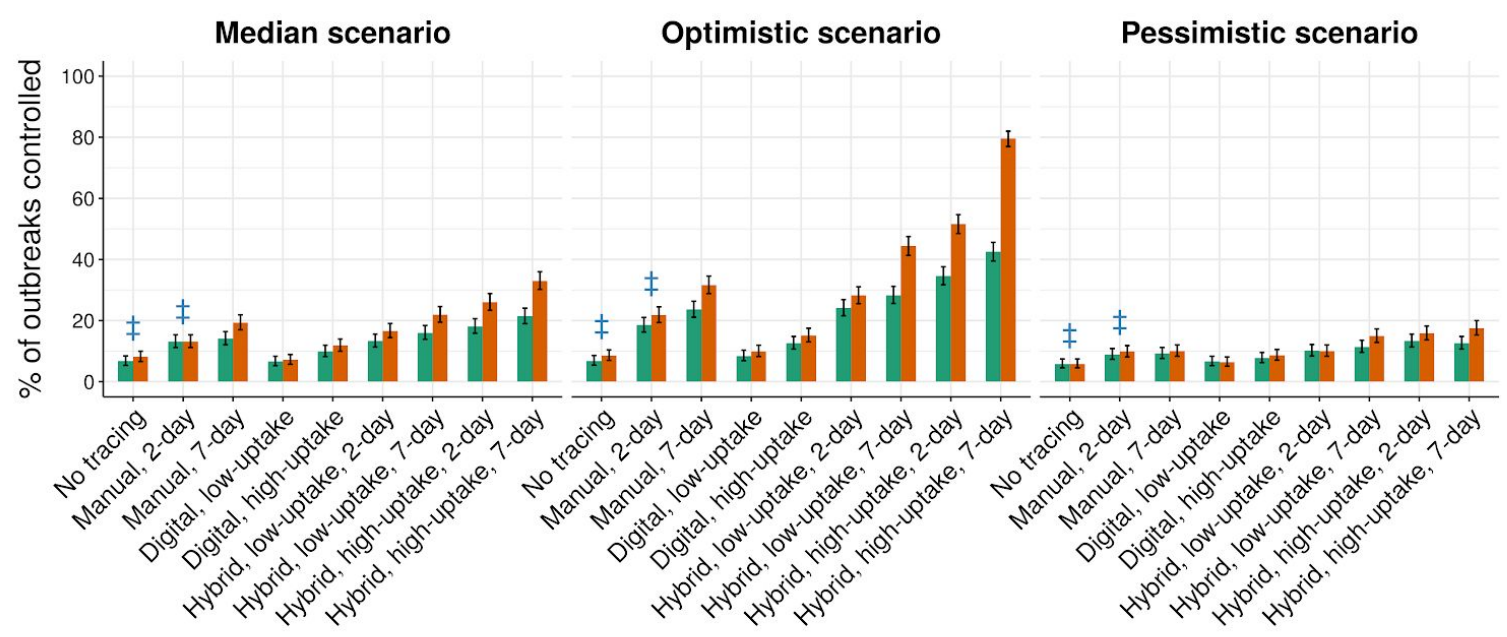

Forward tracing only $\square$ Bidirectional tracing

b

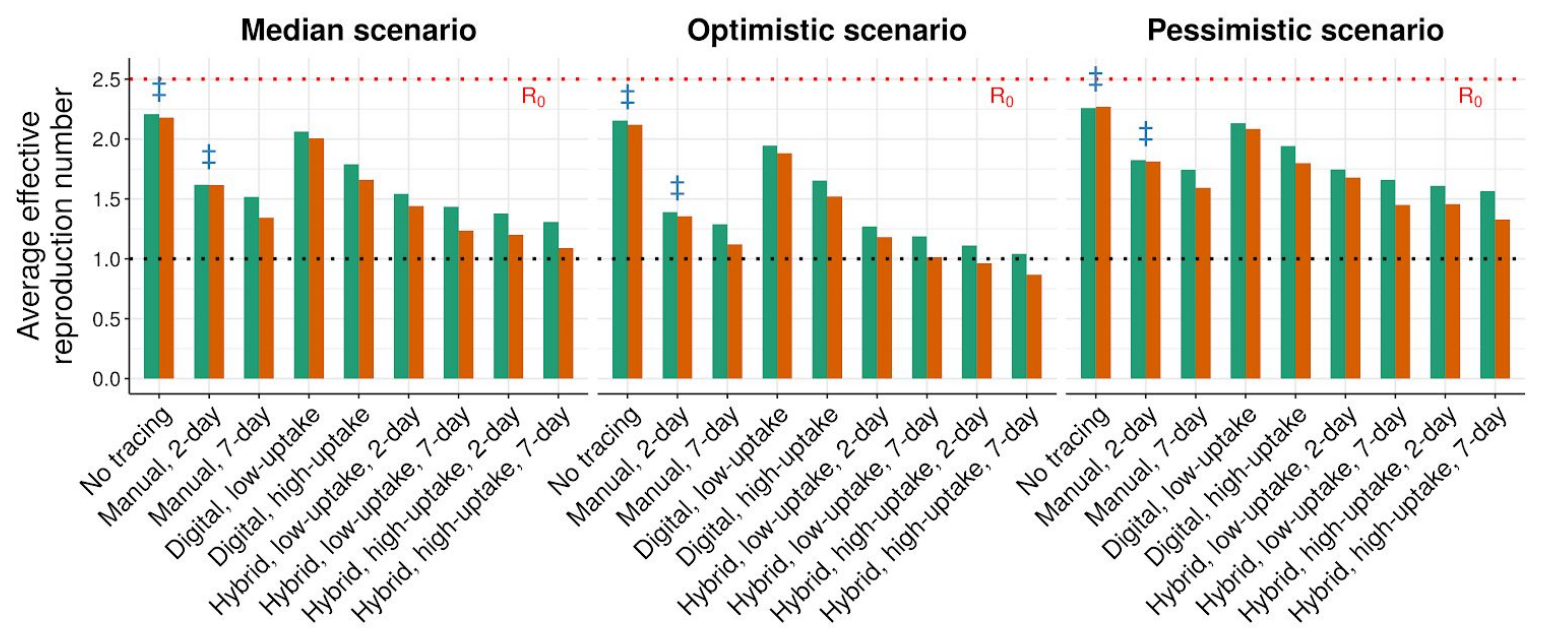

Forward tracing only $\square$ Bidirectional tracing

Figure S35. Tracing strategies for controlling COVID-19 (80\% contacts traced). As Fig. 4, but assuming only $80 \%$ of non-environmental contacts are traced. Blue $\$$ symbols indicate current practice in most regions. Low and high uptake correspond to $53 \%$ and $80 \%$ of cases, respectively, having chirp-enabled smartphones. Error bars in (a) represent 95\% credible intervals across 1000 runs under a uniform beta prior. Without tracing, forward and bidirectional are equivalent. 
a

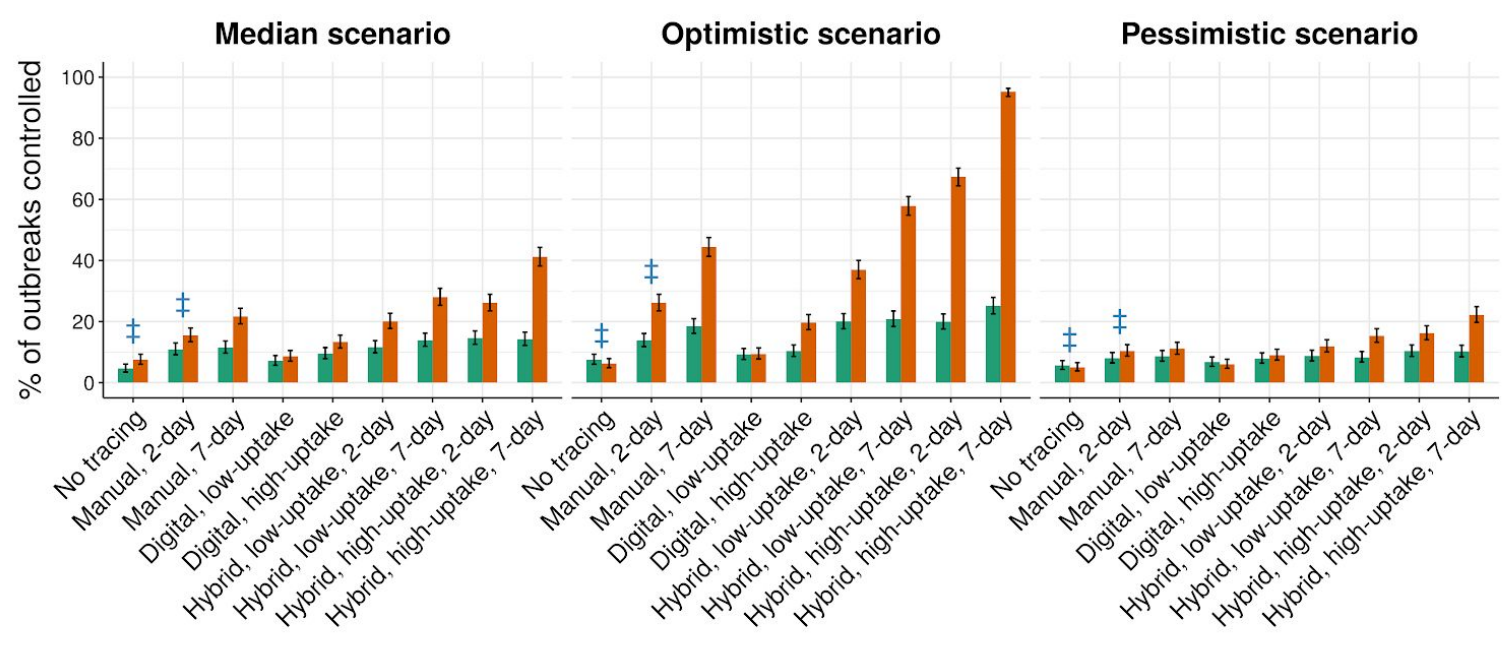

Forward tracing only $\square$ Bidirectional tracing

b

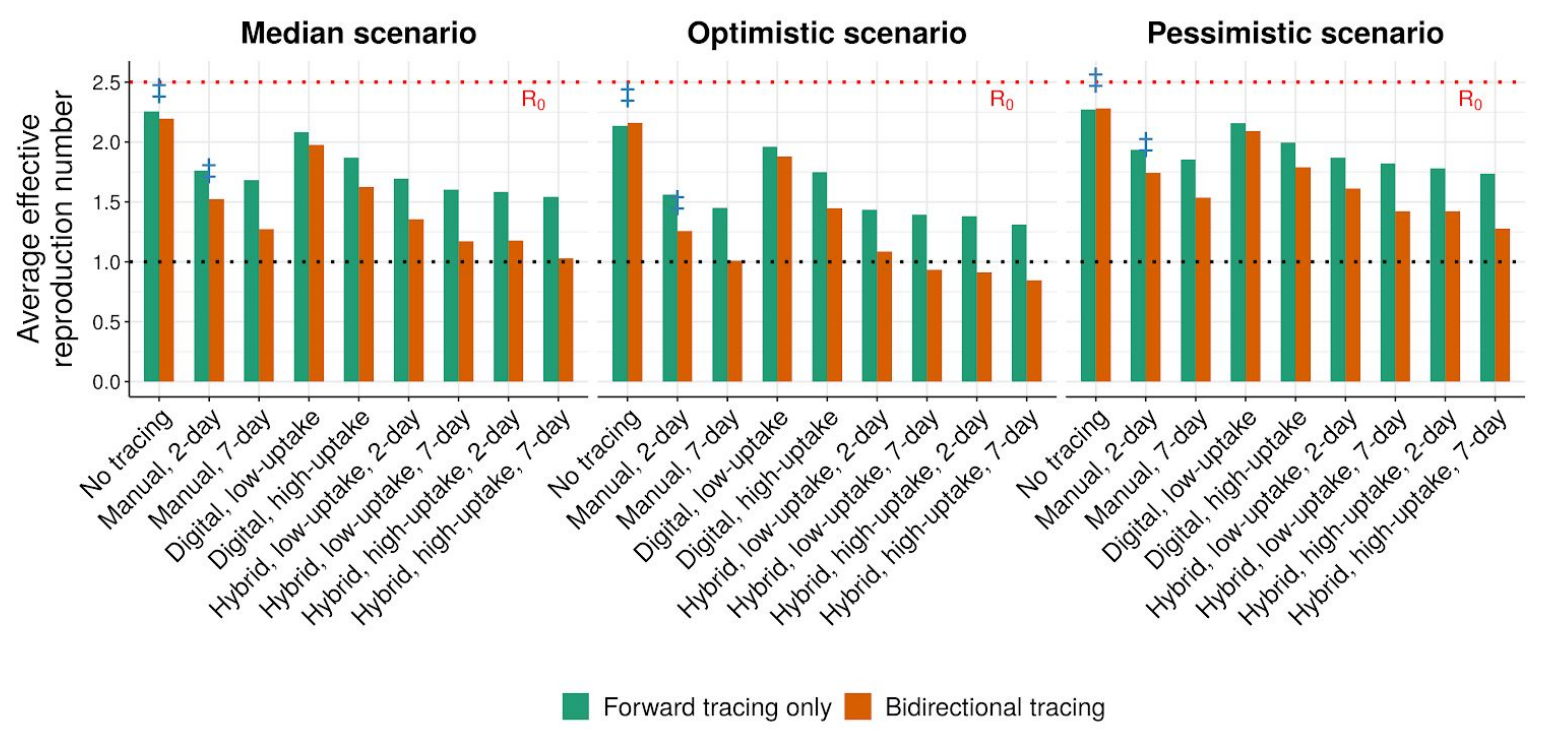

Figure S36. Tracing strategies for controlling COVID-19 (pre-emptive testing). As Fig. 4, but assuming that symptomatic cases require a positive test before their contacts are traced. Blue $\$$ symbols indicate current practice in most regions. Low and high uptake correspond to $53 \%$ and $80 \%$ of cases, respectively, having chirp-enabled smartphones. Error bars in (a) represent $95 \%$ credible intervals across 1000 runs under a uniform beta prior. Without tracing, forward and bidirectional are equivalent. 